University of Louisville

ThinkIR: The University of Louisville's Institutional Repository

\title{
A multi-level analysis using NAEP data : examining the relationships among mathematics coaches and specialists, student achievement, and disability status.
}

Kristin Harbour

University of Louisville

Follow this and additional works at: https://ir.library.louisville.edu/etd

Part of the Curriculum and Instruction Commons

\section{Recommended Citation}

Harbour, Kristin, "A multi-level analysis using NAEP data : examining the relationships among mathematics coaches and specialists, student achievement, and disability status." (2015). Electronic Theses and Dissertations. Paper 2088.

https://doi.org/10.18297/etd/2088

This Doctoral Dissertation is brought to you for free and open access by ThinkIR: The University of Louisville's Institutional Repository. It has been accepted for inclusion in Electronic Theses and Dissertations by an authorized administrator of ThinkIR: The University of Louisville's Institutional Repository. This title appears here courtesy of the author, who has retained all other copyrights. For more information, please contact thinkir@louisville.edu. 
A MULTI-LEVEL ANALYSIS USING NAEP DATA: EXAMINING THE

RELATIONSHIPS AMONG MATHEMATICS COACHES AND SPECIALISTS, STUDENT ACHIEVEMENT, AND DISABILITY STATUS

\author{
By \\ Kristin Harbour \\ B.A., West Virginia University, 2005 \\ M.A., West Virginia University, 2005 \\ A Dissertation Submitted to the Faculty of the \\ College of Education and Human Development of the University of Louisville \\ in Partial Fulfillment of the Requirements \\ for the Degree of \\ Doctor of Philosophy \\ in Curriculum and Instruction \\ Department of Early Childhood and Elementary Education \\ University of Louisville \\ Louisville, KY
}

May 2015 
Copyright 2015 by Kristin E. Harbour

All rights reserved 

A MULTI-LEVEL ANALYSIS USING NAEP DATA: EXAMINING THE RELATIONSHIPS AMONG MATHEMATICS COACHES AND SPECIALISTS, STUDENT ACHIEVEMENT, AND DISABILITY STATUS

\section{By}

Kristin E. Harbour

B.A., West Virginia University, 2005

M.A., West Virginia University, 2005

A Dissertation Approved on

April 6, 2015

by the following Dissertation Committee:

Karen S. Karp, Dissertation Co-Chair

Jill L. Adelson, Dissertation Co-Chair

Elizabeth Todd Brown

Francis (Skip) Fennell

Amy S. Lingo 


\section{DEDICATION}

This dissertation is dedicated to my parents

who have given me a lifetime of opportunities and support. 


\section{ACKNOWLEDGEMENTS}

This dissertation represents a milestone that has allowed me to cross paths with so many wonderful people who have helped to inspire me and support my growth as a teacher and researcher of mathematics education. I would like to take this time to express my gratitude to my extraordinary mentors, family, and friends. Without each of you, this part of my journey could not have been completed.

First, I would like to acknowledge and sincerely thank Dr. Karen Karp, my advisor and dissertation co-chair. Throughout my time at the University of Louisville, Dr. Karp has played a profound and instrumental role in shaping the person I have become both professionally and personally. After meeting Dr. Karp, my decision to attend the University of Louisville was made without hesitation and I have never looked back as I have had the most inspiring and encouraging advisor imaginable. Under her mentoring, I have become a stronger teacher and researcher of mathematics education and feel truly prepared for my new role in academia. Her kindness, supportiveness, and dedication to my success is something for which I will forever be indebted and grateful. In addition to being my advisor and mentor, Dr. Karp has been a wonderful role model and an exemplar scholar. It has been an honor and privilege to have worked with Dr. Karp over the past three years and I look forward to a lifetime of collaboration and friendship.

I would like to sincerely thank Dr. Jill Adelson, my dissertation co-chair. Dr. Adelson entered my doctoral journey in the second year of my program and quickly became a wonderful mentor. Dr. Adelson has provided me numerous opportunities, 
encouragement, support, and advice that far surpassed that of a typical mentor, which has allowed me to advance my statistical and methodological skills beyond what I ever imagined. Through her guidance and patience, not only has my statistical knowledge grown but also my confidence. Dr. Adelson has provided me an amazing example of what it means to be a mentor, teacher, researcher, and friend.

I would also like to thank my committee members, Drs. Amy Lingo, E. Todd Brown, and Francis (Skip) Fennell. Specifically, I would like to thank Dr. Amy Lingo for providing me numerous opportunities of collaboration that allowed me to grow as a researcher and providing me invaluable advice, guidance, and support through my journey at the University of Louisville. I would like to thank Dr. E. Todd Brown for helping me to become a better mathematics educator through her constant encouragement, support, and feedback. I would also like to thank Dr. Skip Fennell for sharing his expertise, as well as providing exceptional feedback and continued advice during my study of mathematics coaches and specialists. Without each of your contributions, this chapter of my life and the completion of my dissertation would not have been possible.

Over the past three years, I have had the opportunity to work alongside many amazing and supportive individuals. I would like to extend a special thank you to those who have helped contribute to my program and dissertation: Dr. Robert Ronau, Dr. Terry Scott, Dr. Maggie McGatha, Dr. Susan Peters, and Dr. Craig Hochbein and other outstanding faculty members at the College of Education and Human Development. Each one of these wonderful people have helped to shape and inspire the path I have chosen and I am forever grateful. 
Lastly, I would like to thank my truly amazing family and friends. Thank you for understanding when it seemed like I "fell off the face of the earth" and was completely absorbed in my work, for always boosting my self-confidence, for listening to me passionately talk about things I know were not as interesting to you as they were to me, and for being my constant support system and band of encouragers. 


\begin{abstract}
A MULTI-LEVEL ANALYSIS USING NAEP DATA: EXAMINING THE

RELATIONSHIPS AMONG MATHEMATICS COACHES AND SPECIALISTS, STUDENT ACHIEVEMENT, AND DISABILITY STATUS

Kristin E. Harbour
\end{abstract}

April 6, 2015

With the need to increase students' mathematics performance and provide a more challenging mathematics curriculum, elementary schools have begun hiring mathematics coaches and specialists (MCSs). However, limited empirical research has been conducted to examine how the use of MCSs relates to student achievement. Using restricted-use data from the 2011 NAEP Mathematics Assessment, the current study examined the relationship between MCSs and the mathematics achievement of more than 190,00 fourthgrade students in more than 7,400 schools nationwide. Additionally, the study examined whether that relationship differed for students with and without disabilities, a vital concern with the continued focus of equity in mathematics education. Lastly, the study examined the relationships between principal-reported time spent on the different NAEPdefined roles and responsibilities of MCSs and fourth-grade students' mathematics achievement.

Hierarchical linear modeling with adjustments for composite covariates and controls as well as sampling weights was used to explore each research question. Findings indicated a statistically significant positive relationship between whether 
elementary schools had full-time MCSs and fourth-grade students' mathematics achievement overall as well as in five specific NAEP-defined mathematics content areas (i.e., number properties and operations; measurement; geometry; data analysis, statistics, and probability; and algebra). This significant relationship between MCSs and achievement did not hold true when schools utilized part-time MCSs. Additionally, results showed that being in a school with a MCS did not moderate the lower achievement that students with disabilities experienced. Significant relationships between principal-reported time spent on various NAEP-defined roles and responsibilities provided by full-time MCS and fourth-grade students' mathematics achievement were noted, including relationships between achievement and MCSs providing assistance to both teachers and students.

The results of this study provided an answer to the call for high-quality educational research by using a large-scale, nationally representative dataset along with advanced statistical analyses to provide methodologically rigorous, empirically-derived evidence of the relationships among elementary MCSs, fourth-grade students' mathematics achievement, and students' disability status. Findings are consistent with prior research, showing that full-time MCSs are a promising practice for increasing student performance. The researcher provides recommendations on the effective use of MCSs in schools and suggestions for extensions of the current study. 


\section{TABLE OF CONTENTS}

PAGE

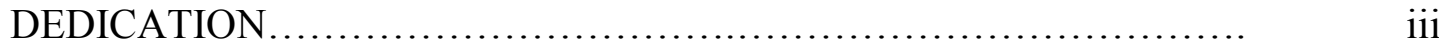

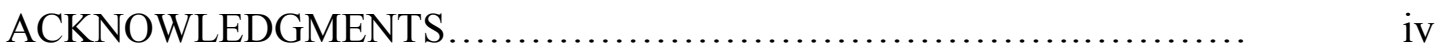

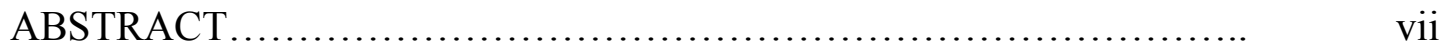

LIST OF TABLES ................................................... xiii

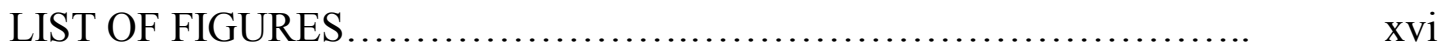

CHAPTER I: INTRODUCTION ..................................... 1

Overview........................................................ 1

Problem Statement................................................. 2

US Student Performance.......................................... 3

International................................................. 3

National ..................................................... 4

Teachers' Mathematical Understanding............................ 6

Implementation of CCSSM and Mathematical Practices................ 7

Existing Literature on Mathematics Coaches and Specialists.............. 9

The Current Study.............................................. 10

Research Question.............................................. 11

Significance of Study ........................................ 13

Organization of the Dissertation...................................... 14

CHAPTER II: LITERATURE REVIEW ............................... 15

Theoretical Framework.......................................... $\quad 15$

Theoretical Framework in Relation to the Current Study................ 17 
Rationale for Mathematics Coaches and Specialists.................... 18

Effective Professional Development Practices....................... 19

Conceptual Framework.......................................... 22

Research on Mathematics Coaches and Mathematics Specialists.......... 25

Roles and Responsibilities of Coaches and Specialists............... 26

Full-time versus Part-time Support......................... 27

Mathematics Coaching and Teacher Change...................... 27

Mathematics Coaching and Student Achievement................... 40

Mathematical Learning Difficulties and Disabilities.................... 48

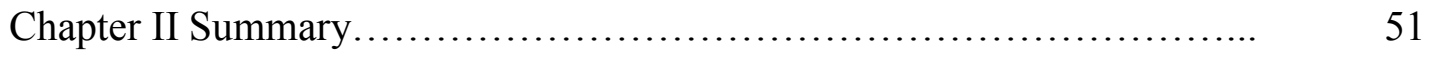

CHAPTER III: METHODOLOGY ................................... 54

Restatement of Purpose and Research Question.................... 54

Research Design and Rationale............................... 55

Population and Sample........................................... $\quad 56$

Data....................................................... 61

Outcome Variables (Student Achievement)....................... 61

Grouping Variable (IEP Status) ............................... 64

Treatment Variable (Mathematics Coach/Specialists)............... 65

Secondary Treatment Variable (Roles and Responsibilities)........... 62

Missing Data.................................................. 66

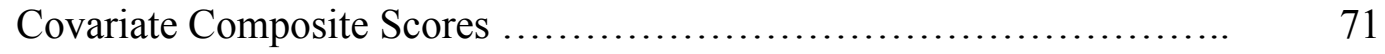

Student Composite Variables............................... 73

Teacher Composite Variables............................... 75 
Additional Control Variables .................................. 77

Data Analytic Techniques......................................... 77

Hierarchical Linear Modeling.................................. 78

Plan of Analysis for Each Research Question..................... $\quad 80$

Chapter III Summary........................................... 81

CHAPTER IV: RESULTS ....................................... 83

Research Question 1: Relationships between MCSs and Achievement........ 84

Overall Mathematics Achievement - Composite Score............... 86

Mathematics Achievement in Number Properties and Operations........ 88

Mathematics Achievement in Measurement ........................ 89

Mathematics Achievement in Geometry........................... 96

Mathematics Achievement in Data Analysis, Statistics, and Probability.. 96

Mathematics Achievement in Algebra............................. 97

Research Question 2: Differentials Based on Disability Status............. 105

Research Question 3: MCS Roles/Responsibilities and Achievement... 109

Relationship between MCS Role 1 and Achievement................... 112

Relationship between MCS Role 2 and Achievement................. 113

Relationship between MCS Role 3 and Achievement.................. 114

Relationship between MCS Role 4 and Achievement.................. 114

Relationship between MCS Role 5 and Achievement.................. 115

Relationship between MCS Role 6 and Achievement.................. 116

Chapter IV Summary............................................. 119

CHAPTER V: DISCUSSION AND IMPLICATIONS................... 120 
Summary of the Study.

Restatement of Problem Statement................................. $\quad 120$

Restatement of Purpose and Research Questions .................... 121

Review of Methodology and Approach to Analyses................... 123

Summary of Findings .......................................... 124

Discussion and Implications for Mathematics Education.................... 125

Limitations and Recommendations ........................................ 133

Future Research ................................................. 135

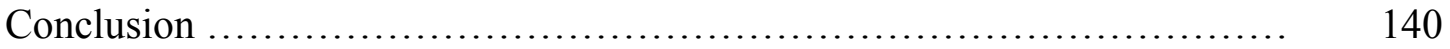

REFERENCES ...................................................... 142

APPENDICES ….................................................... 155

Appendix A: Full List of Potential School, Teacher, and Student Covariates

Considered for PCA Work and All Additional Control Variables Used in the HLM Analyses...........................................

CURRICULUM VITA...................................................... 157 


\section{LIST OF TABLES}

TABLE

1. Roles and Responsibilities of Mathematics Coaches/Specialists as defined in the 2011 NAEP dataset.............................. 12

2. Descriptive Statistics for the 2011 NAEP Mathematics Assessment........ 63

3. Descriptive Statistics for the Roles and Responsibilities of Mathematics Coach/Specialist as Defined in the 2011 NAEP Dataset ............... 66

4. Descriptive Statistics for the Roles and Responsibilities of Mathematics Coaches/Specialists as defined in the 2011 NAEP dataset...............

5. Final Components Resulting from PCA of Student Variables and used as Composite Covariaties.........................................

6. Final Components Resulting from PCA of Teacher Variables and used as Composite Covariaties

7. Final Multi-level Model Examining the Relationship between Overall (Composite) Mathematics Achievement and a School's Policy of Providing a Full-Time or Part-Time Mathematics Coach/Specialist (MCS) 90

8. Final Multi-level Model Examining the Relationship between Number Properties and Operations Mathematics Achievement and a School's Policy of Providing a Full-Time or Part-Time Mathematics Coach/Specialist (MCS) 
9. Final Multi-level Model Examining the Relationship between Measurement Mathematics Achievement and a School's Policy of Providing a Full-Time or Part-Time Mathematics Coach/Specialist (MCS)

10. Final Multi-level Model Examining the Relationship between Geometry Mathematics Achievement and a School's Policy of Providing a Full-Time or Part-Time Mathematics Coach/Specialist (MCS)

11. Final Multi-level Model Examining the Relationship between Data Analysis, Statistics, and Probability Mathematics Achievement and a School's Policy of Providing a Full-Time or Part-Time Mathematics Coach/Specialist (MCS)

12. Final Multi-level Model Examining the Relationship between Algebra Mathematics Achievement and a School's Policy of Providing a Full-Time or Part-Time Mathematics Coach/Specialist (MCS) .......... 103

13. Final Multi-level Models Examining the Relationship between a School's Policy of Providing a Full-Time or Part-Time Mathematics Coach/Specialist (MCS) and Students' Mathematics Achievement based on Disability Status

14. Roles and Responsibilities of Mathematics Coach/Specialist as defined in the 2011 NAEP dataset.......................................

15. Final Multi-level Models Examining the Relationship between Principal-Reported Time Spent on the Six Different Roles and Responsibilities of Full-Time Mathematics Coaches/Specialists (MCS) and Students' Mathematics Achievement 
16. Statistically Significant Relationships between Principal-reported

Time Spent on the NAEP-defined Mathematics Coaches/Specialists

(MCS) Roles and Responsibilities and Fourth-Grade Students'

Mathematics Achievement .......................................... 


\section{LIST OF FIGURES}

FIGURE

PAGE

1. Conceptual Framework for Examining the Relationship between

Mathematics Coaches and Specialists and $4^{\text {th }}$ Grade Students' Mathematics

Achievement....................................................

24

2. Approximate School Sample Size ................................. 59

3. Approximate Student Sample Size .............................. 60

4. Model Predicted Values for Students based on Disability and MCS Status 129 


\section{CHAPTER I}

\section{INTRODUCTION}

\section{Overview}

The current study examines the impact of mathematics coaches and specialists on fourth-grade students' mathematics achievement. As a focus on improving students' understanding and performance in mathematics is of high priority for many stakeholders, including students, parents, teachers, administrators, and policymakers, many districts have turned to mathematics coaches and specialists as a catalyst for these changes (e.g., Fennell, 2006, 2011; Reys \& Fennell, 2003). Viewed under the lens of the cognitive apprenticeship model of learning (Collins, Brown, and Newman, 1987), mathematics

coaches and specialists are the instructional experts that guide and support the learning of the less experienced novice (e.g., teacher or student) in a cooperative and interactive environment. Scaffolding, a structured guidance and support model (initial heavy guidance that fades to limited support), making thinking visible, and situated learning experiences characterize the foundation of cognitive apprenticeship learning model, which provides the basis for the coach-teacher, coach-student, and teacher-student relationships occurring in schools and classrooms across the country.

The research available has shown that mathematics coaches and specialists can be powerful instructional change agents (e.g., Baldinger, 2014, Campbell, 1996; Race, Ho, \& Bower, 2002) and have the ability to positively impact student achievement (e.g., Brosnan \& Erchick, 2010; Campbell and Malkus, 2011; Foster and Noyce, 2004). These 
instructional leaders may be needed now more than ever as the Common Core State Standards for Mathematics (National Governors Association Center for Best Practices \& Council of Chief State School Officers [NGA \& CCSSO], 2010) calls for more in-depth, conceptual understanding in the teaching and learning of mathematics, as well as the call for change in how mathematics instruction is presented to and practiced by students through the implementation of Standards for Mathematical Practices (NGA \& CCSSO, 2010) and the guiding principles for school mathematics outlined in the recently released Principles to actions: Ensuring mathematical success for all book by the National Council of Teachers of Mathematics ([NCTM], 2014). Therefore, substantiation of the successes and benefits of mathematics coaches and specialists is essential, as often policy decisions are currently being made about their implementation in schools without sufficient empirical research (e.g., National Mathematics Advisory Panel [NMAP], 2008).

\section{Statement of the Problem}

In recent years, an emphasis on accountability and an effort to improve student performance and achievement in mathematics has gained national attention (e.g., Campbell \& Malkus, 2011; Hartman, 2013). With the reauthorization of the Individuals with Disabilities Education Act ([IDEA], 2004), the authorization of the No Child Left Behind Act ([NCLB], 2008), states, districts, schools, and teachers have felt an increased pressure to ensure that all students achieve at a high level in mathematics across K-12 (Fennell, 2006; Hartman, 2013), including students at risk for mathematical failure and students with disabilities (Judge \& Watson, 2011). However, it is noted that students continue to struggle in mathematics compared to their international counterparts 
(International Association for the Evaluation of Educational Achievement [IEA], 2013; NMAP, 2008). Furthermore, research indicates that students with learning disabilities and those at risk for mathematic failure continue to perform below students without disabilities in measures of mathematic achievement (Faulkner, Crossland, \& Stiff, 2013; Judge \& Watson, 2011; National Assessment of Educational Progress [NAEP], 2013). In addition to the issues noted in students' mathematics performance, research indicates that teachers often have fragmented mathematical knowledge and focus on procedures as opposed to conceptual understanding during instruction (e.g., Ball, 1991; Ma, 2010; Tatto et. al, 2012). Even with the implementation of the Common Core State Standards (Common Core State Standards Initiative [CCSSI], 2014), which aim to improve the teaching and learning of mathematics, if a change in schools and classrooms that breaks the pattern of algorithm-driven mathematics that focuses on the memorization of steps (Ball, 1990) does not occur, struggles in mathematics will more than likely continue.

\section{US Student Performance}

International. Over the past twenty years, fourth-grade and eighth-grade students from around the world have participated in the Trends in Mathematics and Science Study (TIMSS), which is held on a 4-year testing cycle (IEA, 2013). In the most recent assessment year, 2011, "countries in Eastern Asia continue to lead the word in mathematics achievement" (Mullins, Martin, Foy, \& Arora, 2012, p. 35) for both fourthand eighth-grade students. Fourth-grade students from the United States ranked $11^{\text {th }}$ out of 52 participating countries and $9^{\text {th }}$ out of 45 countries on the eighth-grade assessment. Although TIMSS scores have steadily increased since 2003 for fourth-grade students in the United States, students in eighth-grade from the United States have remained 
relatively stagnant (Mullins et al., 2012). Additionally, the TIMSS data reveals scores above the international centerpoint (500) in the relative achievement of the 2007 US fourth-grade cohort when they reached eighth-grade in 2011, however, the relative position above the benchmark was far below some of their international counterparts (Mullins et al., 2012). For example, in 2007 US fourth-grade students' average performance was 29 points above the scale centerpoint of the assessment, whereas Singapore's fourth-graders were on average 99 points above. Similarly, in 2011 US eightgrade students' performance was 9 points above the centerpoint, whereas Singapore's eight-grade students were 111 points above.

At this time, the TIMSS study does not include an indicator of students' disability status; consequently, information specific to students with disabilities cannot be obtained. Nonetheless, overall patterns in the TIMSS data reveal that students from the United States continue to rank lower than students from other countries and, therefore, a need to improve student progress is necessary.

National. In addition to lagging behind international peers, US students' struggles on national performance tests are noted as well. The National Assessment of Educational Progress (NAEP) Mathematics Assessment, which assessed more than 186,00 fourthgraders and 190,000 eighth-graders nationwide, measures students' knowledge across five content areas: 1) number properties and operations, 2) measurement, 3) geometry, 4) data analysis, statistics, and probability, and, 5) algebra (National Center for Education Statistics [NCES], 2013, p. 3).

In the most recently released data from NAEP, the majority of students continued to perform below proficient on the mathematics portion of the assessment (NAEP, 2013). 
Proficient at the fourth-grade level is defined as “...students...should consistently apply integrated procedural knowledge and conceptual understanding to problem solving in the five NAEP content areas" (NCES, 2013, p. 6). Fourth-grade proficiency is reached when students score between a 249 and 281 out of a possible 500 (eighth grade is between a 299 and 332 out of a possible 500; NCES, 2013). In 2013, 42\% of fourth-graders performed at or above proficient, whereas $35 \%$ of eighth-graders reached this level. Significant gains were shown in fourth-grade achievement scores compared to results in 2011; however, the same gains were not seen among eighth-graders.

When data are compared between higher and lower performing students, additional problems arise. For example, from 2011 to 2013, mathematics score gains in grades 4 and 8 were noted for students at the $75^{\text {th }}$ and $90^{\text {th }}$ percentiles (i.e., higher performing students), but no significant gains were reported during the same time period for students at the $10^{\text {th }}$ and $25^{\text {th }}$ percentiles (i.e., lower performing students; NAEP, 2013). Moreover, an achievement gap remains evident between students with and without disabilities. Since 1996 (when accommodations were allowed on NAEP) to 2013, students without disabilities have experienced a 20-point increase in their average mathematics score compared to a smaller 15-point increase for students without disabilities. Even more troublesome than the slower increase in scores for students with disabilities is the actual disparity of scores between students with and without disabilities. In 2011, the average score for a student with a disability was a 218 , whereas the average score for a student without a disability was a 244 . This disparity slightly increased in 2013, with scores of 218 and 245 for students with and without disabilities, respectively (NAEP, 2013). So not only are student with disabilities earning significantly lower scores 
than students without disabilities, they are making gains at a slower pace, which ultimately widens the notorious gap in scores between students with and without disabilities.

Overall, recent NAEP results do indicate an increase in fourth-grade students mathematics achievement from the 2011 assessment to the 2013 assessment; conversely, these same positive results are not seen among eight-graders. In addition, results comparing students with and without disabilities are troublesome, showing students with disabilities performing well below their peers without disabilities. Results show some promise, however, it is clear that additional support is needed for US students in mathematics.

\section{Teachers' Mathematical Understanding}

A reliance on procedural knowledge and a focus on rules is not only a problem seen among students in the United States, it is a practice often associated with the mathematical knowledge of teachers in the United States as well (e.g., Ball, 1990; Ma, 2010; Newton, 2008; Tatto et al., 2012; Tirosh, Fischbein, Graeber, \& Wilson, 1999). Research acknowledges the link between teacher subject matter knowledge and student learning outcomes (Siegler, et al., 2010); however, this may prove to be problematic as several studies have confirmed that the way teachers have been taught (i.e., procedural focus and rote memorization) influences the way they teach (e.g. Ball, 1990; Zhou et al., 2006). For instance, in a study conducted by Tirosh (2000) on prospective elementary teachers' conceptions of rationale numbers, one teacher's quotation expresses his/her general lack of conceptual knowledge: “I know this rule perfectly well, but I don’t know why. I know how to do many things in mathematics, but I don't know why" (p.16). 
Often, teachers have not been given the opportunity to fully develop the conceptual knowledge of underlying mathematical concepts; therefore, they may be ineffective in teaching for understanding (Ball, 1990, 1991; Tatto et al., 2012; Tirosh, 2000; Zhou et al., 2006). Ball (1991) documented some common assumptions among teachers that support a superficial view of mathematics content. Examples of these assumptions include: if the steps to solve a problem are able to be followed, mathematics is understood; mathematics is learned to be able to move on to the next class; and mathematics only compromises just a group of random facts and rules used to solve a given problem. If these beliefs continue, rote memorization and traditional algorithms may continue to dominate instruction in the classroom.

\section{Implementation of the Common Core Standards for Mathematics and the Standards for Mathematical Practices}

In 2009, a state led effort to establish consistent learning goals across the country culminated in development of the Common Core State Standards (CCSSO, 2010; Common Core State Standards Initiative [CCSSI], 2014). The CCSS aim to "provide a clear and consistent framework for educators...that define the knowledge and skills students should gain throughout their K-12 education in order to graduate high school prepared to succeed in entry-level careers, introductory academic college courses, and workforce training programs" (CCSSI, 2014, para.3-4). In doing so, the CCSS are comprised of a set of standards that are research-based, focus on rigorous content and skills, require the application of higher-order thinking skills, and draw upon prior state standards and top-performing international practices (CCSSI, 2014). 
Specifically, the Common Core State Standards for Mathematics (CCSSM) were designed to address the "mile wide and an inch deep" curriculum problem that has plagued mathematics education in the United States for years (CCSSI, 2014). The CCSSM provide a precise content focus that specifically addresses the mathematics that students need to understand to be successful from grade to grade. The mathematics standards strive for conceptual understanding of core concepts and applications to realworld situations in a manner organized within and across grade-levels that is based on research about how students learn (CCSSI, 2014; NGA \& CCSSO, 2010).

The CCSSM not only requires students to develop a deeper understanding of what it means to learn and do mathematics, it requires educators to have this knowledge and be able to translate it to students in a meaningful way as well. Without first developing more in-depth knowledge among teachers, students may not receive the conceptual instruction (Ball, 1991) that the CCSSM assess, thus perpetuating the cycle of fragmented and procedural mathematical understanding that has consistently been associated with mathematics in the United States (e.g., Ball, 1990; Ma, 2010; Mullins et al., 2012). As such and with the implementation of the Common Core in 43 states (CCSSI, 2014), it is even more paramount that students are being taught for understanding, problem solving, and application rather than memorization and regurgitation of facts and formulas. To do this, our educators must be provided the support needed to make these changes.

In addition to the implementation of the CCSSM, adoption of the eight Standards of Mathematical Practices (NGA \& CCSSO, 2010) has fueled and highlighted this change in the way that mathematics instruction is viewed, learned, and taught. The Mathematical Practices guide how teachers and students should interact with 
mathematics - focusing on changing mathematics instruction into a dynamic process that utilizes research-based instructional strategies to develop effective problem solvers. Without a way to support teachers' growth in both content knowledge and pedagogical knowledge, incorporating the CCSSM and the Mathematical Practices may not produce the meaningful mathematics learning that is the foundation in their development and implementation.

\section{Existing Literature on Mathematics Coaches and Specialists}

With the need to increase student performance and provide a more challenging mathematics curriculum, school systems are exploring ways to support teachers and create teacher leaders who can promote high quality mathematics instruction that meets the needs of all students, incorporates the CCSSM, and supports the Standards of Mathematical Practices (Campbell \& Malkus, 2011; Fennell, 2011, 2006; Polly, Mraz, \& Algonzzine, 2013; Reys \& Fennell, 2003). Relying on research on effective professional development (PD), which indicates that content-specific and prolonged duration of the PD provide the best avenue for impacting teacher knowledge and change (Garet, Porter, Desimone, Birman, \& Yoon, 2001; Guskey, 2003; Ingvarson, Meiers, \& Beavis, 2005), many districts and schools have created positions for mathematics coaches and specialists (e.g., Campbell \& Malkus, 2011; Chval et al., 2010).

McGatha (2009) defines mathematics coaches as "those who work directly with teachers" and mathematics specialists as "those who work directly with students" (p. 1). Although McGatha defines each role distinctly, much of the literature on mathematics coaches and specialists use these terms interchangeably and even by other names, such as teacher leaders (e.g., Campbell \& Malkus, 2011). Whether referred to as a coach, 
specialist, teacher leader, or various other terms, the primary purpose of these instructional leaders is to increase student achievement (Campbell \& Malkus, 2009; Obara, 2010). While serving in numerous roles and holding various responsibilities, mathematics coaches and/or specialists have demonstrated the potential to positively influence teachers' instructional practices and beliefs in both qualitative and quantitative research (e.g., Baldinger 2014; Campbell, 1996; Race, Ho, \& Bower, 2002). However, limited empirical research has been conducted to determine how the use of mathematics coaches and/or specialists (MCS) impacts student learning and achievement (Campbell \& Malkus, 2009; Marsh, McCombs, \& Martorell, 2010; NMAP, 2008).

The dearth of research on the effectiveness of MCS (NMAP, 2008) leaves states, districts, schools, administrators, and educators making policy decisions on the implementation of MCS without a solid evidence base to support this decision. The critical question remains - What are the effects of MCS on students' mathematics learning and achievement? To address this question, we must determine if the school's policy of providing a MCS will increase students' mathematics achievement. Moreover, we must determine how MCS affect mathematics achievement and determine which students benefit most from this level of support. Additionally, we must examine the types of activities that MCS engage in and determine how time spent on roles and responsibilities are related with students' mathematics achievement.

\section{The Current Study}

Although a strong call for MCS has been issued as a way to improve students'mathematics achievement with some states moving or having moved to state certifications (Fennell, 2011), limited research exists to show the impact this policy has 
on students' learning and achievement. Most studies have used purposive samples that focus on teacher changes in instructional practices and beliefs rather than the effect on student performance. Results have shown positive implications from the use of MCS; however, support of these initial findings is needed and connections need to be made from changes in beliefs and instructional practices to actual student achievement.

Additionally, research that addresses how MCS affect different populations of students, such as students with disabilities, is virtually nonexistent and is of great importance with the continued focus of equity in mathematics education. Unfortunately, policy decisions about investing resources and schools utilizing MCS are often made without empirical evidence to substantiate this implementation.

\section{Research Questions}

The purpose of the current study is to examine the relationship between MCS and the mathematics achievement of fourth-grade students; examine whether that relationship differs for students with and without disabilities; and, examines the relationships between principal-reported time spent on the six different roles and responsibilities of MCS and fourth-grade students' mathematics achievement. Specifically, the current study has three empirical research questions focused on MCS at the elementary level. The three research questions are as follows:

1. What is the relationship between having a school-based MCS (full-time or parttime) and students' achievement, specifically: a) their overall mathematics achievement? b) their achievement in five specific mathematics content areas (i.e., number properties and operations; measurement; geometry; data analysis, statistics, and probability; and algebra)? 
2. What are the differentials in achievement of students with and without disabilities when they have a MCS in their school or not, specifically differentials in: a) their overall mathematics achievement? b) their achievement in five specific mathematics content areas (i.e., number properties and operations; measurement; geometry; data analysis, statistics, and probability; and algebra)?

3. For schools that have MCS, how does principal-reported time spent on the six different roles and responsibilities, which include providing assistance to teachers and students (See Table 1 for a complete list), relate to students' achievement, specifically: a) their overall mathematics achievement? b) their achievement in five specific mathematics content areas (i.e., number properties and operations; measurement; geometry; data analysis, statistics, and probability; and algebra)?

Table 1

Roles and Responsibilities of Mathematics Coach/Specialist as defined in the NAEP dataset

Roles and Responsibilities of Math Coach/Specialist
a) Provide technical assistance/support to individual teachers about mathematics content or the teaching of mathematics
b) Conduct professional development for groups of teachers about mathematics content or the teaching of mathematics
c) Provide mathematics instruction to students on various topics
d) Provide mathematics instruction to students at various grade levels
e) Provide mathematics remediation/intervention to some student groups
f) Provide mathematics enrichment to some student groups 


\section{Significance of Study}

As Schneider, Carnoy, Kilpatrick, Schmidt, and Shavelson (2007) note, “among educational leaders and policymakers there has been increasing concern regarding the need for scientifically based evidence on which to base funding decisions for specific educational programs and practices" (p. 1). With decisions about the implementation of MCS made across the country, methodologically rigorous, empirically derived evidence is needed to validate this policy choice. The current study will answer the call for highquality educational research by using a large-scale, nationally representative dataset along with advanced statistical analyses in order to provide sound evidence of the relationship between MCSs and students' mathematics achievement.

Considering relationships between MCS and student achievement at these individual and school levels will add to the limited research base on MCS, as well as further the discussion on the policy of providing schools' with MCS. Policy and school implications that could potentially develop from the study include: evidence to support the implementation of full-time or part-time MCS in schools, evidence to as which groups of students may benefit most from working with MCS, and evidence as to how principal-reported time spent on the roles and responsibilities are related to fourth-grade students' mathematics achievement.

Additionally, the study seeks to examine the often understudied connection between mathematics education and special education (Gersten, Clarke, Mazzocco, 2007). With the known discrepancy between students with and without disabilities performance in mathematics (e.g., NAEP, 2013), it is not surprising that an emphasis on ways to improve the teaching and learning of mathematics to all students is being 
emphasized (NCTM, 2014). Findings from the study aim to not only show the relationship between MCS and overall student achievement, but will also provide valuable information on the differential relationships for students with and without disabilities.

\section{Organization of the Dissertation}

The organization of the remaining chapters in this dissertation are as follows:

Chapter II provides the theoretical and conceptual frameworks for the study, as well as a brief review of literature on research related to the key tenets of effective professional development and an in-depth review of the existing evidence on MCS. Chapter III includes a detailed description of the methodology used in the study, including a description of the study design, the sample, the data and variables, and the analytic approaches used. Chapter IV discusses the results obtained through the quantitative analyses described in Chapter III. Chapter V presents the conclusions and implications, limitations, and recommendations for future research. 


\section{CHAPTER II}

\section{LITERATURE REVIEW}

This chapter first provides the theoretical framework chosen for current study, as well as the how the theoretical framework relates to the topic of mathematics coaches and specialists. The rationale for the use of MCS is then provided followed by a brief review of the effective tenets of professional development, which serve as the foundation for the position of MCS. Next, the conceptual framework for the study is presented. Literature on MCS, including literature on the influence of coaching on teacher practice and student achievement follows. Finally, a brief review of the literature on mathematical learning difficulties and disabilities is presented.

\section{Theoretical Framework}

The theoretical framework for the study centers on the work of Collins, Brown, and Newman (1987) and their cognitive apprenticeship model for learning. Cognitive apprenticeship is similar to the traditional or trade apprenticeship ideals of an expert and a novice socially interacting in order to guide the learning of a task in a specific domain (Collins et al., 1987; Dennen, 2004). Unlike traditional apprenticeship models, "cognitive apprenticeship refers to the fact that the focus of the learning-through-guided-experience is on cognitive and metacognitive, rather than on physical, skills, and processes" (Collins et al., 1987, p. 5). The expert-novice relationship translates into a teacher-learner relationship (Atkinson, 1997), where learning occurs through a sequenced use of three teaching methods: modeling, coaching, and fading (Collins et al., 1987). 
Cognitive apprenticeship begins with the novice repeatedly observing the expert in order to provide a conceptual model of the targeted task or process. During this modeling phase, the expert must externalize the steps taken during the cognitive processes, most of which are usually internalized processes. This externalization of typically internalized steps provides the learner (i.e., novice) with an organizational structure and image of what is expected prior to their initial attempt. In other words, modeling provides the novice with an exemplar of the desired task, skill, or process. Once repeated observations of the modeled process have taken place, the coaching phase follows next. It is during this interactive phase that the novice begins to execute the targeted task or process under the guidance of the expert. Coaching focuses on the expert scaffolding learning and providing experiences that allow the novice to develop the skills necessary to use in problem solving and carrying out the targeted tasks or processes. Coaching may be used to direct the novice to a new aspect of the task or process or be used to focus the novice's attention on an overlooked aspect through "highly situated feedback and suggestions" (p. 19). As the novice develops the knowledge and skills necessary to better approximate the targeted task or process, the expert then begins to fade or reduce their involvement in the learning process, providing only suggestions and feedback in order to hone their novice's skills and execution. During the coaching and fading phases, the expert may focus on ensuring the novice is able to articulate their own reasoning as well as reflect on their own practices and those of others, thus building the confidence and expertise of the learner (i.e., novice). It is important to note that the three teaching methods (i.e., modeling, coaching, and fading) are not discrete behaviors taking 
place in a rigid sequence or in isolation, but are executed in a variety of activities that are set in the context of their application and are integrated into practice.

In general, cognitive apprenticeship teaching methods are designed to expose and make visible the hidden thoughts, steps, and processes (i.e., decontextualize the knowledge) in order to allow learners to observe, practice, and execute through the guidance of the expert and others around them.

Collins and colleagues state that the "...teaching methods should be designed to give students the opportunity to observe, engage in, and invent or discover expert strategies in context. Such an approach will enable students to see how these strategies fit together with their factual and conceptual knowledge, and how they cue off and make use of a variety of resources in the social and physical environment" (1987, p. 18).

By developing a cooperative and interactive environment in which tasks and guidance are sequenced to reflect the nature of the learning (i.e., use of scaffolding), the expert-novice or teacher-learner relationship can provide a model in which the acquisition of expertise and problem-solving skills can improve overall learning.

\section{Theoretical Framework in Relation to the Current Study}

Coaching is viewed as a mechanism to help improve instructional practices and student learning through a form of apprenticeship where the coach is viewed as an instructional leader that provides guidance and support to less proficient teachers and students (Alloway \& Jilk, 2010; Neufeld \& Roper, 2003). As such, this study utilizes the cognitive apprenticeship model of learning to understand the coach-student and teacherstudent relationships in the classrooms, as well as a lens to view the coach-teacher 
relationships that occur in schools. In the classroom, teachers (or coaches) are viewed as the knowledgeable experts and the students as the novice learners. In contrast, when thinking about the coach-teacher relationship, the teacher takes on the role of the novice while the coach is viewed as the instructional expert. In each of these situations, the expert guides the learning through a scaffolded approach that reflects the learning demands of the novice (i.e., student) in hopes of "decontextualizing knowledge so that it can be used in many different settings" (Collins et al., 1987, p. 7). Moreover, Collins and colleagues argue that the use of the cognitive apprenticeship learning model is of upmost importance in foundational elementary subjects, such as mathematics. The cognitive and metacognitive skills developed for domains such as mathematics are "foundational not only because they provide the basis for learning and communication in other school subjects, but also because...the processes are basic to learning and thinking more generally" (p. 7). Based on the situated learning aspect of the expert-novice relationship, as well as strong evidence for the learning model in mathematics, the cognitive apprenticeship model provides a sound theoretical backing for the study of mathematics coaches and specialists.

\section{Rationale for Mathematics Coaches and Specialists}

The rationale for the use of MCS is built upon foundational research on effective professional development. MCSs may work with groups of teachers and students, or even one-on-one with teachers and students, to influence and change instructional practices in an effort to improve teaching and learning. By relying on the tenets of effective professional development (PD), such as providing ongoing, focused, and interactive learning experiences, MCS may be the key to changing teacher practices in the 
classrooms. As Kretlow, Cooke, and Wood (2012) state, "For practicing teachers, PD is perhaps the most important bridge from research to classroom implementation" (p. 349). The essential elements of PD that MCSs engage in through their work with teachers are described next.

\section{Effective Professional Development Practices}

To meet the demands of high stakes testing and the need for higher levels of student achievement, a shift in the way teachers view what students are learning and how they are taught is needed (Borko, 2004; Garet, Porter, Desimone, Birman, \& Yoon, 2001). PD is a way to provide continual support and structured learning opportunities for teachers (Koellner, Jacobs, \& Borko, 2011). Through PD changes in teachers' attitudes, beliefs, and practices can be achieved in the hopes of affecting student learning (Guskey, 2002). High quality PD that makes connections between the key components of a PD system, which include facilitator (e.g., coach), teacher, and the context, heightens the impact on teacher learning (Borko, 2004).

Although not always agreed upon, a general consensus of effective components for PD emerge based on the literature reviewed. Characteristics and practices supported by the research include: a) focus on specific content, b) prolonged duration/time span, c) active learning, d) collaboration, e) coherence, and f) feedback and follow up (Birman,

Desimone, Porter, \& Garet, 2000; Garet et al., 2001; Guskey, 2003; Hill, 2009;

Ingvarson, Meiers, \& Beavis, 2005). The two most common themes seen in the literature on effective PD that showed to impact teacher knowledge was a focus on content (Birman et al., 2000; Garet et al., 2001; Guskey, 2003; Hill, 2009; Ingvarson et al., 2005) 
and the duration of the PD sessions (Birman et al., 2000; Garet et al., 2001; Guskey, 2003; Ingvarson et al., 2005).

With teachers being asked to teach new standards on a more conceptual level, PD must provide the avenue for teachers to gain an advanced understanding of content. PD should focus on specific content areas or content-specific teaching methods, rather than a generic focus on teaching techniques (Birman et al., 2000). Teachers want to expand their knowledge and skills through PD that provides "specific, concrete, and practical ideas" for incorporation into their classroom practice (Guskey, 2002, p. 382).

Duration has been shown to be a key factor of effectiveness in PD. The development of meaning and changes in learning takes considerable time; therefore, the design of PD programs must give teachers sufficient and prolonged time to develop conceptual understanding and gain the confidence needed to incorporate this type of instruction into the classroom (Borko, 2004). Findings show that prolonged PD has a greater chance of impacting teacher knowledge and practice. PD that occurs over an extended time period (i.e., multiple sessions over a period of time) can allow for more learning opportunities, as well as developing a community feel, and focusing on specific content (Birman et al., 2000; Ingvarson et al. 2005). Although, the time spent on PD seems to produce positive results, the time must reflect organized, focused, and carefully structured and directed goals in order to truly be effective (Guskey, 2003).

While content and duration are important factors for effective PD, attention must be given to how PD is delivered. Ingvarson et al. (2005) found that providing teachers the opportunity for active learning and reflection on practice had a strong influence on teacher practice. Active learning incorporates a variety of components, such as engaging 
discussions and planning, analysis of their own teaching and student learning based on quality standards, observations of expert teachers and opportunities to be observed teaching, review of student work, and curriculum development (Birman et al., 2000; Garet et al., 2001; Ingvarson et al., 2005). Regular feedback on their efforts and continued follow-up are also necessary during the active learning process (Guskey, 2002). By providing teachers with this type of learning experience, teachers can increase the knowledge and skills, as well as make meaningful and lasting changes to instructional practices (e.g., Garet et al., 2001).

Active learning can be extended through the use of collective collaboration among teachers (Garet et al., 2001), where teachers can share ideas and practices guided by the goal of student learning (Guskey, 2003). By providing PD to groups of teachers from the same school, department, or grade level, teachers have the opportunity to discuss their specific students' needs, curriculum materials, and how to integrate the information gained into their instructional context. A more coherent experience for teacher learning and development can be achieved by using this collaborative approach (Birman et al., 2000; Garet et al., 2001).

Guskey (2002) concludes, "professional development must be seen as a process, not an event" (p. 388). Research has shown that specific components of PD, such as a focus of content, prolonged duration, and active learning, positively impact and change teacher practice. For these sustained changes to occur, teachers must receive the support they need.

As the need to improve the teaching and learning of mathematics is paramount, school systems are relying on the effective tenets of PD and creating positions for 
instructional change agents, often referred to as mathematics coaches and/or specialists (MCS). By providing job-embedded support to teachers, districts and schools anticipate MCS will be the catalyst needed in schools and classrooms to improve students' mathematical understanding and performance (Campbell \& Malkus, 2011; Chval et al., 2010; Dossey, 1984; Fennell, 2006, 2011; Polly, Mraz, \& Algonzzine, 2013; Reys \& Fennell, 2003).

\section{Conceptual Framework}

The conceptual framework used for the current study (see Figure 1) draws upon Desimone's (2009) model for "studying the effects of professional development on teachers and students" (p. 185) and Campbell and Malkus's (2011) model for "studying the impact of elementary mathematics coaches on teachers and students" (p. 433). Desimone's model highlights the importance of the links between core features of PD, including teacher knowledge, practice, instruction, and beliefs, and student learning and achievement. Campbell and Malkus (2011) modified Desimone's core conceptual model to incorporate elementary mathematics coaches as a distinct aspect of the PD process. In their model, the role of coaches--in their specific study--included interactions with teachers, as well as an influence on the school mathematics program. The mathematics coaches (nested within a larger PD program) formed the basis from which anticipated changes in teachers' instruction and practices would lead to improvements in students' learning and achievement.

By combining attributes from frameworks focused on PD and mathematics coaching, the current conceptual framework provides a roadmap of the specific study at hand. The conceptual framework allows readers to navigate through the specifics of the 
study, which begin with effective components of PD and end with improved student learning and achievement. In the current study, MCS play the role of change agents in the teaching and learning of mathematics. 


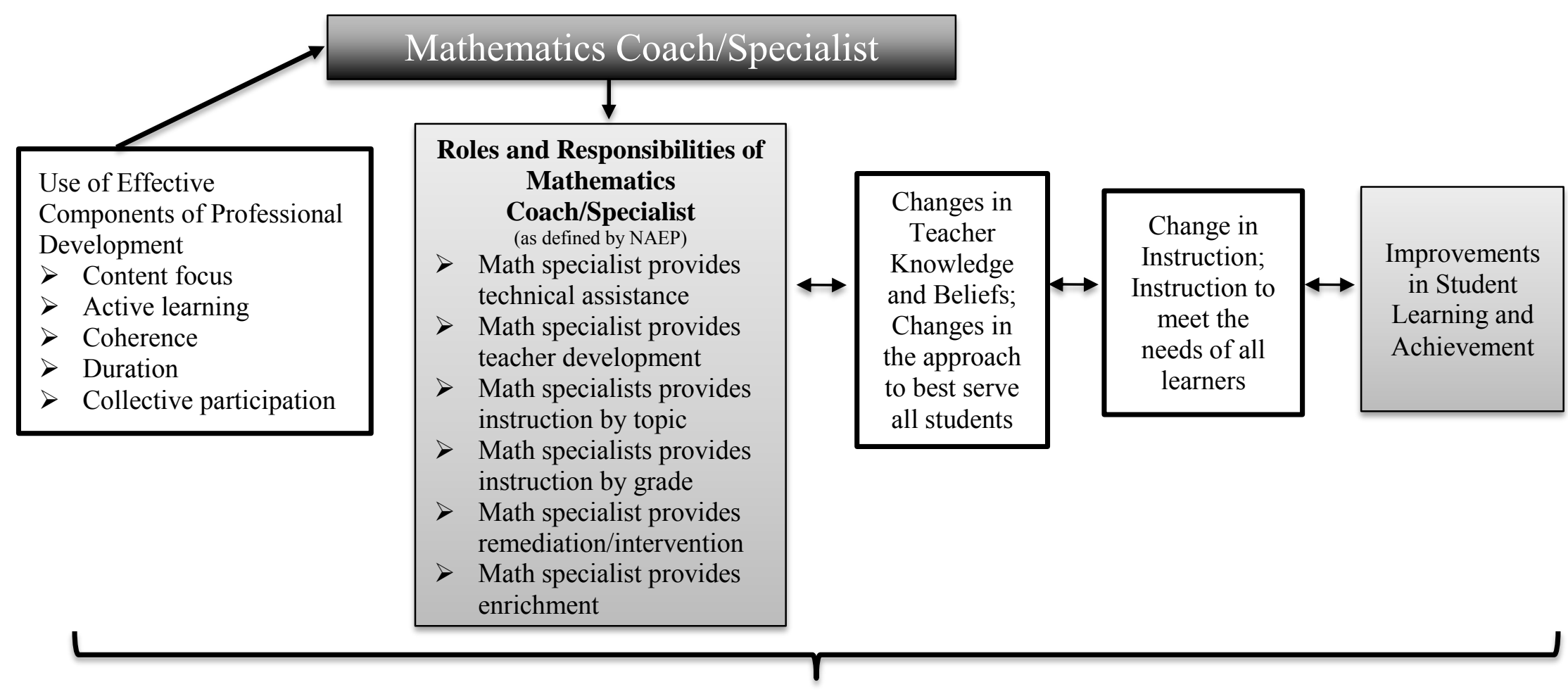

Contexts: Student, Teacher, and School Characteristics and Demographics

Figure 1. Conceptual Framework for Examining the Relationship between Mathematics Coaches and Specialists and ${ }^{\text {th }}$ Grade Students' Mathematics Achievement. The conceptual framework used for the current study draws upon Desimone's (2009) model for "studying the effects of professional development on teachers and students" (p. 185) and Campbell and Malkus's (2011) model for "studying the impact of elementary mathematics coaches on teachers and students" (p. 433). The highlighted boxes designate the scope of the current research project. Additionally, the contextual factors (i.e., student, teacher, and school during-treatment covariates) are controlled for during analyses. 


\section{Research on Mathematics Coaches and Mathematics Specialists}

The terms mathematics coach and mathematics specialist are often defined in various ways; trying to provide distinct definitions of mathematics coaches and specialists is difficult as there is "considerable blurring across the types and roles" (NMAP, 2008, p. 43). As noted, McGatha (2009) provides a distinction between coaches and specialists dependent upon with whom they work: mathematics coaches work with teachers, whereas, mathematics specialists work with students. The Examining Mathematics Coaching (EMC) Project, a five-year project that examined the relationship between mathematics coach's knowledge and their effectiveness with K-8 teachers mainly located in the northwestern region of the U.S., provided the following definition of mathematics coaching: "A mathematics coach is an on-site professional developer who enhances teacher quality through collaboration focusing on research-based, reform-based, and standards-based instructional strategies and mathematics content that includes the why, what, and how of teaching mathematics" (Burroughs, \& Yopp, 2011, p. 16). The Association of Mathematics Teacher Educators (2013) defines mathematics specialists in broader terms as "teachers, teacher leaders, or coaches who are responsible for support effective mathematics instruction and student learning at the classroom, school, district, or state levels" (p. 1). Whether defined specifically or generally, mathematics coaches and specialists are essentially instructional leaders that may work in multiple settings and situations in order to advance mathematics teaching and learning. For the current study's purposes, the terms coaches and specialists shall be used interchangeably depending on the wording of the research reviewed. The term mathematics coaches and/or specialists, 
MCS, will be used when referencing the overarching theme of instructional leaders and when referencing the NAEP variables.

\section{Roles and Responsibilities of MCS}

MCS take on varying roles and responsibilities (McGatha, 2009; Obara, 2010), which are typically established "according to the needs and plans of each setting" (Association of Mathematics Teacher Educators, 2013, p. 1). Whether referred to as a coach, specialist, teacher leader, or various other terms, the primary purpose of these instructional leaders is to increase student achievement (Campbell \& Malkus, 2009; Obara, 2010) by disrupting the "culture of teacher isolation whereby teachers work in private without observation or feedback and to collaborate with other professionals" (Campbell \& Malkus, 2011, p. 431). By concentrating on curriculum, instruction, and assessment, MCS focus on the improvement of mathematics teaching and learning in a multitude of ways (McGatha, 2009; Obara, 2010). MCS may work at the school and district level on issues related to curriculum and instruction (Dossey, 1984; Fennell, 2011), help teachers to prepare and implement lessons and instructional strategies in the classroom (Campbell \& Malkus, 2011; Knight, 2005), as well as acquire resources and research-based practices to use in instruction (Neufeld \& Roper, 2003). Responsibilities may also include modeling and providing PD for teachers (Campbell \& Malkus, 2009;

Chval et al., 2010; Polly et al., 2013; Fennell, 2011); conducting observations and providing feedback to teachers (Kretlow et al., 2012; Neufeld \& Roper, 2003); examining student assessments and data to inform decision making (Chval et al., 2010; Marsh et al., 2010; Polly et al., 2013). Additionally, delivering enrichment for mathematically promising students (Dossey, 1984) and taking part in planning and providing 
interventions to students (Chval et al., 2010; Fennell, 2011) may fall to MCS. Although the list of roles and responsibilities of a MCS is abundant, the research on the effect of MCSs is sparse (e.g., NMAP, 2008; McGatha, 2009). That being said, recent research has shown that coaching is a promising practice and policy that could potentially advance instructional growth and teacher change (e.g., Campbell \& Malkus, 2011; Kretlow et al., 2012; McGatha, 2009).

Full-time versus Part-time Support. Districts have taken two approaches to the implementation of MCSs: placing a full-time MCS in one school or having one MCS service multiple schools (creating a part-time MCS position for each school). For instance, in Campbell and Malkus's (2011) study on the impact of elementary coaches on student achievement, one coach was assigned to each treatment school and was therefore involved in designated coaching activities with one school on a daily basis. On the other hand, Balfanz, Mac Iver, and Byrnes's (2006) study on the implementation and impact of reforms (including coaching) in high poverty schools assigned each middle school a curriculum coach that spent one-to-two days per week in each school. Often times, the amount of coaching support (i.e., full-time versus part-time) provided in schools is not reported. Furthermore, in the current literature search, no evidence on the effects of fulltime versus part-time coaching support was found.

\section{Mathematics Coaching and Teacher Practice}

The majority of studies conducted on MCS have addressed how mathematics coaching is a means to changing teachers' instructional practices and beliefs through the use of PD, guidance, and support. Both quantitative and qualitative research has found positive relationships between mathematics coaching and improved mathematics 
instruction (e.g., Alloway \& Jilk, 2010; Baldinger, 2014; Campbell, 1996; Kretlow et al., 2012; Kretlow, Wood, \& Cooke, 2011; Race, Ho, \& Bower, 2002; Rudd, Lambert, Satterwhite, \& Smith, 2009). Although the majority of studies conducted on mathematics coaches show the potential to influence teachers' instructional practices in a positive direction, results are influenced by the type and intent of the coach (e.g., Becker, 2001; McGatha, 2008) and teachers' varying experiences and ideas of how mathematics should be taught (e.g., Ai \& Rivera, 2003; Olson and Barrett, 2004).

Campbell (1996), Race, Ho, and Bower (2002), and Alloway and Jilk (2010) all found that by using a mathematics coaching component as part of a large-scale professional development program, teachers were able to make noteworthy changes towards improving their instruction. Teachers reportedly increased their use and variety of effective instructional practices (Race et al., 2002), engaged students in developing a more in-depth understanding of mathematical content (Campbell, 1996), and utilized their planning time in a more focused manner and generalized their experiences to other context (Alloway \& Jilk, 2010).

As part of an effort to improve mathematics instruction and student achievement in urban, public elementary schools, the University of Maryland at College Park and Maryland's Montgomery County Public Schools formed a partnership to address the call for reform in mathematics education, Project IMPACT (Increasing the Mathematical Power for All Children and Teachers; Campbell, 1996). A summer in-service program for mathematics teachers, an on-site mathematics specialists for each participating school, as well as materials and common planning time were among the school-wide reform efforts involved in the project. Teachers reported mathematics specialists as a critical component 
to the project model. The mathematics specialists became a "mechanism to support change, to foster implementation, to promote reflection, to applaud efforts, and to challenge further growth" (p. 462). In the vast majority of classrooms, instructional change was apparent. Teachers became more focused on the mathematical goals of each lesson, encouraged students to use materials to aid their learning, engaged students and increased participation through sharing of multiple strategies and describing their mathematical thinking, as well as increased their students' and their own ability to reflect and reevaluate their work.

Race, Ho, and Bower (2002) found similar positive influences to teachers' mathematics and science instruction in their 3-year intensive professional development program targeted towards high-risk elementary schools in the Chicago, Illinois public school system. The study examined 265 elementary teachers' classroom behaviors during the first year of the professional development program, which was provided by a nonprofit organization (Teachers Academy for Mathematics and Science). The PD program included coaches' support that was to transition from modeling lessons, to co-teaching lessons, to observing and supporting lessons. Implementation logs, a set of standardized set of closed-and-open ended questions, were used to document the classroom visits and reflection sessions between each of the teachers and the PD provider. All logs (approximately 1,541 fully completed logs) were quantitatively analyzed with a smaller portion of logs (159 visit logs from 20 teachers) qualitatively analyzed for additional support to the findings. Results on both primary and intermediate grade-level classes revealed a decrease in the level of support that teachers needed as the PD progressed, an increase in the use of standards-based curriculum aligned with state standards in 
mathematics and science lessons, and an increase in the use of best practices and a variety of instructional strategies (e.g., hands-on activities, discussion, group work). Although attrition was a limitation of the study (reported time commitment issues and scheduling conflicts), a substantial number of coaching sessions and implementation logs were completed and produced an overall positive picture for the use of coaching as a means to positively influence teachers' instructional practices.

Furthermore, as part of a larger research and professional development project, Alloway and Jilk (2010) investigated the activities of one high school instructional coach as part of an effort to improve algebra and geometry teachers' instruction and student learning. All teachers participated in a variety of professional development activities, such as a monthly Video Club, common planning time in their professional learning communities, and weekly instructional coach visits. During these visits, the instructional coaches facilitated teachers' common planning time and provided one-on-one coaching. Fourteen secondary mathematics teachers from three high schools participated in the larger research project; this study focused on four teachers from one high school as this school had showed tremendous progress both instructionally and academically. Data relevant to the research project included videotapes of common planning time and teacher interview transcripts. The four teachers expressed that their work with the instructional coach (the principal investigator of the study) was critical for improving their instructional practices. Through strategic questioning and pointed observations, the instructional coach was able to guide discussions and develop an understanding of new pedagogical approaches. The instructional coach was able to positively influence teachers' work by keeping the planning time focused on students' progress and 
mathematics instruction (maintaining focus), detailing specific instructional activities/moves that teachers were successful at during her classroom observations (assigning competence), and providing connections between teachers' isolated events in their classrooms to more generalized contexts dealing with creating engaging classrooms for all students (generalizing stories).

Additional support of coaching as a way to influence classroom practices was observed in small-scale studies by Rudd and colleagues (2009), Baldinger (2014), Kretlow and colleagues $(2011,2012)$, and Neuberger (2012). Findings indicated that teachers increased their use of research-based practices (Kretlow, 2011, 2011; Rudd et al., 2009), shifted their beliefs about effective mathematics instruction (Neuberger, 2012), and viewed coaching as an integral aspect in leading to changes in their practice (Kretlow et al., 2012).

Rudd and colleagues (2009) conducted a study to investigate how side-by-side coaching influenced the level of implementation of the usage of math mediated language by 12 teachers at a university childhood development center. A survey, the Observational Coding Matrix (OCM), was developed by the researchers for data collection and was used to collect data on the frequency and duration of math mediated language in the classroom. The OCM was broken down into 8 categories (i.e., use of numbers, measurement, graphical display, etc.) and then categorized as either low-level or highlevel depending on the complexity of the mathematics concept. Data were collected during 30-minute observations by handheld computers. Inter-rater reliability of 0.83 was reported, whereas no reliability or validity of the OCM was mentioned. Teachers attended a two-hour training session on the use of math mediated language in the classroom, 
followed by two observations to obtain baseline level of implementation of the training. Using a design similar to a single subject, multiple-baseline design, coaching was introduced using a staggered delivery in an attempt to discern the influence of the twohour session compared to the two-hour session paired with coaching. Each teacher received four sessions of in-class coaching where the coach provided feedback from classroom observations, suggestions, and answered questions. Using aggregated (i.e., whole group) data analyses, the majority of the participants increased their use of math mediated language following the professional development, with an additional increase following the implementation of coaching. Specifically, during the coaching condition, participants averaged a $39.5 \%$ increase in the use of math mediated language over the professional development condition. However, in a follow-up probe this additional bump in usage was no longer evident, but instances of math mediated language were found to be identical to the levels during professional development (i.e., there was still an increase in overall use).

Neuberger (2012) provided additional evidence on the effectiveness of coaching as a way to positively influence teachers' beliefs and practices through a case study of the interactions between one mathematics teacher and one mathematics coach. The study was situated within a large coaching initiative in New York City's public elementary schools that required all new teachers to work with coaches while other teachers were invited to work with coaches. The participating teacher taught in a combined $3^{\text {rd }} / 4^{\text {th }}$ grade classroom in progressive, lower middle-class elementary school. The researcher spent over two months in the school and collected interview and observational data for analysis. Initially, the coach and teacher had different beliefs about mathematics; the 
coach viewed mathematics as a reasoning endeavor, whereas the teacher viewed mathematics as a rigid process with either a right or wrong answer. Evidence showed that the teacher's beliefs about mathematics, as well as the teaching of mathematics, shifted towards the beliefs of the coach. Furthermore, the participating teacher reported an increase in pedagogical and content knowledge, along with the integration of practices that incorporated her new beliefs about mathematics instruction (such as an increased focus on student interaction and promoting discussions during class). Findings indicated that coaching appeared to be an effective form of professional development in changing teacher's beliefs and practices.

Baldinger (2014) presented findings on a study that looked at two coach-high school mathematics teacher pairs and how this relationship and their experiences were situated within the context of their teaching practices. Additionally, the study aimed to develop a visual method for representing these interactions, which the author refers to as a code profile. Coaching was conducted as part of a professional development project entitled Complex Instruction for Secondary Math, which has equity-related goals and helps teachers to support student learning through a learning environment that challenges students and develops rich mathematical thinking. Coaching sessions (provided by the researcher) consisted of three parts: a pre-session to discuss the upcoming lesson, a lesson observation, and post-session to discuss the lesson and steps to move forward. Data for the study included conversations, some recorded, between the coach and the two participating high school teachers. Conversations were coded using an open coding procedure and produced three main categories of talk: learning mathematics, classroom environment and norms, and student compliance. Based on the analysis, the two teachers' 
pattern of talk changed over the course of the coaching sessions. One teacher's focus moved from worries and discussions about student compliance (i.e., classroom management) towards a focus on creating a productive learning environment and the actual mathematical subject matter and mathematical learning. The second teacher, whom already focused more on content than the previous teacher, was able to focus on the larger picture of creating an environment for learning, as well as the mathematics learning. In other words, her conversation "became more integrated....as she reflected on lessons and considered areas of her own growth" (p. 24). In both cases, the shift in teachers' conversations seemed to be based on the coach's responses, intensions, and direction provided during their interactions. This evidence of the influence of the coach on teachers' beliefs about the teaching and learning of mathematics serves to substantiate the findings from Neuberger (2012) in that teacher's beliefs seem to shift towards the beliefs of the coach (i.e., instructional expert) during the coaching process.

Kretlow and colleagues $(2011,2012)$ have also found success from the use of elementary coaches to achieve changes in mathematics teaching and learning, specifically for instruction strategies targeted for students' at risk for academic failure, including students with disabilities. Kretlow, Wood, and Cooke (2011) studied the effects of inservice training and coaching on three kindergarten teachers' accurate delivery of group instructional units in mathematics lessons in a Title 1 elementary school. Group instructional units, a three-part process consisting of an antecedent (teacher)-behavior (student)-consequence (teacher), were used to capture the relationship between teacher and student responses. All three teachers received one group in-service training session, as well as side-by-side and supervisory follow-up coaching sessions. Using a multiple- 
baseline-across-subjects design, data on the percentage of correctly implemented group instructional strategies during 10-minute segments during mathematics instruction were collected for each teacher throughout the three phases of the study: baseline, post-in service training, and post-coaching. Each lesson was audiotaped and analyzed to observe the changes in teachers' accurate use of the instructional strategy presented. Results indicated that the in-service training combined with the coaching sessions improved teachers' group instructional unit accuracy. Additionally, findings showed that each teacher made gains following the staggered introduction of coaching, showing that increased improvements in instructional strategies were gained only after providing teachers with individualized support through coaching sessions. Similar to study implemented by Kretlow and colleagues (2011), Kretlow, Cooke, and Wood (2012) used a multiple-baseline-across-teachers design to examine the effects of an in-service session followed by a coaching session on three first grade teachers' correct implementation of three research based strategies during mathematics instruction. In addition, the study sought to investigate how the inservice training and coaching session lead to generalization of correct implementation of instructional strategies in numeracy and problem solving, which were not specifically addressed by the coach. Teachers were provided one group professional development inservice session and one follow-up coaching session on strategies for introducing new concepts and correcting errors and student response strategies. Audio-recorded lessons served as the data for the study and were collected during regularly scheduled math periods in the general education classroom. Three phases of data were collected and evaluated, which included baseline (no in-service or coaching sessions), post in-service session, and post-coaching session. 
Findings showed that all teachers increased the number of correct instructional strategy implementations both after the in-service session and again after the coaching session. In addition, similar patterns of increased use of desired practices during numeracy and problem solving were noted, however they were not as consistent as those found in math instruction specifically focused on during training. Teachers reportedly found the coaching session more helpful than the in-service session, however both were viewed positively. Teachers also reported the coaching session allowed time for useful dialogue, including time for questions and feedback, about their classroom practices and individual students. Another positive finding was that students appeared to be more engaged and motivated during the implementation of the research-based instructional strategies.

Becker (2001) and McGatha (2008) found somewhat similar positive results based on their qualitative work that studied mathematics coaches and teachers' instructional practices, however their results were somewhat mixed based on the type and intent of the coach. As part of an ongoing project focused on the efficacy of coaching in elementary mathematics classrooms, Becker (2001) used qualitative methodology, including field notes, interviews, observations, and classroom artifacts, to investigate the relationship between the patterns of coaching work and teachers' practice. Six full-time mathematics coaches and 14 elementary teachers participated in the study. Findings showed that coaches took on one of three roles: coach as collaborator, coach as model, and coach as leader. The roles differed on their approach to coaching and ranged from least to most directive in coaching style; however, all roles emphasized helping teachers to improve their mathematics instruction. Becker (2001) found that teachers believed their experiences with mathematics coaches, regardless of classified role, improved their 
instruction and knowledge of the curriculum, which allowed their dialogue and lessons to focus more on the processes of developing student understanding rather than working from page to page in the textbook. Teachers also reported characteristics of coaches that proved effective, which included a non-judgmental demeanor, approachability, and openness to name a few. Becker (2001) tentatively concludes that the role of coach as leader, the most directive approach, may be the most efficacious in deepening teachers' mathematical content and pedagogical knowledge.

McGatha (2008) also used a qualitative approach (case study) while investigating the levels of engagement of two mathematics coaches as they worked to improve their coaching ability and help two elementary teachers improve their mathematics instruction. Reflective analysis was used on a variety of data sources, including data collected from the coaches themselves and data collected from the researcher, to examine how coaches' interactions with teachers progressed over the seven-month investigation and how these interactions related to the actual coaching relationship. Drawing from Cognitive Coaching ${ }^{\mathrm{SM}}$, the roles of consulting, collaboration, and coaching (Costa \& Garmston, 2002) were used to frame the researchers analyses. McGatha found that effective mathematics coaching experiences helped teachers to use student work to guide future instruction and promote student thinking and communication. Results also indicated that as coaches progressed from the role of consultant, to collaborator, and/or to coach, the coaching relationship became more effective. In other words, results showed that the role of "coach", which is when the coach serves as a mediator of the teachers' thinking through strategic questions and prompts, the coach and teacher found the experience 
more valuable. These results are in line with prior research and indicate that the role and goal of the coaching experience is essential for successful coaching relationships.

Although the majority of studies conducted on the relationship between mathematics coaches and the potential to influence teachers' instructional practices are positive, Olson and Barrett (2004) found mixed results when working with three teachers with varying experience and ideas of how mathematics should be taught. Their work was part of a larger project, Primary Mathematics Education Project, which increased the use professional development to improve teachers' pedagogical approaches in mathematics instruction. Similar to McGatha (2008), this study also utilized Cognitive Coaching ${ }^{\text {SM }}$ (Costa \& Garmston, 1994; modified on a need-to-need basis), which was used by two classroom coaches as they worked with three case-study teachers. Constant comparative analysis was used to examine the field notes, samples of student work, audiotaped lessons, and pre- and post-observation conferences. Olson and Barrett (2004) found that the three teachers persisted in using traditional approaches, albeit with innovative materials, in their mathematics instruction. Through coaching, teachers did seem to become more aware of students' construction of mathematical ideas, however, the desired changes in teacher practices were not persistent.

Olson (2005) conducted a small-scale follow up study to her work with Barrett (Olson \& Barrett, 2004) in which coaching was used to support the mathematics reform efforts of one first-grade teacher. Coaching was provided by the researcher and focused on incorporating rich mathematical tasks and questioning into classroom instruction. Through the use of targeted coaching, the participating teacher was able to utilize her own pedagogical curiosity to improve instruction through higher-order questions and 
discussions during mathematics lessons. In contrast to the mixed results noted by Olson and Barrett (2004), coaching had a positive influence on the teacher's practices as noted by the researcher. Of important note is the participating teacher was inclined to use student-centered learning and reform teaching practices prior to the implementation of coaching. This may have promoted the success of the coaching sessions; therefore, it is noted that additional research on the approach of evoking pedagogical curiosity as a viable coaching strategy is needed.

Ai and Rivera (2003) noted a similar discrepancy between teacher's reported effectiveness of coaching and their actual practices as reported in Olson and Barrett's (2004) work with three teachers. Ai and Rivera's (2003) study was set within large-scale studies examining the urban districts' mathematics plan and professional development. A two-tiered random selection process was used to obtain the 40 schools (elementary, middle, and high) and 160 teachers chosen to participate in the current study that focused on the teachers' participation in coaching activities: 1) observing mathematics coaches modeling a lesson, and, 2) being observed while teaching and receiving post-observation feedback from the math coach. A mixed methods approach was used, including survey data, interviews, and observations, to evaluate teacher practice and the influence mathematics coaches may have had on these practices. Results indicated that teacher practice was not influenced by the implementation of mathematics coaches. These results may have been obtained as a result of teachers' resistance to change and the lack of involvement between teachers and coaches. The majority of teachers selected had not participated in either coaching activity, namely $62 \%$ of the elementary teachers and $88 \%$ of secondary teachers, and those that did participate were typically only involved in one 
form of coaching activity. Only four elementary and three secondary teachers participated in both types of coaching activities. Nevertheless, teachers that worked with mathematics coaches reported it as being an effective and positive experience. However, results on a mathematics evaluation demonstrated an inconsistency in teachers' positive views of coaching and their teaching practice; this inconsistency showed that positive selfperceptions may not have actually translated into improved teacher practice.

Summary of Mathematics Coaching and Teacher Practice. Overall, research on MCS largely focuses on the influence coaching has on teachers' beliefs and instructional practices. Studies from large-scale PD projects that utilize coaches to smallscale case studies have documented the positive influence MCSs have on teachers' efforts to improve instruction and incorporate research-based strategies into their classrooms. Findings from numerous studies indicate the implementation of MCS as a promising avenue in providing teachers the guidance and support needed to make meaningful and lasting changes to their practice. Although the majority of studies view MCSs' work as beneficial to influencing positive changes in mathematics instruction, there are studies that have noted limited changes in teachers' practices after working with a MCS. Often teachers' resistance or lack of time with the coach is cited as potential reasons for the limited changes.

\section{Mathematics Coaching and Student Achievement}

The link between student achievement and MCS is of upmost importance; however, limited research has provided evidence on the impact of MCS on students' mathematics performance. Research from only five projects (less than one-third of the 
total projects reviewed) have reported on the relationship between mathematics coaching and students' learning and achievement. Each of the five projects is described next.

Project IMPACT. Dating back almost 2 decades ago, Campbell (1996) conducted research on the effects of Project IMPACT, a professional development initiative that utilized mathematics specialists as a key component (This study is also cited in teacher practice section). Project IMPACT was a large-scale PD program that addressed reform in elementary mathematics in one of Maryland's urban school districts. Mathematics specialists were cited an integral component in influencing instructional change among elementary school teachers involved in the project. Additionally, results of Project IMPACT revealed that students in the treatment schools did out perform students in control schools; however, this was a gradual process. Although the implementation of Project IMPACT began when participating students were in kindergarten, students in treatment schools did not show a statistically significantly higher mathematics achievement score compared to students in control schools until the middle of second grade. Once this performance increase occurred, students in Project iMPACT continued to outperform students in control schools during their third-grade year. These findings showed that a targeted focus on conceptual understanding and problem solving along with the inclusion of coaches as a key instructional leader produced beneficial results to teachers and students.

Silicon Valley Mathematics Initiative. As part of a large-scale, longitudinal professional development project known as the Silicon Valley Mathematics Initiative (SVMI), school districts participated in a collaborative process to improve mathematics teaching and learning, and in turn, raise student achievement. As part of this initiative, 44 
mathematics coaches served as instructional leaders in 28 school districts where they worked primarily with teachers in grades 2 through 7 (Foster \& Noyce, 2004). Foster and Noyce (2004) found that high quality, prolonged professional development that incorporated mathematics coaches to drive instructional change and data-based decisionmaking had a positive impact on student achievement. It was noted that students whose teachers participated in the SVMI initiative, which included mathematics coaching, earned higher averages on the state test and the Mathematics Assessment Resource Service (MARS) exam than students whose teachers did not participate. Increases in student achievement on both measures of academic performance continued to rise through the years the professional development initiative was in place. However, this study did not account for pre-treatment differences, did not provide assessment information for a control group, and used a post-test only design, thus making inferences, comparisons, and generalizations difficult.

Talent Development Middle School Mathematics Program. Balfanz, Mac Iver, and Byrnes (2006) provided evidence of the connection between intensive school reform, including coaching as a component of professional development, and an increase in student achievement in mathematics in high poverty middle schools in Pennsylvania over a four-year period. Similar to the SVMI professional development initiative (Foster \& Noyce, 2004), coaching was situated within a larger, whole-school reform effort, the Talent Development Middle School, which included a component specific to mathematics reform efforts, the Talent Development (TD) Middle School Mathematics Program. As a new mathematics curriculum was implemented, teachers were offered various avenues of professional development, which included summer training, monthly 
workshops, and in-classroom support from a curriculum coach. Data were analyzed from three TD middle schools and three equivalent control middle schools chosen by the district. Findings revealed similar poor performance (i.e., over $70 \%$ of student were performing below grade-level upon entering middle school in both the control and treatment schools) prior to the reform initiative. Using hierarchical linear modeling, the fourth-year data showed that students in the TD schools performed significantly higher on both standardized (i.e., Stanford 9 test) and state assessments than students in the control schools. Additionally, students in the TD schools increased the number of students scoring above the $25^{\text {th }}$ percentile (i.e., the below basic categorization) at a higher rate than their control counterparts. In line with prior research, however, it was noted that students identified as special education showed less achievement growth than students not identified as special education. Interviews and focus groups with teachers in TD schools revealed that teachers believed the in-classroom coaching was beneficial and had a positive view on coaching's intensive support. Evidence also supported that schools with higher levels of implementation averaged higher levels of achievement gains, showing that fidelity of implementation plays a significant role in the success of reform efforts. One limitation to the findings is the difficulty in showing the specific effects of the coaching, as opposed to the effects of the overall reform initiative. Results show significant improvements in student achievement in mathematics during the four-year mathematics reform initiative studied by the researchers; however, data specific to the effects of coaching on student achievement cannot be discerned.

Mathematics Coaching Program. In a series of papers presented at the 2010 and 2011 North American Chapter of the International Group for the Psychology of 
Mathematics Education Annual Conferences, researchers from The Ohio State University (Brosnan \& Erchick, 2010; Coniam, 2010; Harrison, Higgins, Zollinger, Brosnan, \& Erchick, 2011; Zollinger, Brosnan, Erchick, \& Bao, 2010) presented evidence of a positive impact of coaching on students' mathematics achievement in regards to research on their professional development model, the Mathematics Coaching Program (MCP). Through coursework and professional development, the MCP model focuses on developing mathematics coaches that are capable of improving mathematics teaching and learning, including increasing teachers' pedagogical and content knowledge and developing ways to encourage students to become active participants in their mathematical learning. The structure of the MCP model is as follows: Coaches work with four teachers daily for a period of six weeks. The coaches then begin working with another four teachers, while providing a small amount of support to the previous group. During this time, coaches are provided support from the MCP. Coaching activities are focused on low-performing urban and rural schools. The overall results of the studies were encouraging and provide support for the use of mathematics coaches. Evidence from the individual studies is presented next.

Zollinger and colleagues (2010) compared students' mathematics achievement scores in schools with first-year MCP coaches and similar schools not involved in the program. Participants included students in grades 3-8 across 18 schools. For both MCP and non-MCP schools, data from the 2007-2008 and 2008-2009 Ohio Assessment Tests were analyzed according to grade-level and proficiency level (e.g., below proficient, above proficient). Based on aggregated grade level scores, analysis revealed that in in grades 4, 5, 6, and 8 students in MCP schools had significantly higher achievement 
scores than students in non-MCP schools. It is noted that there was no statistically significant difference in students' scores in grade 3. Results in grade 7 showed that, surprisingly, students in non-MCP schools significantly outperformed students in MCP schools. Small to medium effect sizes were noted (ranging from 0.27 to 0.65 ) in relation to the higher performance of students in MCP schools, which shows support for the impact MCP coaches may have on students' mathematics achievement.

Coniam (2010) presented standardized mathematics achievement results of 97 fourth-grade students at 10 urban schools (after exclusions) with second-year MCP coaches using a pre-post test design. Specifically, Coniam examined the impact MCP coaching had on students' performance on the five NCTM mathematical content strands (i.e., measurement, number, algebra, data analysis and probability, and geometry). The pretest consisted of released items from the state achievement test (2005), OAT, and the end-of the year administration of the OAT (spring 2007) served as the posttest. Findings showed that students made great gains in all five mathematical content strands, with a large decrease in the number of students categorized as below standard and a large increase in the number of students categorized as above standard. These preliminary findings are promising in regards to the effects of coaching, however, there are no comparison schools or students in order to determine if these gains were a result of the MCP coaching or the result of typical year of mathematics instruction.

Brosnan and Erchick (2010) sought to investigate if mathematics coaches, those using their MCP model for four years, had a significant impact on student achievement. State achievement test scores, the Ohio Assessment Test (OAT) from 2005-2009, were analyzed across schools participating in $\mathrm{MCP}$ and those not participating for students in 
grades 3-8. Structural equation modeling and simple t-tests were used to determine the impact of MCP on students' mathematics achievement. Results indicated that that students' mean scores on the OAT were higher in schools where teachers were supported by MCP coaches as opposed to schools where teachers were not supported by MCP coaches. Additionally, schools with MCP coaches had a higher percentage of students scoring at or above proficient on the OAT compared to schools without MCP coaches.

Lastly, Harrison et al. (2011) provided similar results found by Balfanz et al. (2006) in which the implementation of coaching influences student achievement gains. Harrison et al. (2011) conducted a document analysis of inventories and weekly logs from 2009-2010 from ten coaches in the MCP program, five coaches from the top performing schools and five coaches from the bottom performing schools. Using an interpretative-case study approach to analysis, four themes that seemed to determine schools success, or lack thereof, emerged: leadership skills of the coach within the school, schools' alignment with MCP guiding principles, the type of activities the coach engaged in, and emphasis the coach and teachers placed on students' thinking. Preliminary evidence showed that coaches who focused on a three-part approach, meaning the coach participated in the planning, co-teaching, and reflection of the lessons, tended to see greater improvements in student achievement. Information regarding specific substance of these roles was not available; even so, the evidence indicates that coaches involved in all facets of instruction may be related to positive changes in instruction and student achievement.

Elementary Mathematics Coaches. In the most recent study reviewed linking mathematics coaching and student achievement, Campbell and Malkus (2011) used a 
randomized, control-treatment design to determine if mathematics coaches had an effect on student achievement in grades 3-5 across schools in Virginia. Unlike some of the large-scale studies reviewed (i.e., Balfanz et al., 2006; Foster \& Noyce, 2004), this study (no specific project name provided) is not situated within a larger PD or reform effort project and was solely developed to investigate the impact of mathematics coaches on teacher knowledge and beliefs in an effort to bring about instructional change that improves student achievement. Mathematics coaches were placed in schools to address mathematical content, pedagogy, and curriculum through ongoing, collaborative professional development. The five participating districts (36 schools) provided triples of schools with comparable student demographics and performance. Triples of schools were used in order stagger the implementation of coaches, while maintaining control schools. In other words, 12 schools were randomly selected to receive coaches (final analyses included 10 treatment schools for year 1), while the remaining 24 schools did not receive coaches. The following year, 12 additional schools were randomly chosen to receive coaches, while the remaining 12 schools did not receive coaches. During the third year, coaching status was maintained in all schools, therefore providing a total of 3-year controlled, data collection. In other words, schools were randomly assigned to either receive 3 year of coaching, 2 years of coaching, or 3 years of control status. Results indicated no significant effect of mathematics coaches on student achievement in the first year of the mathematics coaches' placement. However, over the 3-year data collection period, students in schools with mathematics coaches performed significantly higher than students in schools without mathematics coaches on their state's standardized achievement test in grades 3-5, with a stronger impact on students in grades 4 and 5 . 
Although limitations to the study were present (e.g., the use of unstandardized student achievement scores), Campbell and Malkus's (2011) study provided strong empirical evidence for the continued use of MCS by employing advanced statistical analysis to demonstrate that over a 3-year period, upper elementary students in the treatment group outperformed those in the control group on Virginia's mathematics achievement tests.

Summary of Mathematics Coaching and Student Achievement. Although the relationship between the use of MCS and student achievement is essential when examining the overall impact of MCS, this link has only been tentatively established through research on five separate projects. In addition to the limited number of studies addressing the impact of MCS on student achievement, a number of the studies had methodological issues making inferences and generalizations difficult. Even so, the evidence reported is overwhelming positive in favor of the implementation of MCS as a way to improve students' learning and achievement. Continued research in establishing the link between MCS and improved learning and achievement in mathematics is needed to substantiate and expand upon the current research base.

\section{Mathematical Learning Difficulties and Disabilities}

Over the past few decades, the composition of the student population in US classrooms has changed dramatically, including an increase in the number of students with disabilities being educated in general education classrooms (Mayrowetz, 2009). The passing of recent legislature and emphasis on accountability requires schools and teachers

to ensure that students are provided equitable access to standards-based curriculum and to ensure that all students achieve academic success (e.g., Broderick, Mehta-Parekh, \& Reid, 2005; IDEA, 2004; NCLB, 2002). With the increased diversity in classrooms, 
equity in mathematics education continues to receive a great deal of attention. For instance, the CCSSM (NGA \& CCSSO, 2010) states "all students must have the opportunity to learn and meet the same high standards if they are to access the knowledge and skills necessary in their post-school lives" (p. 4). Additionally, access and equity in mathematics education is a primary focus in the guiding principles for school mathematics in NCTM's recently released Principles to Actions: Ensuring Mathematical Success for All (2014). Coupled with the implementation of effective teaching of mathematics, schools and teachers must systematically address the obstacles that pose a threat to the "meaningful learning of mathematics and to achievement outcomes" for all students, regardless of the students' background or characteristics (NCTM, 2014, p. 60). Although the current focus of equity in mathematics education is apparent, students with disabilities have notoriously performed below students without disabilities in measures of mathematic achievement (e.g., Bryant et al., 2008; Faulkner, Crossland \& Stiff, 2013; Judge \& Watson, 2011). Moreover, in the most recently released data from the 2013 NAEP Mathematics Assessment, students with disabilities continue to perform significantly lower than their peers (NAEP, 2013). The percent of fourth-grade students without a disability scoring at the proficient level on the 2013 NAEP Mathematics Assessment is much higher (37\%) compared to the percent of fourth-grade students with a disability scoring at the proficient level (16\%). A similar discrepancy is noted among eighth-grade students as well (29\% for students without a disability and $7 \%$ for students with a disability). Even more problematic is difference in the proportion of students with and without disabilities that are performing at the below basic level. Forty-five percent of fourth-grade students with a disability performed at the below basic level, whereas a 
much smaller 14 percent of students without disabilities performed at the below basic level. In eighth-grade, students with disabilities continued to have a far larger proportion of students perform at the below basic category compared to students without disabilities (65\% and 21\%, respectively; NAEP, 2013). Unfortunately, this notorious mathematics achievement gap between students with and without disabilities will likely continue until preventative measures are implemented in classrooms to allow all students access to the curriculum through high quality, evidence-based instruction (Bryant et al., 2008).

Mathematical learning disabilities have typically received far less attention than students with reading disabilities. Although this discrepancy has declined over years, Gersten et al. (2007) noted the ratio of research studies conducted on reading disabilities versus mathematical learning disabilities was 14:1 from 1995-2005. With the need for improvement in mathematics learning and academic performance, especially among students with disabilities, continued research to identify effective systems and teaching strategies that support students who struggle in mathematics is essential. As stated in Principles to Actions: Ensuring Mathematical Success for All, "the question is not whether all students can succeed in mathematics but whether the adults organizing mathematics learning opportunities can alter traditional beliefs and practices to promote success for all” (NCTM, 2014, p. 61).

MCS may provide a way to enhance the mathematics instruction and learning for students at risk for mathematical failure, including students with disabilities. MCS are not only charged with the task to aid in the development of, provide support to, and afford guidance to teachers (e.g., Campbell \& Malkus, 2011; Knight, 2005; Neufeld \& Roper, 2003), but often times work directly with students in an effort to positively impact 
learning and achievement (e.g., Dossey, 1984). MCS may be a way to not only improve the mathematics instruction during the whole-classroom setting (i.e., instruction received by all students), but also ensure that students who struggle in mathematics receive targeted, research-based interventions that provide the additional support they may need to ensure success (Chval et al., 2010; Fennell, 2011).

\section{Chapter II Summary}

In summary, this literature review beings with a discussion of the theoretical framework, the cognitive apprenticeship learning model, as a lens to view the position of MCS. Cognitive apprenticeship (Collins et al., 1987) focuses on a learning-throughguided experiences where an expert uses a three-method approach of modeling, coaching, and fading, to support the learning of the novice. The expert-novice relationship translates into a teacher-learner relationship that provides the underpinnings of the coachteacher, coach-student, and teacher-student relationships in the classrooms.

In addition to the theory behind the cognitive apprenticeship model, the position of MCSs was built upon the effective tenets of PD. PD research indicates that providing content-specific, engaging in PD multiple sessions (i.e., prolonged duration), creating active learning experiences, focusing on collaboration and coherence, and providing feedback and follow up provide the best avenues for impacting teacher knowledge and change (e.g., Garet et al., 2001; Guskey, 2003; Ingvarson et al., 2005),

By integrating the characteristics of effective PD (Desimone, 2009) and prior work on MCS (Campbell \& Malkus, 2011), a conceptual framework for the current study was then developed. The conceptual framework provides a visual representation of the 
development and implementation of MCS in elementary schools and their hypothesized impact on student outcomes for the present study.

During the largest portion of the literature review, the focus is on the influence of mathematics coaching on teacher practices and student achievement. Large- and smallscale studies have both contributed to the literature base on the effectiveness of MCS. Both quantitative and qualitative evidence, although limited in quantity, exists to support the implementation of MCS in schools as a way to improve the teaching and learning of mathematics. The majority of studies on MCS have focused on the relationship between the implementation of MCS and changes in teachers' beliefs and instructional practices. Research indicates that through the use of $\mathrm{PD}$, guidance, and support, MCS positively influence teachers' practices related to the teaching and learning of mathematics (e.g., Campbell, 1996; Race, Ho, \& Bower, 2002); however, some studies have noted limited changes in teachers' beliefs and practices even after the coaching process (e.g., Ai and Rivera, 2003; Olson \& Barrett, 2004). In addition to the positive influence on teacher practice, MCS have shown to be effective on positively impacting students' mathematics learning and achievement (e.g., Balfanz et al., 2006; Brosnan and Erchick, 2010; Campbell \& Malkus, 2011). Five large-scale projects on the effects of MCS on student achievement provide ample evidence that these instructional leaders may provide districts and schools the avenue needed for improved student learning and achievement in mathematics. However, noted methodological issues in addition to the limited number of empirical studies, requires additional research to corroborate the promising findings.

Chapter II concludes with a brief review of literature on students with mathematical learning difficulties and disabilities. Although a strong focus on equity in 
mathematics education is evident (e.g., NCMT, 2014; NGA \& CCSSO, 2010), the notorious discrepancy in mathematics' performance between students with and without disabilities remains (e.g., NAEP, 2013). The implementation of MCS in schools to enhance mathematics instruction and provide interventions for students may be a way to support and ensure success for students at risk for mathematical failure, including students with disabilities (Chval et al., 2010; Fennell, 2011). Chapter IV provides the research design and methodology used for the current study. 


\section{CHAPTER III}

\section{METHODOLOGY}

This chapter describes the methodology used for the current study, a secondary data analysis of the 2011 National Assessment of Educational Progress Mathematics Assessment (NAEP) dataset. The chapter contains a restatement of the purpose and research questions, followed by a description of the study design, the sample, the data and variables used in the study, and the analytic approach used to answer the research questions.

\section{Restatement of the Purpose and Research Questions}

The purpose of the study was to examine the relationship between MCS and the mathematics achievement of fourth-grade students; examine whether that relationship differs for students with and without disabilities; and, examine the relationship between principal-reported time spent on the six different NAEP-defined roles and responsibilities of MCS and fourth-grade students' mathematics achievement. Overall, the study aimed to determine if a significant relationship between the presence of a MCS and students' mathematics achievement (overall and by content strand) exists. The study also intended to delve deeper into the issue of MCS by examining whether schools having a MCS would moderate the lower achievement that students with disabilities generally experience and by examining how principal-reported time spent on the roles and responsibilities provided by the MCS are related with achievement.

The three research questions for the study are as follows: 
1. What is the relationship between having an elementary school-based MCS (full or part time) and fourth-grade students' achievement on the NAEP, specifically a) their overall mathematics achievement and b) their achievement in five specific mathematics content areas (i.e., number properties and operations; measurement; geometry; data analysis, statistics, and probability; and algebra)?

2. What are the differentials in achievement of students with and without disabilities when they have a MCS in their elementary school or not, specifically differentials in a) their overall mathematics achievement and b) their achievement in five specific mathematics content areas (i.e., number properties and operations; measurement; geometry; data analysis, statistics, and probability; and algebra)?

3. For schools that have a MCS, how does principal-reported time spent on the six different NAEP-defined roles and responsibilities, which include providing assistance to teachers and students (see Table 3 for a complete list), relate to students' achievement, specifically a) their overall mathematics achievement and b) their achievement in five specific mathematics content areas (i.e., number properties and operations; measurement; geometry; data analysis, statistics, and probability; and algebra)?

\section{Research Design and Rationale}

This study employed a quantitative research design. Specifically, the proposed study used a quasi-experimental design, or an observational study design (Schneider et al., 2007; Shadish, Cook, \& Campbell, 2002), with a nationally representative, large-scale database. A quasi-experimental design does not include key features of an experimental design, such as randomization of participants but can rely on statistically controlling for 
alternative explanations to explain observed treatment effects (Shadish et al., 2002). Schneider et al. (2007) note several other advantages of using large-scale, nationally representative datasets, such as results that generalize to a larger population and the ability to study the achievement of subgroups (p. 39).

Originally, propensity score analysis (PSA) was going to be used to estimate the conditional probability of receiving treatment (i.e., a school having a MCS; Guo \& Fraser, 2010) in order to approximate randomization and produce tentative casual inferences (Schneider et al., 2007; Shadish et al., 2002). However, PSA using subclassification $(5,10$, and 20 strata) was not possible with the variables available in the NAEP dataset, which of note does not include prior achievement. The propensity scores were not able to achieve balance on the pretreatment variables. Therefore, the current study relies on the use of numerous pretreatment and during-treatment composite covariates and control variables to strengthen the quasi-experimental study design.

\section{Population and Sample}

Participants in the study were selected from the 2011 NAEP dataset. NAEP is conducted using a probability sampling design to select a nationally representative sample of U.S. children in grades 4, 8, and 12 and assesses students in various subject areas (e.g., reading, mathematics, science, writing). Matrix sampling is used, as each assessment samples a different number of students. Nationally representative samples of more than 420,000 fourth-graders and 340,000 eight-graders were assessed in either reading or mathematics in 2011 (twelfth-graders were not assessed in reading or mathematics in 2011; NCES, 2013). NAEP provides results on subject-matter achievement through cognitive assessments, as well as results on instructional 
experiences and school environment through multiple questionnaires completed by students, teachers, and administrators.

As noted, NAEP employs a probability sampling design that allows all schools and students who are taking the NAEP throughout the United States to have a chance to be selected (NCES, 2009). The selection is a three part process: (1) Using data from the Common Core of Data file, schools are grouped into strata that are based on characteristics such as location of the school, urbanicity of the school, and the extent of the school's minority enrollment. (2) Schools are then selected (without replacement). Purposive oversampling based on certain characteristics such as nonpublic schools and schools with high minority enrollment, is sometimes used. (3) Students are then sampled from schools' rosters of individual names. In other words, students are selected from a school list as opposed to whole classrooms of students being chosen. During some years, an oversampling at the school or students stages occurs to enhance the precision of estimates of certain student populations, such as students with disabilities, students with limited English proficiency (LEP), and private school students. On average, approximately 100 grade-eligible public schools are selected within each jurisdiction and within each school approximately 60 students are selected to take the assessment. For private schools, approximately 700 schools are included with up to 60 students selected to take the assessment (NCES, 2009). Because of the complex sampling design (i.e., the schools and students selected to participate in the assessment constitute only a small portion of the full population) and the oversampling of certain populations, NAEP incorporates both school and student sampling weights, SMSBASW and ORIGWT, respectively. Weights were incorporated into all analyses to attempt to ensure that the 
results were representative of the targeted populations by taking the disproportionate representation of students into account during the estimation processes (NCES, 2009). This study focused on the results obtained from the 2011 NAEP Mathematics Assessment for fourth-grade students. NAEP assessed approximately 209,000 students across 8,500 elementary schools in mathematics at grade 4 (NCES, 2011). The study sample included all schools (public and private) that reported on the presence or nonpresence of a MCS and the student sample included all students in those schools (see Figures 2 and 3, respectively, for the breakdown of the school and student samples and approximate unweighted and weighted sample sizes) 

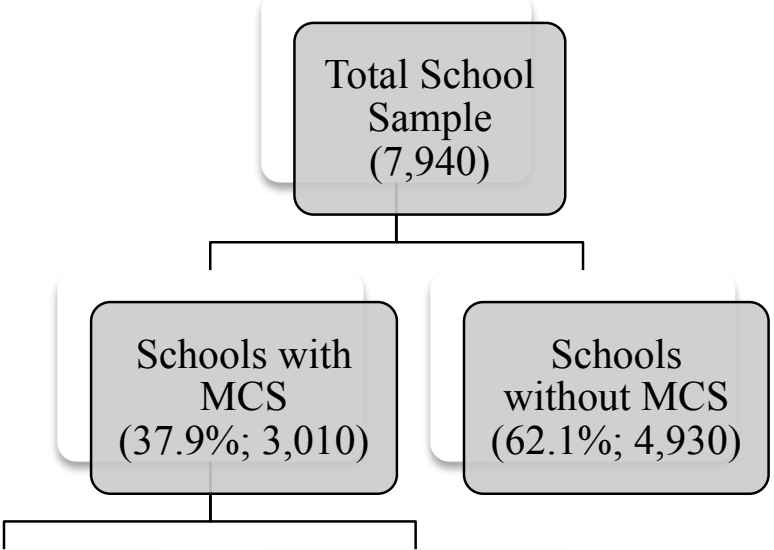

Schools with

Full-time MCS $(49.8 \% ; 1,500)$
Schools with Part-time MCS $(50.2 \% ; 1,510)$
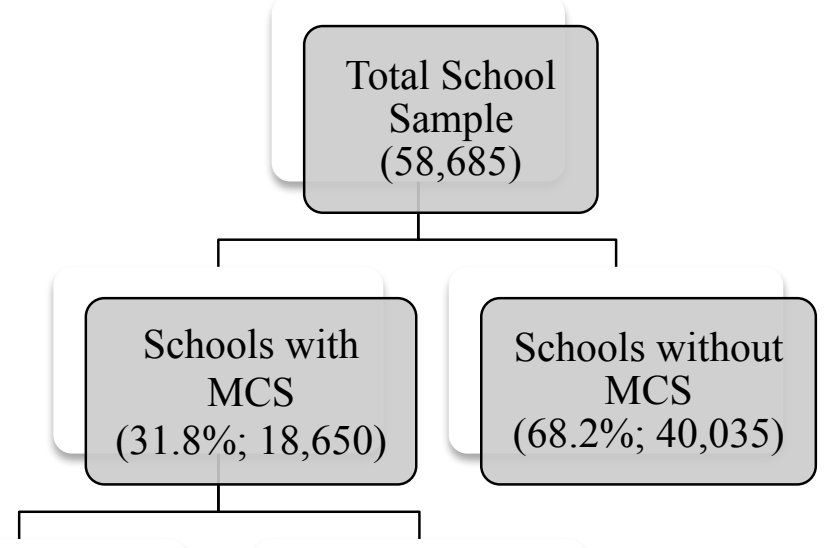

Schools with Full-time MCS $(48.7 \% ; 9,080)$
Schools with Part-time MCS

$(51.3 \% ; 9,570)$

\section{Unweigthed School Sample}

\section{Weighted School Sample}

Note. Unweighted sample sizes are rounded to the nearest 10 to meet the restricted-use data requirements of the National Center for Education Statistics.

Figure 2. Approximate School Sample Size (unweighted and weighted) 


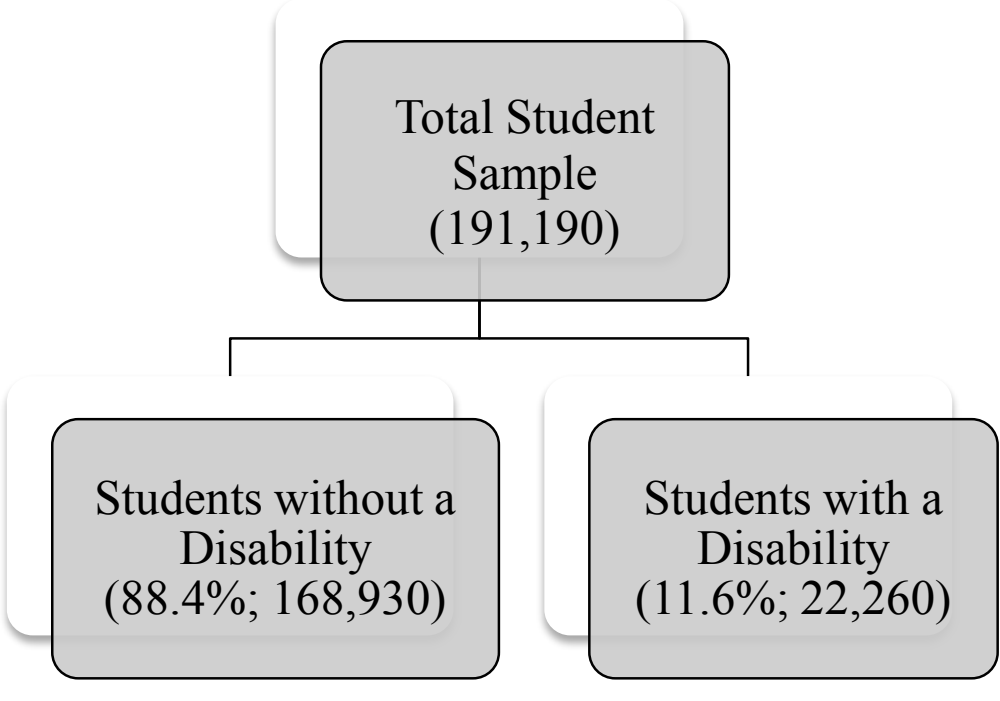

Unweigthed Student Sample

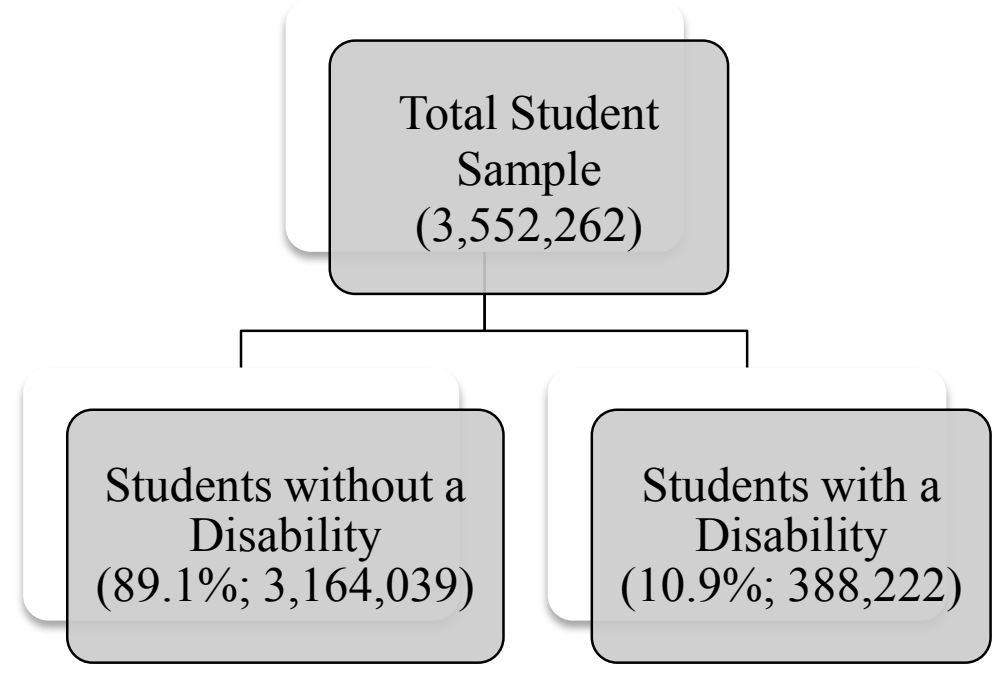

Weigthed Student Sample

Note. Unweighted sample sizes are rounded to the nearest 10 to meet the restricted-use data requirements of the National Center for Education Statistics.

Figure 3. Approximate Student Sample Size (unweighted and weighted) 


\section{Data}

After the data were recoded (i.e., creating dummy codes for categorical variables, coding missing data, and recoding to provide meaningful zeros for all variables), potential during-treatment control variables were identified by running correlations on theoretically important student-level variables (both student and teacher variables) with fourth-grade mathematics achievement composite scores (outcome) and the treatment variable, having a full- or part-time MCS. Additionally, correlations between theoretically important school-level variables (those collected from the school survey and aggregates of some student-level variables) and the outcome and treatment variables were run. This work allowed for the identification of variables with statistically significant correlations with either mathematics achievement or the provision of MCS (i.e., duringtreatment covariates; see Table 2 for descriptive statistics of covariates).

\section{NAEP Grade 4 Mathematics Assessment (Outcome Variables)}

The NAEP mathematics assessment focused on aspects of mathematical content and cognitive demand while assessing students in five content areas 1) number properties and operations, 2) measurement, 3) geometry, 4) data analysis, statistics, and probability, and 5) algebra. The 2011 NAEP Grade 4 Mathematics Assessment included items with the following specifications: $40 \%$ number properties and operations; $20 \%$ measurement; $15 \%$ geometry; $10 \%$ data analysis, statistics, and probability; and 15\% algebra (NCES, p. $6,2011)$. The complete fourth-grade assessment contained 158 total questions, including multiple-choice, short constructed-response, and extended constructed-response questions. As this was such a large number of total questions, the assessment was divided into 10 sections, each containing 15-19 questions for each selected student to complete 
(NCES, 2013). With the use of matrix sampling, a representative sample of students took each smaller portion of the assessment questions. Item response theory (IRT) was used to estimate average scale scores for each of the five content strands as well as a composite mathematics score (i.e., a weighted average of the subscales) to provide a common scale to compare scores. Because of the matrix sampling, each student received five plausible values for each of the content strands and five plausible values for the composite score in the NAEP dataset. A scale of 0-500 was used to report performance in each domain. Table 2 provides descriptive statistics for student scores (averaged plausible value scores) on the overall (i.e., composite) achievement score and achievement scores by content areas based on disability status and the presences of a full-time, part-time, or no MCS.

High-speed scanners completed scoring for multiple-choice items, whereas trained personnel completed scoring for the short constructed-items and the extended constructed-response items. During the scoring process, a randomly chosen percentage of scored responses are rescored to check the consistency of the scores. Reliability for dichotomized items was estimated using Cohen's Kappa and ranged from .82 to .99. Reliability estimates for polytomously-scored items were calculated using intraclass correlations and ranged from .83 to .99 . High reliability estimates for both the short constructed-response items and the extended constructed-response items are apparent; however, these estimates are for the 2007 assessment, as they were the most recent data reliability estimates available (NCES, 2010). Documentation of the target standards for within-year agreement reported in the NAEP technical documentation are as quoted: (a) items scored on 2-point scales: 85\% exact agreement, (b) items scored on 3-point scales: 
80\% exact agreement, (c) items scored on 4-point and 5-point scales: 75\% exact

agreement, and (d) items scored on 6-point scales: 60\%exact agreement (NCES, 2009).

Table 2

Descriptive Statistics for the 2011 NAEP Mathematics Assessment

\begin{tabular}{|c|c|c|c|}
\hline Averaged Plausible Values & $\begin{array}{c}\text { Full-Time } \\
\text { MCS } \\
\text { Mean }(S D)^{*}\end{array}$ & $\begin{array}{c}\text { Part-Time } \\
\text { MCS } \\
\text { Mean }(S D) *\end{array}$ & $\operatorname{Mean}(S D) *$ \\
\hline $\begin{array}{l}\text { Sample size* - students without a } \\
\text { disability }\end{array}$ & $(n=614,606)^{*}$ & $(\mathrm{n}=551,213)^{*}$ & $(n=1,998,221)^{*}$ \\
\hline $\begin{array}{l}\text { Sample size* - students with a } \\
\text { disability }\end{array}$ & $(\mathrm{n}=80,365)^{*}$ & $(\mathrm{n}=68,176)^{*}$ & $(\mathrm{n}=239,681)^{*}$ \\
\hline \multicolumn{4}{|l|}{ Composite Score } \\
\hline Students without a disability & $240.24(27.28)$ & $244.52(27.48)$ & $244.60(27.03)$ \\
\hline Students with a disability & $215.68(32.35)$ & $219.29(32.38)$ & $219.16(31.81)$ \\
\hline \multicolumn{4}{|l|}{ Number Properties \& Operations } \\
\hline Students without a disability & $239.57(29.44)$ & $243.93(29.81)$ & $244.14(29.26)$ \\
\hline Students with a disability & $211.94(35.53)$ & $215.39(35.98)$ & $216.09(34.97)$ \\
\hline \multicolumn{4}{|l|}{ Measurement } \\
\hline Students without a disability & $237.48(33.62)$ & $242.40(33.33)$ & $242.95(32.68)$ \\
\hline Students with a disability & $210.25(38.93)$ & $215.31(38.43)$ & $214.59(38.28)$ \\
\hline \multicolumn{4}{|l|}{ Geometry } \\
\hline Students without a disability & $240.67(25.11)$ & $243.79(24.87)$ & $243.57(24.59)$ \\
\hline Students with a disability & $222.84(28.79)$ & $225.60(28.42)$ & $225.16(28.22)$ \\
\hline \multicolumn{4}{|l|}{ Data Analysis, Statistics, \& } \\
\hline \multicolumn{4}{|l|}{ Probability } \\
\hline Students without a disability & $241.57(29.29)$ & $246.88(29.45)$ & $246.31(29.11)$ \\
\hline Students with a disability & $220.22(34.24)$ & $224.28(34.06)$ & $223.24(33.88)$ \\
\hline \multicolumn{4}{|l|}{ Algebra } \\
\hline Students without a disability & $244.43(25.39)$ & $248.06(25.55)$ & $247.95(25.56)$ \\
\hline Students with a disability & $222.68(31.17)$ & $225.30(31.47)$ & $224.72(30.61)$ \\
\hline
\end{tabular}

* Weighted means, standard deviations, and sample sizes. 


\section{IEP status (Grouping Variable)}

Students' status in the category of disability was determined by the presence of an IEP or a 504 Plan for the current study. IEP status was coded as a dichotomous variable with 0 indicating the student did not have a disability (i.e., no IEP or 504 Plan) and a 1 indicating that students had a disability (i.e., had an IEP or 504 Plan). Accommodations similar to those provided to students in other testing situations were permitted (e.g., extended time, small-group testing location, and responding orally with a scribe), except for accommodations that may alter the construct (e.g., test items read aloud for the reading assessment), in an effort to ensure all students capable of participating in the assessment were included (NCES, 2013).

\section{Mathematics Coach/Specialist (Treatment Variable)}

A school's policy of providing a MCS was obtained at the school level and was gathered by posing the question, "Is there a math specialist or coach available (full- or part-time) to fourth-graders at your school?" The school-reported response, which was provided by the principal or vice principal, was characterized in one of three ways: available full-time, available part-time, or no (NCES, 2013). Two different dummy codes were created to address treatment status for the different research questions. The dummy code "MCS full-time" was coded as $0=$ schools with no MCS or schools with part-time MCS and 1 = schools with full-time MCS. "MCS part-time" was coded as $0=$ schools with full-time MCS and schools with no MCS and 1 = part-time MCS. 


\section{Mathematics Coach/Specialist Roles and Responsibilities (Secondary Treatment Variables)}

For the third research question, the principal-reported time spent on the six NAEP-defined roles and responsibilities of the MCS were analyzed. As with the treatment variable (presence of a MCS), the extent to which MCSs engaged in the various roles and responsibilities was a school-level variable reported on by principal or vice principal of each elementary school. The extent to which the six roles and responsibilities presented (see Table 3 for the NAEP-defined roles and responsibilities) were available to fourth-grade students at their school was measured on a scale ranging from "not at all" to a "large extent" (NCES, 2013). The recoded scale for extent to which the activity was performed is as follows: $0=$ not at all, $1=$ small extent, $2=$ moderate extent, and $3=$ large extent. One response per role/responsibility was requested on the questionnaire. 
Table 3

Descriptive Statistics for the Roles and Responsibilities of Mathematics Coach/Specialist as Defined in the 2011 NAEP Dataset

\begin{tabular}{|c|c|c|}
\hline \multicolumn{3}{|c|}{ Roles and Responsibilities of the Mathematics Coach/Specialist } \\
\hline ID & Variable Description & Mean $(S D) *$ \\
\hline $\mathrm{C} 071401$ & $\begin{array}{l}\text { Provide technical assistance/support to individual teachers } \\
\text { about mathematics content or the teaching of mathematics }\end{array}$ & $2.72(0.92)$ \\
\hline $\mathrm{C} 071402$ & $\begin{array}{l}\text { Conduct professional development for groups of teachers } \\
\text { about mathematics content or the teaching of mathematics }\end{array}$ & $2.01(1.05)$ \\
\hline C071403 & tion to students on various topics & $.97)$ \\
\hline C071404 & $\begin{array}{l}\text { Provide mathematics instruction to students at various grade } \\
\text { levels }\end{array}$ & $2.03(1.01)$ \\
\hline $\mathrm{C} 071405$ & $\begin{array}{l}\text { Provide mathematics remediation/intervention to some student } \\
\text { groups }\end{array}$ & $2.04(1.04)$ \\
\hline $\mathrm{C} 071406$ & Provide mathematics enrichment to some student groups & $1.36(1.06)$ \\
\hline
\end{tabular}

* Means and standard deviations are weighted (weighted $n=9,006$; unweighted $n=$ 1490) Roles and responsibilities coding: $0=$ not at all, $1=$ small extent, $2=$ moderate extent, and 3=large extent; MCS role and responsibility time allocation reported by the principal or vice-principal of each elementary school.

Note. Unweighted sample sizes are rounded to the nearest ten to meet the restricted-use data requirements of the National Center for Education Statistics.

\section{Missing Data}

Missing data are often problematic in large datasets (Rubin, 1996) in that they can weaken a strong study design, pose a threat to the casual inferences that can be drawn, and impact results (McKnight \& McKnight, 2011). Multiple techniques can be used to address missing data, such as deleting cases or replacing missing data with the mean of the targeted variable; however, these methods can lead to biased results (Rubin, 1987, 1996). Multiple imputation (MI), on the other hand, is an approach to missing data that "provides an estimate of the impact of missing data" (McKnight and McKnight, 2011, p. 
98) and allows the analyst to deal with the missing data problem in the outset and move forward with standard complete-data methods of analysis (Rubin, 1987; Schafer, 1999).

The idea behind multiple imputation is that replacement values representing a distribution of possibilities (i.e., plausible values) are imputed for each missing piece of the data in the original dataset (McKnight \& McKnight, 2011; Rubin, 1987). The imputation process is generally run anywhere from two to 10 times (McKnight \& McKnight, 2011; Rubin, 1987), thus creating multiple complete data sets with plausible values in place of the missing data. In other words, each imputation process yields one compete dataset. The data sets with imputed values are then analyzed independently using "standard complete-data procedures just as if the imputed data were the real data obtained from the nonrespondents" (Rubin, 1987, p. 15). In essence, multiple imputation allows the analyst to use simulated estimates in complete-data methods and to compare the results obtained from the multiple runs to examine the nature and extent of influence on the results caused by the missing data (McKnight \& McKnight, 2011; Rubin, 1987, 1996).

For the current study, the covariates that were previously identified through theory and by having statistically significant correlations with either the outcome or treatment variable were used to create five MI datasets that were used for all analyses. In an effort to achieve the best plausible values for the MI files, MI was conducted separately on student, teacher, and school variables and later combined when necessary for analyses. Using SPSS version 22, 17 student variables (excluding variables of interest: disability status and achievement variables) were used to create the five MI student files. The same process was then used to create the teacher and school MI files, 
using 22 and 18 variables respectively. As with the student variables, variables of particular interest, including all MCS variables, were left out of the imputation process and merged into the files for later analyses. Table 4 provides the descriptive statistics for all demographic and control variables utilized in the current study. 
Table 4

Descriptive Statistics for Demographic and Control Variables

\begin{tabular}{|c|c|c|c|c|}
\hline \multirow[t]{2}{*}{ ID } & Variable Label & Full-Time MCS & Part-Time MCS & MCS Not Available \\
\hline & & Mean $(S D)^{*}$ & Mean $(S D)^{*}$ & Mean $(S D)^{*}$ \\
\hline \multicolumn{2}{|c|}{ School variables } & $(\mathrm{n}=9080)$ & $(\mathrm{n}=9570)$ & $(\mathrm{n}=40035)$ \\
\hline PUBPRIV & Public/Private School & $.06 \quad(0.24)$ & $.15(0.35)$ & $.25(0.44)$ \\
\hline PCTTFRL $^{\mathrm{a}}$ & Percent FRL & $57.74(26.92)$ & $46.34(26.35)$ & $46.42(23.86)$ \\
\hline $\mathrm{SSCHWHT}^{\mathrm{b}}$ & Percent Minority & $54.29(34.74)$ & $37.09(33.07)$ & $36.48(33.34)$ \\
\hline $\mathrm{C} 046501^{\mathrm{a}}$ & Percent LEP & $1.93(1.65)$ & $1.55(1.50)$ & $1.35(1.52)$ \\
\hline $\mathrm{C} 044004^{\mathrm{a}}$ & Percent Gifted and Talented & $1.23(1.12)$ & 1.17 (1.12) & $1.06(1.17)$ \\
\hline $\mathrm{C} 044007^{\mathrm{a}}$ & Percent Special Education & $2.25(0.96)$ & $2.10 \quad(0.87)$ & $1.87(0.98)$ \\
\hline \multicolumn{5}{|c|}{ Teacher variables } \\
\hline \multicolumn{2}{|c|}{ (all variables pertaining to mathematics) } & $(n=694971)$ & $(n=619389)$ & $(\mathrm{n}=2237902)$ \\
\hline T077101 & Years experience (elem/second) & $12.12(8.91)$ & $13.76(9.34)$ & $13.95(9.45)$ \\
\hline Combined $^{\mathrm{c}}$ & Math Degree (minor or major) & $.17(0.37)$ & $.16(0.37)$ & $.14(0.34)$ \\
\hline Т047402 & AssessMath_Problem sets & $2.60(0.65)$ & $2.55(0.69)$ & $2.57(0.67)$ \\
\hline T047403 & AssessMath_Written response & $2.23(0.89)$ & $2.11(0.93)$ & $2.07(0.94)$ \\
\hline T057404 & AssessMath_Projects & $1.18(0.96)$ & $1.03(0.94)$ & $0.96(0.93)$ \\
\hline T075352 & Emphasis on Measurement & $1.33(0.55)$ & $1.26(0.56)$ & $1.25(0.55)$ \\
\hline T075353 & Emphasis on Geometry & $1.37(0.52)$ & $1.33(0.54)$ & $1.31(0.54)$ \\
\hline T075354 & Emphasis on Data Analysis & $1.29(0.58)$ & $1.22(0.58)$ & $1.19(0.58)$ \\
\hline T075355 & Emphasis on Algebra & $1.42(0.58)$ & $1.40(0.58)$ & $1.39(0.58)$ \\
\hline T106601 & StudentComputerUse_Practice & $1.59(0.98)$ & $1.38(0.99)$ & $1.41(0.98)$ \\
\hline T016602 & StudentComputerUse_Extend & $1.35(0.98)$ & $1.11(0.97)$ & $1.17(0.97)$ \\
\hline T106609 & StudentComputerUse_Games & $1.52(0.91)$ & $1.34(0.90)$ & $1.37(0.88)$ \\
\hline T044201 & Groups Created by A $\bar{b}$ ility & $0.69(0.46)$ & $0.61(0.49)$ & $0.58(0.49)$ \\
\hline T106801 & Different Standards for Some & $1.70(0.92)$ & $1.63(0.92)$ & $1.59(0.92)$ \\
\hline T106802 & Use Other Materials for Some & $2.15(0.78)$ & $2.05(0.82)$ & $2.02(0.84)$ \\
\hline T106803 & Different Activities for Some & $1.91(0.86)$ & $1.75(0.89)$ & $1.70(0.89)$ \\
\hline $\mathrm{T} 106804$ & Different Methods for Some & $2.16(0.78)$ & $2.03(0.82)$ & $1.96(0.82)$ \\
\hline
\end{tabular}




\begin{tabular}{|c|c|c|c|c|}
\hline T106805 & Different Pace for Some & $2.02(0.85)$ & $1.86(0.89)$ & $1.83(0.88)$ \\
\hline T107001 & Discuss Performance Level & $2.36(0.95)$ & $2.16(0.96)$ & $2.15(0.98)$ \\
\hline T107002 & Set Goals for Specific Program & $2.06(1.02)$ & $1.83(1.03)$ & $1.84(1.01)$ \\
\hline T107003 & Discuss Progress Towards Goals & $2.08(1.00)$ & $1.85(1.02)$ & $1.87(0.99)$ \\
\hline T107004 & Adjusting Teaching_Meet Needs & $2.91(1.04)$ & $2.78(1.12)$ & $2.71(1.12)$ \\
\hline \multicolumn{5}{|c|}{ Student variables } \\
\hline \multicolumn{2}{|c|}{ (all variables pertaining to mathematics) } & $(n=694971)$ & $(n=619389)$ & $(n=2237902)$ \\
\hline DSEX & Gender & $.50(0.50)$ & $.49(0.50)$ & $.49(0.50)$ \\
\hline SRACE10 ${ }^{\mathrm{d}}$ & Student Minority Status & $.58(0.49)$ & $.42(0.49)$ & $.43(0.49)$ \\
\hline LEP & Student ELL Status & $.13(0.33)$ & $.10(0.30)$ & $.10(0.30)$ \\
\hline $\mathrm{IEP}^{\mathrm{e}}$ & Student Disability Status (IEP) & $.12(0.32)$ & $.11(0.31)$ & $.11(0.31)$ \\
\hline B018101 & Days Absent Last Month & $0.83(1.02)$ & $0.79(1.01)$ & $0.77(0.99)$ \\
\hline M814301 & Use Computer at School_Math & $1.10(1.37)$ & $0.91(1.29)$ & $0.92(1.29)$ \\
\hline M823901 & Use Computer at Home_- & $0.23(0.42)$ & $0.21(0.41)$ & $0.21(0.41)$ \\
\hline M814601 & Use Computer_Practice or Drill & $0.48(0.50)$ & $0.45(0.50)$ & $0.45(0.50)$ \\
\hline M814701 & Use Computer_Play Games & $0.77(0.42)$ & $0.74(0.44)$ & $0.74(0.44)$ \\
\hline M814501 & Use Computer_Charts/Graphs & $0.18(0.39)$ & $0.16(0.37)$ & $0.16(0.37)$ \\
\hline M814901 & Use Internet Learn about Math & $0.50(0.50)$ & $0.43(0.50)$ & $0.45(0.50)$ \\
\hline $\mathrm{M} 824201^{\mathrm{e}}$ & Math Work is Too Hard & $2.10(0.75)$ & $2.14(0.75)$ & $2.13(0.75)$ \\
\hline M824301 & Math work is Too Easy & $1.40(0.92)$ & $1.37(0.92)$ & $1.40(0.92)$ \\
\hline M824401 & Like What is Done_Math Class & $1.91(0.99)$ & $1.85(0.99)$ & $1.84(0.98)$ \\
\hline M824501 & Can Do Good Job_Math Tests & $2.14(0.92)$ & $2.14(0.90)$ & $2.16(0.90)$ \\
\hline M824601 & Can Do Good Job_Math Assign & $2.12(0.91)$ & $2.13(0.89)$ & $2.14(0.88)$ \\
\hline M824701 & Like Math & $1.99(1.05)$ & $1.92(1.06)$ & $1.93(1.06)$ \\
\hline M824801 & Math is a Favorite Subject & $1.81(1.16)$ & $1.74(1.18)$ & $1.73(1.17)$ \\
\hline
\end{tabular}

* Weighted means, standard deviations, and sample sizes

a Aggregated variables at the school-level.

${ }^{\mathrm{b}}$ Percent minority was calculated by 100-SSCHWHT (100 - Percent white).

${ }^{c}$ Math degree variable was created by combining dummy coded variables pertaining to receiving any type of math degree.

${ }^{\mathrm{d}}$ SRACE10 was initially dummy coded for each race. Minority status was created by reverse coding white.

'Students' disability status was not multiply imputed. 


\section{Covariate Composite Scores}

Composite scores of during-treatment covariates were created using principal component analysis (PCA; Stevens, 2009) to control for covariates that may affect the outcomes. These composite covariate scores served as controls in the final models during analysis. Potential control variables were from the fourth-grade mathematics assessment and survey data and included variables at the individual level (student and teacher variables). As previously noted, potential variables were initially selected based on theory and prior research regarding the relationship. Significant correlations between the covariates and the provision of a MCS (treatment condition) or to the mathematics achievement scores (outcome variable) then served as the additional criterion for inclusion. Student variables included items such as students' mathematics self-efficacy and attitudes towards mathematics; teacher variables included items such as teachers' instructional and assessment practices and emphasis on certain mathematics content strands.

Using the variables that were covariates (related to the provision of MCS or mathematics achievement), principal component analyses (PCAs) were conducted in to obtain the composite variable scores. The purpose of conducting a PCA is to determine empirically how many underlying constructs account for most of the variance in order to reduce the number of predictors (thus alleviating multicollinearity; Stevens, 2009). As the current dataset contains numerous during-treatment variables and contains well over the recommended ratio of participants to variables (Meyers, Gamst, \& Guarino, 2006), PCA was an appropriate statistical technique to reduce the number of independent variables 
and create constructs that can be treated as composite scores and utilized as controls in further analyses.

PCAs using oblimin rotation were conducted on the during-treatment covariates. Oblimin (oblique) rotation, as opposed to varimax (orthogonal) rotation, was chosen because it takes into account possible correlations among the factors, which many view as more reasonable (Stevens, 2009).

Separate PCAs were conducted for student and teacher covariates. The same process for each PCA was used regardless of the type of covariates (i.e., student or teacher). Prior to running each PCA, the Kaiser-Meyer Olkin (KMO) measure of sampling adequacy, which is an index for comparing the magnitudes of the observed correlation coefficients to the magnitudes of the partial correlation coefficient, was conducted. Additionally, the Bartlett's Test of Sphericity was examined as it is another indicator of the strength of the relationship among variables and tests the null hypothesis that the residual covariance matrix is proportional to an identify matrix (Stevens, 2009) and indicates sufficient correlation among the dependent variables to proceed with analysis. All values obtained for the KMO tests were above .70 and were therefore considered adequate and indicated that a factor analysis of the given variables was appropriate (Kaiser, 1970). Additionally, all Bartlett's Test of Sphericity were significant $(p<.05)$, which indicated analyses could proceed.

Numerous criteria were used to determine the number of components to retain. First, Kaiser (1960) suggested that any component with an eigenvalue greater than 1.0 should be retained. The eigenvalues reflect the amount of variance captured by a factor of the total variance. Only the factors having eigenvalues greater than 1.0 are considered 
significant because each factor should account for the variance in at least one item. Second, using Cattell's graphical method (1966), a scree plot also was examined. In a scree plot, the eigenvalues are graphed for each successive factor. When analyzing a scree plot, one looks for a sharp drop and retains those factors that lie above the "elbow." Third, a parallel analysis (Horn, 1965) was conducted. A parallel analysis compares eigenvalues from the study's data set to a randomly generated set of eigenvalues. To determine the number of factors to retain, the two sets of eigenvalues are compared. The parallel analysis tested whether the calculated eigenvalues for the dataset were higher than the mean of the randomly determined eigenvalues. Finally, when comparing solutions when differing number of components were recommended by the criteria, interpretability and theory were employed to ensure that the solution made sense and the variables shared a common theme.

Per Steven's suggestion (2009), factor loadings that are statistically significant with factor loadings of 40 or greater should be used for interpretation purposes. Therefore, any variables not meeting this criterion were eliminated. Finally, the reliability of weighted items were calculated for each component; components with low reliability $(<.70)$ were eliminated.

To create the composite variables, factor scores were created using the regression method in SPSS version 22. The factor scores were then later used in the HLM analyses with teacher and student composite scores modeled at level-1.

Student composite variables. Initially, 16 theoretically important duringtreatment student covariates were identified (see Appendix A). Of these 16 variables, 13 variables were retained during the PCA process. Three composite variables were used to 
represent the student during-treatment covariates (see Table 5). The first component was comprised of three covariates, had a high reliability coefficient of .971 , and included items about students' opinions on how much they liked mathematics and mathematics class. The second component had a slightly lower, although still high, reliability of .847 and included six covariates that reflected students' use of technology (i.e., computer use) as it related to mathematics. The third student component included four covariates related to students' mathematics self-efficacy and obtained a high reliability of .963 .

Table 5

Final Components Resulting from PCA of Student Variables and Used as Composite

\section{Covariates}

\begin{tabular}{|c|c|}
\hline Variable Name & Variable Description \\
\hline \multicolumn{2}{|c|}{ Component 1: Students' opinions of mathematics and mathematics class $(\alpha=.971)$} \\
\hline M824701 & Like math \\
\hline M824801 & Math is a favorite subject \\
\hline M824401 & Like what is done in math class \\
\hline \multicolumn{2}{|c|}{ Component 2: Students' use of technology for mathematics $(\alpha=.847)$} \\
\hline M814301 & Use computer at school for math \\
\hline M823901 & Use computer at home for math homework \\
\hline M814601 & Use computer to practice or drill on math \\
\hline M814701 & Use computer to play math games \\
\hline M814501 & Use computer to make charts or graphs for math \\
\hline M814901 & Use the Internet to learn things about math \\
\hline \multicolumn{2}{|c|}{ Component 3: Students' attitudes or self-efficacy about mathematics $(\alpha=.963)$} \\
\hline M824201 & Math work is too hard \\
\hline M824301 & Math work is too easy \\
\hline M824501 & Can do good job on math tests \\
\hline M824601 & Can do good job on math assignments \\
\hline
\end{tabular}

$\mathrm{a}=$ reverse coded prior to analysis 
Teacher composite variables. Initially, 30 theoretically important duringtreatment teacher covariates were identified (see Appendix A). Of these 30 variables, 20 variables were retained during the PCA process. Five composite variables were used to represent the teacher during-treatment covariates (see Table 6). Similar to the student components, all teacher components exhibited high reliability. The first of these components included six covariates, had a reliability of .969, and included items pertaining to differentiated instructional practices. The amount of emphasis on content areas was the second component created, which consisted of four covariates exhibiting a reliability of .982 . The third component included three covariates, had a reliability of .979 , and included items related to how students used computers for mathematics. The fourth component included four covariates related to practices used to meet the needs of individual students and obtained a high reliability of .981 . Assessment practices used in the classroom was the fifth component, which exhibited a reliability of .899 and included 3 covariates. 
Table 6

Final Components Resulting from PCA of Teacher Variables and Used as Composite

\section{Covariates}

\begin{tabular}{cc}
\hline Variable Name & Variable Description \\
\hline Component 1: Differentiated Instructional Practices $(\alpha=.969)$ \\
T044201 & Create groups in math class based on ability \\
T106801 & Teaching math-set different standards for some students \\
T106802 & Teaching math-use other materials some students \\
T106803 & Teaching math-engage some students in different activities \\
T106804 & Teaching math-use different methods for some students \\
T106805 & Teaching math-change pace for some students \\
& \\
Component 2: Amount of emphasis on certain content areas $(\alpha=.982)$ \\
T075352 & Emphasis on measurement \\
T075353 & Emphasis on geometry \\
T075354 & Emphasis on data analysis \\
T075355 & Emphasis on algebra and functions \\
\multicolumn{3}{c}{ Component 3: Students use of computers for mathematics $(\alpha=.979)$} \\
T106601 & Students use computer to practice/review math \\
T016602 & Students use computer to extend math learning \\
T106609 & Students use computer to play math games \\
Component 4: & Practices used to meet the needs of individual students $(\alpha=.981)$ \\
T107001 & Individual math students-discuss current performance level \\
T107002 & Individual math students-set goals for specific program \\
T107003 & Individual math students-discuss progress toward goal \\
T107004 & Individual math students-adjust teaching strategies to meet needs of \\
T047402 & students \\
T057404 & Assess math with problem sets \\
\hline & Assess math with individual or group projects \\
\hline
\end{tabular}




\section{Additional Control Variables}

In addition to the composite variables created, additional variables were used as student, teacher, and school covariates, such as teachers' year experience and schools' percent of students identified as a minority. See Table 4 for all additional covariates.

\section{Data Analytic Techniques}

When studying issues in an educational setting, it is important to acknowledge that the assumption of independence does not hold true. Students are clustered (or nested) within schools, which influences their outcomes (i.e., mathematics achievement), as well as the relationships and interactions between variables at multiple levels of the data (McCoach \& Adelson, 2010). This clustering "leads to correlated error terms, biased estimates of parameter standard errors, and possible substantive mistakes when interpreting the importance of one or another predictor variable" (Garson, 2013, p. 5). Because of the nesting issue that occurs from a school setting, the current study used hierarchical linear modeling (HLM; Raudenbush \& Bryk, 2002) to analyze the data obtained from the 2011 Mathematics NAEP assessments and surveys.

Although there are a vast number of advantages for using large-scale, nationally representative datasets, such as NAEP, selection bias remains problematic (Schneider, Carnoy, Kilpatrick, Schmidt, \& Shavelson, 2007). To adjust for selection bias, the composite scores of during-treatment covariates that may affect the outcomes, which were created using PCA, were entered as composite covariates (in additional to other control variables) in the HLM models.

A detailed description of the approach used for the HLM analysis and details about the analyses for each of the three research questions follow. 


\section{Hierarchical Linear Modeling}

In the current study, two-level HLMs were conducted using full maximum likelihood in HLM Version 7.0 (Raudenbush, Byrk, \& Congdon, 2011) to examine each of the research questions. Full maximum likelihood was chosen as the type of estimation (over restricted maximum likelihood) for its consistent and efficient estimates, particularly with large sample sizes (Raudenbush \& Bryk, 2002), as well as its recommendation for use with datasets containing missing values, given we did not conduct multiple imputation on the outcomes or predictors of interest (Garson, 2013).

The same general process, recommended by Raudenbush and Bryk (2002), was used for all HLM analyses. The first analysis was a One-Way Random Effects ANOVA, often times called an unconditional or null model, which used the five plausible values for mathematics achievement as the outcome variables and included no predictor variables at level-1 or level-2. The unconditional model was used to calculate the intraclass correlation (ICC), which allows us to determine the need for a mixed model (Garson, 2013; McCoach \& Adelson, 2010) by providing an indication of the magnitude of the cluster effect (Hox, 2002). Specifically, the ICC was used to determine the amount of variance in the level-1 mathematics scores (level-1 dependent variables) attributed to the clustering (school).

Next, individual-level predictors and covariates (student and teacher covariates) were added to create a Random Coefficient Model (i.e., a level-1 model). Categorical variables were that had been recoded in SPSS version 22 in order created dummy codes that provide meaningful interpretations for analyses were entered as uncentered in HLM. Continuous variables were centered around the grand mean (CGM) in HLM, as CGM 
allows for easy interpretability and may reduce multicollinearity (Garson, 2013). In order to have a consistent model across all content areas and research questions, variables remained in the model regardless of their significance levels. Due to model complexity restrictions and in an effort for parsimony, only the slope of disability status (the level-1 variable of interest in this study) and the intercept were permitted to randomly vary between schools. The level-1 model provided the needed information to determine the within-school and between-school proportion reduction in variance, or the proportion of variance explained at level-1(within-school) and the proportion of variance explained at level-2 (between-school) by the addition of the student-level variables (Garson, 2013; Raudenbush \& Bryk, 2002).

Then, school-level variables were incorporated into the model containing individual-level variables to create the Contextual Model or the Intercepts-and-Slopes as Outcomes Model (i.e., level-2 model). Simply put, this is done in order to reduce the variance in the intercepts and slopes by incorporating contextual or group characteristics. As with the random coefficient model, dummy-coded variables were entered as uncentered in HLM, while continuous variables were entered CGM. With the addition of the set of contextual variables, the between-school proportion reduction of variance, or the proportion of variance explained at level-2 (between schools) was then determined by comparing the random coefficient model between-school variance to the contextual model between-school variance (Garson, 2013; Raudenbush \& Bryk, 2002). Lastly, the inclusion of the treatment variable (i.e., MCS) in the final contextual model allowed the proportion of variance explained by the treatment variables above and beyond the control variables to be determined. 


\section{Plan of Analysis for Each Research Question}

For the first research question, the relationship between having a school-based MCS (full-time or part-time) and students' achievement, 2-level HLMs using composite covariates and controls were used. Because schools are not randomly assigned to have a MCS (full- or part-time) or not, PCAs were conducted in order to create composite covariates for student and teacher during-treatment control variables in an effort to reduce selection bias. As noted, composite covariates and control variables were not eliminated from the model based on their significance in order to compare the same model across content areas. Once the final model (including all covariates) was established, the relationship between MCSs and achievement was examined by the addition of two variables: MCS full-time and MCS part-time. The inclusion of these two variables allowed for the relationship between schools having a full-time MCS and mathematics achievement to be compared to the relationship between schools having a part-time MCS and mathematics achievement (composite scores, as well as the five content areas).

For the second research question, the differentials in achievement for students with and without disabilities when they have a MCS in their school or not, the same final contextual model, including MCS variables, from research question 1 was used. To examine whether being in a school with a MCS would moderate the lower achievement that students with disabilities generally experience, a cross-level interaction between the MCS variables and the IEP slope was created using the HLM software.

For the third research question, the relationship between principal-reported time spent on different roles and responsibilities of MCS and students' achievement, an examination of how the six different roles and responsibilities (see Table 3 for specific 
roles and responsibilities) of MCS relate to students' mathematics achievement was conducted using only those schools that had a full-time MCS (determination of whether to include all schools with a MCS or those only with a full-time MCS was based on research question 1). This research question was exploratory and did not include a comparison group. A two-level HLM regression equation, with the roles and responsibilities as Level-2 predictors, was used to examine these relationships. As with research questions 1 and 2, the same composite covariates and control variables were appropriately modeled at level-1 and level-2 prior to the inclusion of the MCS variable (i.e., roles and responsibilities). Each role was included as a level-2 predictor of mathematics achievement (composite score, as well as the five content areas) one at a time in order to determine the specific relationships and to account for multicollinearity between the different roles

\section{Chapter III Summary}

This chapter described the research design and methodology used for the current study, including the sample, variables, and analytic techniques. Using secondary data analysis of the 2011 NAEP Mathematics Assessment dataset and HLM with adjustments for during-treatment composite covariates and controls, a research design was developed that allowed for an examination of relationships among MCS, fourth-grade students' mathematics achievement, and disability status.

By analyzing these three research questions together, this provides policy makers, administrators, and educators with quantitative evidence on the existence of a significant relationship between the presence of a MCS and students' mathematics achievement (overall and by content area), while also addressing if being in a school with a MCS 
would moderate the lower achievement that students with disabilities generally experience. Lastly, the study provides relevant information on how principal-reported time spent on the roles and responsibilities provided by the MCS are related with fourthgrade students' mathematics achievement on the NAEP.

By investigating the relationship between MCS and fourth-grade mathematics achievement of all students, including students with and without disabilities, this research was designed to expand the current research base and provide methodologically rigorous and substantial evidence in relation to a relatively understudied, yet, current issue. Chapter IV presents the results to the analyses described in this chapter. 


\section{CHAPTER IV}

\section{RESULTS}

Chapter IV presents the quantitative results of several analyses examining the relationship between MCSs and fourth-grade students' mathematics achievement through a secondary data analysis of the 2011 National Assessment of Educational Progress Mathematics Assessment (NAEP) dataset. The research questions that guided this study were as follows:

1. What is the relationship between having a school-based MCS (full or part time) and fourth-grade students' achievement on the NAEP, specifically a) their overall mathematics achievement and b) their achievement in five specific mathematics content areas (i.e., number properties and operations; measurement; geometry; data analysis, statistics, and probability; and algebra)?

2. What are the differentials in achievement of students with and without disabilities when they have a MCS in their school or not, specifically differentials in a) their overall mathematics achievement and b) their achievement in five specific mathematics content areas (i.e., number properties and operations; measurement; geometry; data analysis, statistics, and probability; and algebra)?

3. For schools that have a MCS, how does principal-reported time spent on the six different NAEP-defined roles and responsibilities, which include providing assistance to teachers and students (see Table 3 for a complete list), relate to students' achievement, specifically a) their overall mathematics achievement and 
b) their achievement in five specific mathematics content areas (i.e., number properties and operations; measurement; geometry; data analysis, statistics, and probability; and algebra)?

\section{Research Question 1: The Relationship between having a School-based MCS (full- time or part-time) and Students' Mathematics Achievement}

The goal of the first set of analyses was to examine the relationship between having a full-time or part-time MCS and fourth-grade students' overall mathematics achievement (i.e., composite score), as well as mathematics achievement in the five content areas as defined in the NAEP dataset (i.e., number properties and operations; measurement; geometry; data analysis, statistics, and probability; and algebra).

Using the 2011 NAEP dataset, six school-level and 53 individual-level (32 teacher and 21 student) covariates with a bivariate association with either the school's policy of providing a MCS or the school's mean composite mathematics achievement score were initially identified (see Appendix A). Principle component analysis (PCA) allowed for a reduction in the overall number of covariates, resulting in four student composite covariates and four student covariates (included at the individual level; Table 5) and five teacher composite covariates and two teacher covariates (included at the individual-level; Table 6).

To address the relationship between having a full-time or part-time MCS and fourth-grade students' mathematics achievement, a model-based approach (i.e., HLM) was used as it allowed for adjustments for the effects of covariates and addressed the nested nature of the data. Moreover, the model-based approach allowed outcomes (mathematics achievement on the NAEP) and treatment (provision of MCS) to be 
modeled at the appropriate level (level 1 and level 2, respectively).

All control variables remained in the models, regardless of significance, to enable comparisons of results across the six measures of mathematics achievement (i.e., composite, number properties and operations; measurement; geometry; data analysis, statistics, and probability; and algebra). The final contextual model for all achievement outcomes allowed the intercept and students' disability status (IEP status) to vary between groups, as these were variables of interest. The remaining variables served as control variables at the school-and student-level and, therefore, their variances were not allowed to randomly vary. Equation 1 illustrates the contextual model, prior to entering the treatment variables, for the current study:

$$
\begin{aligned}
& \text { COMP }_{i j}=\gamma_{00}+\gamma_{01} * \text { PUBPRIV } V_{j}+\gamma_{02} * \text { PERFRL }_{j}+\gamma_{03} * \text { PERMINOR }_{j}+\gamma_{04} * \text { PERLEP }_{j}+
\end{aligned}
$$

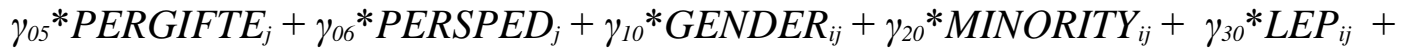

$$
\begin{aligned}
& \gamma_{40} * \text { DAYSABS } i j+\gamma_{50} * \text { LIKEMATH }_{i j}+\gamma_{60} * \text { TECHMATH }_{i j}+\gamma_{70} * \operatorname{SELFEFF}_{i j}+ \\
& \gamma_{80} * \operatorname{YRSEXP}_{i j}+\gamma_{90} * \text { MTHDGRE }_{i j}+\gamma_{100}{ }^{*} \text { DIFFINST }_{i j}+\gamma_{110}{ }^{*} \text { EMPCONT }_{i j}+ \\
& \gamma_{120} * \operatorname{COMPUSE}_{i j}+\gamma_{130} * \operatorname{INDPRAC}_{i j}+\gamma_{140} * \operatorname{ASSESSPR}_{i j}+\gamma_{150} * I E P_{i j}+u_{0 j}+ \\
& u_{15 j}^{*} I E P_{i j}+r_{i j}
\end{aligned}
$$

where $C O M P_{i j}$ is the averaged plausible value composite mathematics score for student $i$ in school $j$. Similar equations for the five content areas were used (substituting the specific content outcome variable into the equation for $\left.C O M P_{i j}\right)$.

The addition of two level 2 predictors of the intercept allowed for the examination of the relationship between treatment (full- or part-time MCS) and outcome (mathematics 
achievement). Equation 2 illustrates the final contextual model estimating fourth-grade students' mathematics achievement after the inclusion of treatment variables:

$$
\begin{aligned}
& \text { COMP }_{i j}=\gamma_{00}+\gamma_{01} * \text { PUBPRIV } V_{j}+\gamma_{02} * \text { PERFRL }_{j}+\gamma_{03} * \text { PERMINOR }_{j}+\gamma_{04} * \text { PERLEP } P_{j}+
\end{aligned}
$$

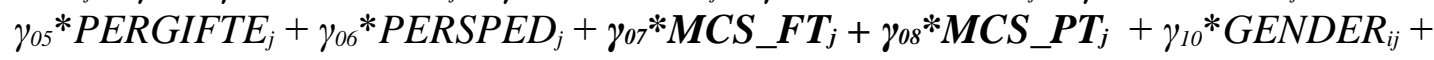

$$
\begin{aligned}
& \gamma_{20} * \text { MINORITY }_{i j}+\gamma_{30} * \operatorname{LEP}_{i j}+\gamma_{40} * \text { DAYSABS } i j+\gamma_{50}{ }^{*} \text { LIKEMATH }_{i j}+\gamma_{60} * \operatorname{TECHMATH}_{i j}+ \\
& \gamma_{70} * \operatorname{SELFEFF}_{i j}+\gamma_{80} * \operatorname{YRSEXP}_{i j}+\gamma_{90} * \text { MTHDGRE } E_{i j}+\gamma_{100} * \text { DIFFINST }_{i j}+ \\
& \gamma_{110} * E M P C O N T_{i j}+\gamma_{120} * \operatorname{COMPUSE}_{i j}+\gamma_{130} * \operatorname{INDPRAC}_{i j}+\gamma_{140} * \operatorname{ASSESSPR}_{i j}+\gamma_{150} * I E P_{i j}+ \\
& u_{0 j}+u_{15 j} * I E P_{i j}+r_{i j}
\end{aligned}
$$

where $C O M P_{i j}$ is the averaged plausible value composite mathematics score for student $i$ in school $j, \gamma_{07}$ is the differential composite score for a full-time MCS compared to no MCS, $\gamma_{08}$ is the differential composite score for a part-time MCS compared to no MCS, $M C S \_F T_{j}$ indicates whether the school had a full-time MCS, and $M C S \_P T_{j}$ indicates whether the school had a part-time MCS. Similar equations for the five content areas were used (substituting the specific content outcome variable into the equation for $\operatorname{COMP}(i j)$

\section{Overall Mathematics Achievement - Composite Score}

The intraclass correlation (ICC) for the composite score outcome was .250, which indicates that $25.0 \%$ of the variance in composite mathematics achievement scores was attributed to the school level. This ICC value is consistent with other studies that report ICC's ranging from $13.8 \%$ to $26.4 \%$ in mathematics achievement for $\mathrm{K}-12$ schools (Hedges \& Hedberg, 2007). As noted, the final model for the relationship between having a full-time or part-time MCS and fourth-grade students' composite (i.e., overall) 
mathematics achievement (see Table 7) included six school covariates (included at level 2); five teacher composite covariates and two teacher covariates (included at level 1); four student composite covariates and four student covariates (included at level 1), and two variables indicating whether a school had a full-time or part-time MCS (included at level 2).

After adjusting for all covariates, the differential relationship between schools with a full-time MCS and no MCS was 1.71 with a standard error of 0.35 , favoring schools with full-time MCSs, which was statistically significant $(p<.001)$. The differential relationship between schools having a part-time MCS and those without was 0.18 with a standard error of 0.35 , which was not statistically significant $(p=.595)$. Thus, it can be concluded that there is a significant relationship between schools having a fulltime MCSs and students' overall mathematics achievement; however, this relationship does not hold true for schools with part-time MCSs. On average and after adjusting for all controls in the final model with MCS predicting the intercept, fourth-grade students in a school with a full-time MCS can expect a 1.71 point greater overall mathematics achievement score on the NAEP than students in a school without an MCS, whereas fourth-grade students in a school with a part-time MCS do not differ on their achievement from students in schools without an MCS. The overall (composite) mathematics achievement model, including the MCS variables as a predictor of the intercept, explained $63 \%$ of the variability in achievement between schools; although, there was still statistically significant $(p<.001)$ between-school variability remaining. This indicates that there may be additional individual- and/or school-level variables that may explain variability in overall mathematics achievement. 


\section{Mathematics Achievement in Number Properties and Operations}

The intraclass correlation (ICC) for the number properties and operations outcome $(\rho=.245)$ indicates that $24.5 \%$ of the proportion of variance in number properties and operations mathematics achievement scores was attributed to the school level. Using the same predictors and treatment variables as the overall mathematics achievement model, the differential relationship for schools with full-time MCSs was 1.66 with a standard error of 0.45 and the differential for the relationship for schools with part-time MCSs was 0.17 with a standard error of 0.41 . Results indicated that there is a statistically significant relationship between schools with full-time MCSs and students' mathematics achievement in number properties and operations $(p<.001)$, whereas there is not a statistically significant relationship between schools with part-time MCSs and students' mathematics achievement in number properties and operations $(p=.687$; see Table 8$)$. After adjusting for all controls in the model, on average, fourth-grade students in a school with a full-time MCS can expect achievement in number properties and operations on the NAEP that is 1.66 points greater than students in a school without an MCS; however, students in schools with a part-time MCSs do not differ on their achievement from students in schools without an MCS.

The number properties and operations mathematics achievement model, including the MCS variables as a predictor of the intercept, explained $57 \%$ of the variability in achievement between schools. There was still statistically significant $(p<.001)$ betweenschool variability remaining, thus indicating that there may be additional individualand/or school-level variables that may explain variability in number properties and operations achievement on the NAEP. 


\section{Mathematics Achievement in Measurement}

The ICC for the measurement outcome $(\rho=.275)$ indicates that $27.5 \%$ of the proportion of variance in measurement mathematics achievement scores on the NAEP was attributed to the school level. The final model (see Table 9) showed there was not a statistically significant relationship between schools with part-time MCSs and measurement achievement (coefficient $=-0.31, S E=0.47, p=.510)$. However, the final model did show a statistically significant relationship between schools providing a fulltime MCS and students' measurement achievement (coefficient $=1.81, S E=0.44$, $p<.001)$. These results indicate that fourth-grade students in schools with part-time MCSs do not achieve higher on the NAEP measurement assessment than students in schools with no MCS, whereas students in schools with full-time MCSs can expect an average of 1.81 points higher on their NAEP measurement achievement than students in schools without an MCS after controlling for all covariates in the final model.

The full measurement model, including the MCS variables as a predictor of the intercept, explained $57 \%$ of the variability in achievement between schools. Although, statistically significant $(p<.001)$ between-school variability remained, indicating that there may be additional individual-level and/or school-level variables that may explain variability in measurement achievement. 
Table 7

Final Multi-level Model Examining the Relationship between Overall (Composite) Mathematics Achievement and a School's Policy of Providing a Full-Time or Part-Time Mathematics Coach/Specialist (MCS)

\begin{tabular}{|c|c|c|c|c|c|c|c|c|}
\hline \multirow[b]{2}{*}{ Fixed effects } & \multicolumn{2}{|c|}{$\begin{array}{c}\text { Unconditional } \\
\text { Model } \\
\end{array}$} & \multicolumn{2}{|c|}{$\begin{array}{l}\text { Full Model } \\
\text { (all covariates) }\end{array}$} & \multicolumn{2}{|c|}{$\begin{array}{l}\text { Full Model - MCS } \\
\text { (intercept) }\end{array}$} & \multicolumn{2}{|c|}{$\begin{array}{l}\text { Full Model - MCS } \\
\text { (int. \& IEP slope) }\end{array}$} \\
\hline & Coefficient & $S E$ & Coefficient & $S E$ & Coefficient & $S E$ & Coefficient & $S E$ \\
\hline \multicolumn{9}{|l|}{ Model for intercept math ach. $\left(\beta_{0}\right)$} \\
\hline Intercept $\left(\gamma_{00}\right)$ & $240.35 *$ & 0.20 & $246.68 *$ & 0.18 & $246.32 *$ & 0.21 & $246.33 *$ & 0.21 \\
\hline $\operatorname{Sector}\left(\gamma_{01}\right)$ & & & $3.30 *$ & 0.53 & $3.50 *$ & 0.53 & $3.50 *$ & 0.53 \\
\hline$\%$ Free Lunch $\left(\gamma_{02}\right)$ & & & $-0.21 *$ & 0.01 & $-0.21 *$ & 0.01 & $-0.21 *$ & 0.01 \\
\hline$\%$ Minority $\left(\gamma_{03}\right)$ & & & $-0.07 *$ & 0.01 & $-0.08 *$ & 0.01 & $-0.08 *$ & 0.01 \\
\hline$\% \operatorname{LEP}\left(\gamma_{04}\right)$ & & & $1.75^{*}$ & 0.10 & $1.75^{*}$ & 0.10 & $1.75^{*}$ & 0.10 \\
\hline$\%$ Gifted $\left(\gamma_{05}\right)$ & & & $1.77^{*}$ & 0.12 & $1.77 *$ & 0.12 & $1.77^{*}$ & 0.12 \\
\hline$\%$ Special Education $\left(\gamma_{06}\right)$ & & & $-0.50 *$ & 0.17 & $-0.52 *$ & 0.17 & $-0.52 *$ & 0.17 \\
\hline Full-time MCS $\left(\gamma_{07}\right)$ & & & & & $1.71 *$ & 0.35 & $1.69 *$ & 0.35 \\
\hline Part-time MCS ( $\left.{ }^{08}\right)$ & & & & & 0.18 & 0.35 & 0.16 & 0.34 \\
\hline \multicolumn{9}{|l|}{ Model for Gender slope $\left(\beta_{1}\right)$} \\
\hline Intercept $\left(\gamma_{10}\right)$ & & & $-1.68 *$ & 0.11 & $-1.68 *$ & 0.11 & $-1.68 *$ & 0.11 \\
\hline \multicolumn{9}{|l|}{ Model for Minority slope $\left(\beta_{2}\right)$} \\
\hline Intercept $\left(\gamma_{20}\right)$ & & & $-8.06^{*}$ & 0.19 & $-8.07 *$ & 0.19 & $-8.07 *$ & 0.19 \\
\hline \multicolumn{9}{|l|}{ Model for LEP slope $\left(\beta_{3}\right)$} \\
\hline Intercept $\left(\gamma_{30}\right)$ & & & $-12.90 *$ & 0.29 & $-12.89 *$ & 0.30 & $-12.88 *$ & 0.29 \\
\hline \multicolumn{9}{|l|}{ Model for Days Absent slope $\left(\beta_{4}\right)$} \\
\hline Intercept $\left(\gamma_{40}\right)$ & & & $-2.34 *$ & 0.09 & $-2.35 *$ & 0.09 & $-2.35^{*}$ & 0.09 \\
\hline \multicolumn{9}{|l|}{ Model for LIKEMATH ${ }^{\mathrm{a}}$ slope $\left(\beta_{5}\right)$} \\
\hline Intercept $\left(\gamma_{50}\right)$ & & & $0.93 *$ & 0.07 & $0.93 *$ & 0.07 & $0.93 *$ & 0.07 \\
\hline \multicolumn{9}{|c|}{ Model for TECHMATH ${ }^{\mathrm{a}}$ slope $\left(\beta_{6}\right)$} \\
\hline Intercept $\left(\gamma_{60}\right)$ & & & $-2.39 *$ & 0.07 & $-2.39 *$ & 0.07 & $-2.39 *$ & 0.07 \\
\hline \multicolumn{9}{|l|}{ Model for SELFEFFa slope $\left(\beta_{7}\right)$} \\
\hline Intercept $\left(\gamma_{70}\right)$ & & & $8.53 *$ & 0.07 & $8.53 *$ & 0.07 & $8.53 *$ & 0.07 \\
\hline
\end{tabular}




\begin{tabular}{|c|c|c|c|c|c|c|c|}
\hline \multicolumn{8}{|c|}{ Model for Yrs Experience slope $\left(\beta_{8}\right)$} \\
\hline Intercept $\left(\gamma_{80}\right)$ & & $0.05^{*}$ & 0.01 & $0.05^{*}$ & 0.01 & $0.05^{*}$ & 0.01 \\
\hline Model for Math Degree slop & & & & & & & \\
\hline Intercept $\left(\gamma_{90}\right)$ & & $1.31 *$ & 0.17 & $1.30^{*}$ & 0.17 & $1.30^{*}$ & 0.17 \\
\hline Model for DIFFINST $^{\mathrm{a}}$ slope & & & & & & & \\
\hline Intercept $\left(\gamma_{100}\right)$ & & $-0.94 *$ & 0.09 & $-0.95^{*}$ & 0.09 & $-0.95^{*}$ & 0.09 \\
\hline $\begin{array}{l}\text { Model for EMPCONT a slop } \\
\text { Intercept }\left(\gamma_{110}\right)\end{array}$ & & $0.92 *$ & 0.10 & $0.91 *$ & 0.10 & $0.91^{*}$ & 0.10 \\
\hline $\begin{array}{l}\text { Model for COMPUSE }{ }^{\text {a }} \text { slop } \\
\text { Intercept }\left(\gamma_{120}\right)\end{array}$ & & -0.07 & 0.09 & -0.06 & 0.09 & -0.06 & 0.09 \\
\hline Model for INDPRAC ${ }^{\text {a }}$ slope & & & & & & & \\
\hline $\begin{array}{l}\text { Intercept }\left(\gamma_{130}\right) \\
\text { Model for ASSESSPR }{ }^{\mathrm{a}} \text { slop }\end{array}$ & & $0.41^{*}$ & 0.10 & $0.41^{*}$ & 0.10 & $0.41^{*}$ & 0.10 \\
\hline $\begin{array}{l}\text { Intercept }\left(\gamma_{140}\right) \\
\text { Model for IEP slope }\left(\beta_{15}\right)\end{array}$ & & $0.93 *$ & 0.07 & $0.92 *$ & 0.07 & $0.92 *$ & 0.07 \\
\hline $\begin{array}{l}\text { Model for IEP slope }\left(\beta_{15}\right) \\
\text { Intercept }\left(\gamma_{150}\right)\end{array}$ & & $-20.90 *$ & 0.24 & $-20.90 *$ & 0.24 & $-21.06^{*}$ & 030 \\
\hline Full-time MCS $\left(\gamma_{151}\right)$ & & & & & & 0.41 & 0.62 \\
\hline Part-time MCS $\left(\gamma_{152}\right)$ & & & & & & 0.45 & 0.63 \\
\hline Variance estimates (random & & & & & & & \\
\hline Var. in intercepts $\left(\tau_{\mathrm{oo}}\right)$ & $207.81^{*}$ & 77.34* & & $77.03 *$ & & $77.03 *$ & \\
\hline Var. in IEP slope $\left(\tau_{15}\right)$ & & $95.84 *$ & & $95.85^{*}$ & & $95.75^{*}$ & \\
\hline Var. within schools $\left(\sigma^{2}\right)$ & 622.18 & 429.73 & & 429.72 & & 429.73 & \\
\hline
\end{tabular}

${ }^{\text {a }}$ Composite Covariates created using principal component analysis (see Tables 5 and 6 for more details) 
Table 8

Final Multi-level Model Examining the Relationship between Number Properties and Operations Mathematics Achievement and a School's Policy of Providing a Full-Time or Part-Time Mathematics Coach/Specialist (MCS)

\begin{tabular}{|c|c|c|c|c|c|c|c|c|}
\hline \multirow[b]{2}{*}{ Fixed effects } & \multicolumn{2}{|c|}{$\begin{array}{c}\text { Unconditional } \\
\text { Model }\end{array}$} & \multicolumn{2}{|c|}{$\begin{array}{c}\text { Full Model } \\
\text { (all covariates) }\end{array}$} & \multicolumn{2}{|c|}{$\begin{array}{l}\text { Full Model - MCS } \\
\text { (intercept) }\end{array}$} & \multicolumn{2}{|c|}{$\begin{array}{l}\text { Full Model - MCS } \\
\text { (int. \& IEP slope) }\end{array}$} \\
\hline & Coefficient & $S E$ & Coefficient & $S E$ & Coefficient & $S E$ & Coefficient & $S E$ \\
\hline \multicolumn{9}{|l|}{ Model for intercept math ach. $\left(\beta_{0}\right)$} \\
\hline Intercept $\left(\gamma_{00}\right)$ & $239.48 *$ & 0.20 & $245.63 *$ & 0.22 & $245.29 *$ & 0.26 & $245.29 *$ & 0.26 \\
\hline $\operatorname{Sector}\left(\gamma_{01}\right)$ & & & $5.37 *$ & 0.63 & $5.33^{*}$ & 0.61 & $5.33^{*}$ & 0.61 \\
\hline$\%$ Free Lunch $\left(\gamma_{02}\right)$ & & & $-0.23^{*}$ & 0.01 & $-0.23^{*}$ & 0.01 & $-0.23 *$ & 0.01 \\
\hline$\%$ Minority $\left(\gamma_{03}\right)$ & & & $-0.06^{*}$ & 0.01 & $-0.06^{*}$ & 0.01 & $-0.06^{*}$ & 0.01 \\
\hline$\% \operatorname{LEP}\left(\gamma_{04}\right)$ & & & $1.99 *$ & 0.12 & $2.00 *$ & 0.12 & $2.00^{*}$ & 0.12 \\
\hline$\%$ Gifted $\left(\gamma_{05}\right)$ & & & $1.92 *$ & 0.12 & $1.92 *$ & 0.12 & $1.92 *$ & 0.12 \\
\hline$\%$ Special Education $\left(\gamma_{06}\right)$ & & & $-0.64^{*}$ & 0.21 & $-0.65^{*}$ & 0.21 & $-0.65^{*}$ & 0.21 \\
\hline Full-time MCS $\left(\gamma_{07}\right)$ & & & & & $1.66^{*}$ & 0.45 & $1.66^{*}$ & 0.46 \\
\hline Part-time MCS ( $\left.\gamma_{08}\right)$ & & & & & 0.17 & 0.41 & 0.18 & 0.40 \\
\hline \multicolumn{9}{|l|}{ Model for Gender slope $\left(\beta_{1}\right)$} \\
\hline Intercept $\left(\gamma_{10}\right)$ & & & $-1.93 *$ & 0.15 & $-1.93 *$ & 0.15 & $-1.93 *$ & 0.15 \\
\hline \multicolumn{9}{|l|}{ Model for Minority slope $\left(\beta_{2}\right)$} \\
\hline Intercept $\left(\gamma_{20}\right)$ & & & $-7.93 *$ & 0.22 & $-7.93 *$ & 0.22 & $-7.93 *$ & 0.22 \\
\hline \multicolumn{9}{|l|}{ Model for LEP slope $\left(\beta_{3}\right)$} \\
\hline Intercept $\left(\gamma_{30}\right)$ & & & $-12.57 *$ & 0.44 & $-12.56^{*}$ & 0.45 & $-12.56^{*}$ & 0.45 \\
\hline \multicolumn{9}{|l|}{ Model for Days Absent slope $\left(\beta_{4}\right)$} \\
\hline Intercept $\left(\gamma_{40}\right)$ & & & $-2.57 *$ & 0.08 & $-2.57 *$ & 0.08 & $-2.57^{*}$ & 0.08 \\
\hline \multicolumn{9}{|l|}{ Model for LIKEMATH ${ }^{\mathrm{a}}$ slope $\left(\beta_{5}\right)$} \\
\hline Intercept $\left(\gamma_{50}\right)$ & & & $1.31 *$ & 0.09 & $1.31 *$ & 0.09 & $1.31 *$ & 0.09 \\
\hline \multicolumn{9}{|c|}{ Model for TECHMATH ${ }^{\mathrm{a}}$ slope $\left(\beta_{6}\right)$} \\
\hline Intercept $\left(\gamma_{60}\right)$ & & & $-2.58^{*}$ & 0.08 & $-2.58 *$ & 0.08 & $-2.58^{*}$ & 0.08 \\
\hline \multicolumn{9}{|l|}{ Model for SELFEFF ${ }^{\mathrm{a}}$ slope $\left(\beta_{7}\right)$} \\
\hline Intercept $\left(\gamma_{70}\right)$ & & & $9.20 *$ & 0.10 & $9.20 *$ & 0.10 & $9.20 *$ & 0.10 \\
\hline
\end{tabular}




\begin{tabular}{|c|c|c|c|c|c|c|c|}
\hline \multicolumn{8}{|c|}{ Model for Yrs Experience slope $\left(\beta_{8}\right)$} \\
\hline Intercept $\left(\gamma_{80}\right)$ & & $0.05^{*}$ & 0.01 & $0.05^{*}$ & 0.01 & $0.05^{*}$ & 0.01 \\
\hline Model for Math Degree slop & & & & & & & \\
\hline Intercept $\left(\gamma_{90}\right)$ & & $1.29 *$ & 0.23 & $1.29 *$ & 0.23 & $1.29 *$ & 0.23 \\
\hline Model for DIFFINST ${ }^{\mathrm{a}}$ slope & & & & & & & \\
\hline Intercept $\left(\gamma_{100}\right)$ & & $-1.01 *$ & 0.10 & $-1.01 *$ & 0.10 & $-1.01 *$ & 0.10 \\
\hline Model for EMPCONT ${ }^{\text {a }}$ slop & & & & & & & \\
\hline $\begin{array}{l}\text { Intercept }\left(\gamma_{110}\right) \\
\text { Model for COMPUSE } \text { slop }^{\text {sol }}\end{array}$ & & $0.80^{*}$ & 0.15 & $0.80^{*}$ & 0.15 & $0.80^{*}$ & 0.15 \\
\hline Intercept $\left(\gamma_{120}\right)$ & & -0.13 & 0.10 & -0.13 & 0.10 & -0.13 & 0.10 \\
\hline Model for INDPRAC ${ }^{\mathrm{a}}$ slope & & & & & & & \\
\hline Intercept $\left(\gamma_{130}\right)$ & & $0.48^{*}$ & 0.10 & $0.48^{*}$ & 0.09 & $0.48^{*}$ & 0.09 \\
\hline Model for ASSESSPR ${ }^{\text {a }}$ slop & & & & & & & \\
\hline $\begin{array}{c}\text { Intercept }\left(\gamma_{140}\right) \\
\text { Model for IEP slope }\left(\beta_{15}\right)\end{array}$ & & $0.96^{*}$ & 0.08 & $0.95^{*}$ & 0.08 & $0.95^{*}$ & 0.08 \\
\hline Intercept $\left(\gamma_{150}\right)$ & & $-23.11 *$ & 0.30 & $-23.11 *$ & 0.30 & $-23.06^{*}$ & 0.41 \\
\hline Full-time MCS $\left(\gamma_{151}\right)$ & & & & & & -0.07 & 0.71 \\
\hline Part-time MCS $\left(\gamma_{152}\right)$ & & & & & & 0.15 & 0.73 \\
\hline Variance estimates (random & & & & & & & \\
\hline Var. in intercepts $\left(\tau_{\mathrm{oo}}\right)$ & $240.41^{*}$ & $103.43 *$ & & $103.16^{*}$ & & $103.16^{*}$ & \\
\hline Var. in IEP slope $\left(\tau_{15}\right)$ & & $123.62 *$ & & $123.62 *$ & & $123.59 *$ & \\
\hline Var. within schools $\left(\sigma^{2}\right)$ & 742.13 & 516.14 & & 516.13 & & 516.13 & \\
\hline
\end{tabular}

${ }^{a}$ Composite Covariates created using principal component analysis (see Tables 5 and 6 for more details) 
Table 9

Final Multi-level Model Examining the Relationship between Measurement Mathematics Achievement and a School's Policy of

Providing a Full-Time or Part-Time Mathematics Coach/Specialist (MCS)

\begin{tabular}{|c|c|c|c|c|c|c|c|c|}
\hline \multirow[b]{2}{*}{ Fixed effects } & \multicolumn{2}{|c|}{$\begin{array}{c}\text { Unconditional } \\
\text { Model }\end{array}$} & \multicolumn{2}{|c|}{$\begin{array}{c}\text { Full Model } \\
\text { (all covariates) }\end{array}$} & \multicolumn{2}{|c|}{$\begin{array}{l}\text { Full Model - MCS } \\
\text { (intercept only) }\end{array}$} & \multicolumn{2}{|c|}{$\begin{array}{l}\text { Full Model - MCS } \\
\text { (int. \& IEP slope) }\end{array}$} \\
\hline & Coefficient & $S E$ & Coefficient & $S E$ & Coefficient & $S E$ & Coefficient & $S E$ \\
\hline \multicolumn{9}{|l|}{ Model for intercept math ach. $\left(\beta_{0}\right)$} \\
\hline Intercept $\left(\gamma_{00}\right)$ & $238.42 *$ & 0.25 & $246.58 *$ & 0.26 & $246.30 *$ & 0.28 & $246.33 *$ & 0.28 \\
\hline $\operatorname{Sector}\left(\gamma_{01}\right)$ & & & $3.52 *$ & 0.82 & $3.71 *$ & 0.82 & $3.70 *$ & 0.82 \\
\hline$\%$ Free Lunch $\left(\gamma_{02}\right)$ & & & $-0.22 *$ & 0.01 & $-0.23 *$ & 0.01 & $-0.22 *$ & 0.01 \\
\hline$\%$ Minority $\left(\gamma_{03}\right)$ & & & $-0.11 *$ & 0.01 & $-0.12 *$ & 0.01 & $-0.12 *$ & 0.01 \\
\hline$\% \operatorname{LEP}\left(\gamma_{04}\right)$ & & & $2.06^{*}$ & 0.13 & $2.07 *$ & 0.13 & $2.07 *$ & 0.13 \\
\hline$\%$ Gifted $\left(\gamma_{05}\right)$ & & & $1.80 *$ & 0.17 & $1.80 *$ & 0.17 & $1.80 *$ & 0.17 \\
\hline$\%$ Special Education $\left(\gamma_{06}\right)$ & & & $-0.71^{*}$ & 0.25 & $-0.73^{*}$ & 0.24 & $-0.73^{*}$ & 0.24 \\
\hline Full-time MCS $\left(\gamma_{07}\right)$ & & & & & $1.81 *$ & 0.44 & $1.75^{*}$ & 0.44 \\
\hline Part-time MCS ( $\left.\gamma_{08}\right)$ & & & & & -0.31 & 0.47 & -0.39 & 0.48 \\
\hline \multicolumn{9}{|l|}{ Model for Gender slope $\left(\beta_{1}\right)$} \\
\hline Intercept $\left(\gamma_{10}\right)$ & & & $-2.53 *$ & 0.20 & $-2.53 *$ & 0.20 & $-2.53 *$ & 0.20 \\
\hline \multicolumn{9}{|l|}{ Model for Minority slope $\left(\beta_{2}\right)$} \\
\hline Intercept $\left(\gamma_{20}\right)$ & & & $-10.97 *$ & 0.30 & $-10.97 *$ & 0.30 & $-10.97 *$ & 0.30 \\
\hline \multicolumn{9}{|l|}{ Model for LEP slope $\left(\beta_{3}\right)$} \\
\hline Intercept $\left(\gamma_{30}\right)$ & & & $-15.17 *$ & 0.38 & $-15.16^{*}$ & 0.38 & $-15.16^{*}$ & 0.38 \\
\hline \multicolumn{9}{|l|}{ Model for Days Absent slope $\left(\beta_{4}\right)$} \\
\hline Intercept $\left(\gamma_{40}\right)$ & & & $-2.55^{*}$ & 0.13 & $-2.55^{*}$ & 0.13 & $-2.55^{*}$ & 0.13 \\
\hline \multicolumn{9}{|l|}{ Model for LIKEMATH ${ }^{\mathrm{a}}$ slope $\left(\beta_{5}\right)$} \\
\hline Intercept $\left(\gamma_{50}\right)$ & & & $0.91 *$ & 0.09 & $0.91 *$ & 0.09 & $0.91 *$ & 0.09 \\
\hline \multicolumn{9}{|c|}{ Model for TECHMATH ${ }^{\mathrm{a}}$ slope $\left(\beta_{6}\right)$} \\
\hline Intercept $\left(\gamma_{60}\right)$ & & & $-2.64 *$ & 0.07 & $-2.64 *$ & 0.07 & $-2.64 *$ & 0.07 \\
\hline \multicolumn{9}{|l|}{ Model for SELFEFF ${ }^{a}$ slope $\left(\beta_{7}\right)$} \\
\hline Intercept $\left(\gamma_{70}\right)$ & & & $9.62 *$ & 0.12 & $9.62 *$ & 0.12 & $9.62 *$ & 0.12 \\
\hline
\end{tabular}




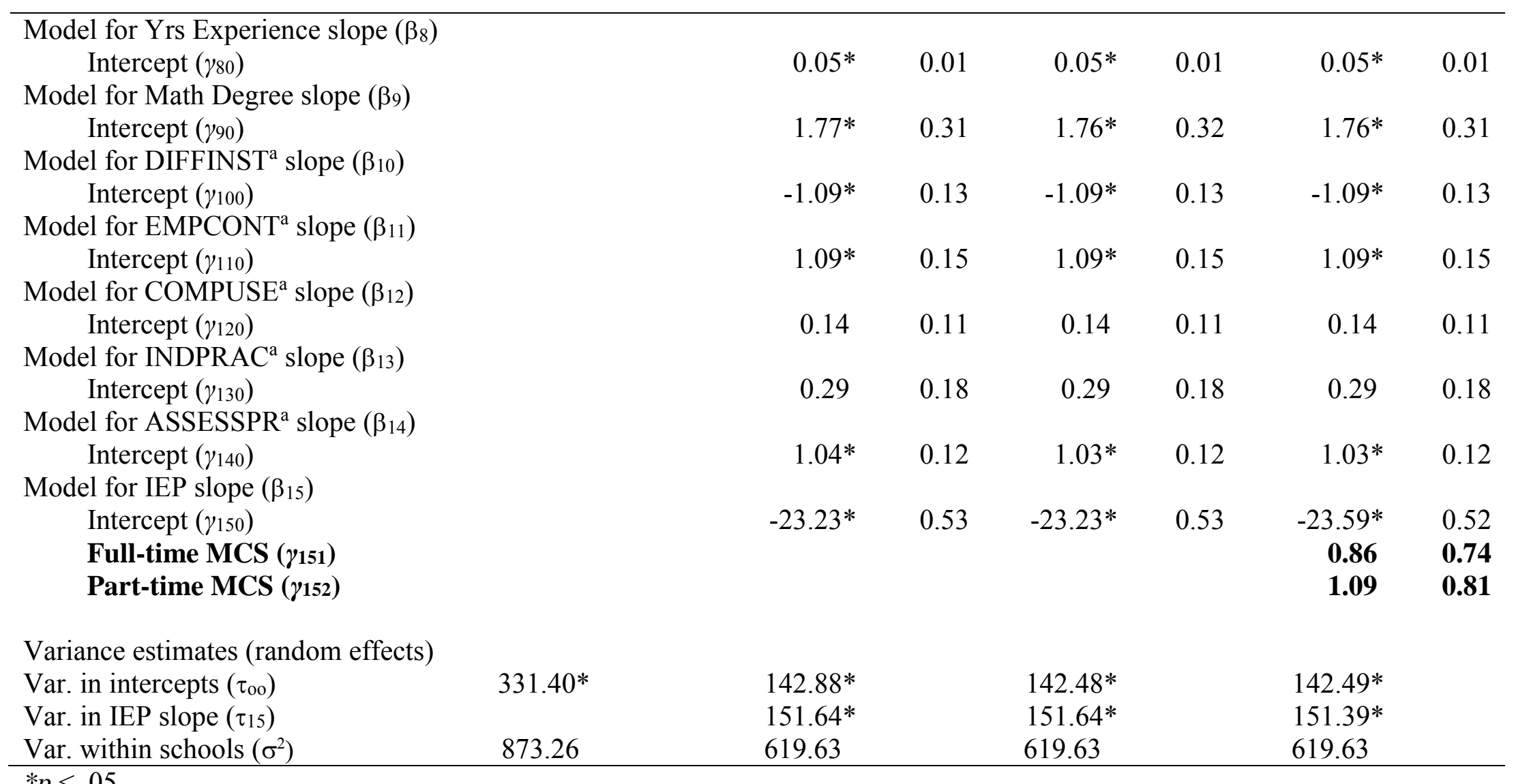

$* p<.05$

${ }^{a}$ Composite Covariates created using principal component analysis (see Tables 5 and 6 for more details) 


\section{Mathematics Achievement in Geometry}

Using the null model, the geometry achievement model had an ICC value of .269; meaning that approximately $27 \%$ of the proportion of variance in geometry achievement on the NAEP is between schools. Using the full model with MCS variables as predictors of the intercept (see Table 10), findings show similar results as the previous achievement models: no statistically significant relationship between schools with part-time MCSs and geometry achievement (coefficient $=0.27, S E=0.40, p=.511$ ) and a statistically significant relationship between schools providing a full-time MCS and students' geometry achievement (coefficient $=1.42, S E=0.47, p=.006$ ). After adjusting for all controls in the model, on average, fourth-grade students in schools with part-time MCSs do not achieve higher on their NAEP geometry achievement, whereas students in a school with a full-time MCS can expect achievement in NAEP geometry that is 1.42 points, compared to students in schools without an MCS. Although the geometry model with MCS as a predictor of the intercept explains $44 \%$ of the variability between schools, statistically significant $(p<.001)$ variability remains to be explained.

\section{Mathematics Achievement in Data Analysis, Statistics, and Probability}

The ICC for the data outcome $(\rho=.273)$ indicates that $27.3 \%$ of the proportion of variance in data analysis, statistics, and probability achievement is between-schools. After adjusting for all covariates, the differential relationship between schools with a fulltime MCS and no MCS was 2.12 with a standard error of 0.42 , favoring schools with full-time MCSs. This value was statistically significant $(p<.001)$. The differential relationship between schools having a part-time MCS and those without was 0.87 with a standard error of 0.53 , which was not statistically significant $(p=.126$; see Table 11). 
Thus, it can be concluded that there is a statistically significant relationship between schools having a full-time MCSs and fourth-grade students' data analysis, statistics, and probability achievement on the NAEP; however, this relationship does not hold true for schools with part-time MCSs. In other words, on average and after adjusting for all controls in the final model, students in a school with a full-time MCS can expect a 2.12point higher score on their NAEP data analysis, statistics, and probability achievement. The data analysis, statistics, and probability achievement model, including the MCS variables as a predictor of the intercept, explained $56 \%$ of the variability in achievement between schools; although, there was still statistically significant $(p<.001)$ betweenschool variability remaining. This indicates that there may be additional individualand/or school-level variables that may explain variability in data analysis, statistics, and probability achievement.

\section{Mathematics Achievement in Algebra}

The ICC for the algebra outcome $(\rho=.249)$ indicates that $24.9 \%$ of the proportion of variance in algebra achievement scores was attributed to the school level. Using the same predictors and treatment variables as the previous models, the differential relationship for schools with full-time MCSs was 1.93 with a standard error of 0.43 and the differential for the relationship for schools with part-time MCSs was 0.34 with a standard error of 0.34 . Results indicated that there is a statistically significant relationship between schools with full-time MCSs and fourth-grade students' NAEP achievement in algebra $(p<.001)$, whereas there is not a significant relationship between schools with part-time MCSs and students' NAEP achievement in algebra ( $p=.323$; see Table 12). After adjusting for all controls in the model, on average, fourth-grade students in a school 
with a full-time MCS can expect a score in algebra achievement on the NAEP of 1.93 points higher than those in a school without an MCS; however, students in schools with part-time MCSs do not have a higher score in their algebra achievement.

The algebra achievement model, including the MCS variables as a predictor of the intercept, explained $55 \%$ of the variability in achievement between schools. There was still statistically significant $(p<.001)$ between-school variability remaining, thus indicating that there may be additional individual-level and/or school-level variables that may explain variability in algebra achievement. 
Table 10

Final Multi-level Model Examining the Relationship between Geometry Mathematics Achievement and a School's Policy of Providing a Full-Time or Part-Time Mathematics Coach/Specialist (MCS)

\begin{tabular}{|c|c|c|c|c|c|c|c|c|}
\hline \multirow[b]{2}{*}{ Fixed effects } & \multicolumn{2}{|c|}{$\begin{array}{l}\text { Unconditional } \\
\text { Model }\end{array}$} & \multicolumn{2}{|c|}{$\begin{array}{c}\text { Full Model } \\
\text { (all covariates) }\end{array}$} & \multicolumn{2}{|c|}{$\begin{array}{l}\text { Full Model - MCS } \\
\text { (intercept only) }\end{array}$} & \multicolumn{2}{|c|}{$\begin{array}{l}\text { Full Model - MCS } \\
\text { (int. \& IEP slope) }\end{array}$} \\
\hline & Coefficient & $S E$ & Coefficient & $S E$ & Coefficient & $S E$ & $\begin{array}{c}\text { Coefficien } \\
t\end{array}$ & $S E$ \\
\hline \multicolumn{9}{|l|}{ Model for intercept math ach. $\left(\beta_{0}\right)$} \\
\hline Intercept $\left(\gamma_{00}\right)$ & $239.89 *$ & 0.19 & $244.82 *$ & 0.20 & $244.51 *$ & 0.26 & $244.53 *$ & 0.26 \\
\hline $\operatorname{Sector}\left(\gamma_{01}\right)$ & & & $-3.64 *$ & 0.55 & $-3.47 *$ & 0.56 & $-3.37 *$ & 0.56 \\
\hline$\%$ Free Lunch $\left(\gamma_{02}\right)$ & & & $-0.16^{*}$ & 0.01 & $-0.16^{*}$ & 0.01 & $-0.16^{*}$ & 0.01 \\
\hline$\%$ Minority $\left(\gamma_{03}\right)$ & & & $-0.07^{*}$ & 0.01 & $-0.07 *$ & 0.01 & $-0.07 *$ & 0.01 \\
\hline$\% \operatorname{LEP}\left(\gamma_{04}\right)$ & & & $1.38^{*}$ & 0.11 & $1.38^{*}$ & 0.11 & $1.38^{*}$ & 0.11 \\
\hline$\%$ Gifted $\left(\gamma_{05}\right)$ & & & $1.65^{*}$ & 0.13 & $1.65^{*}$ & 0.13 & $1.65^{*}$ & 0.13 \\
\hline$\%$ Special Education $\left(\gamma_{06}\right)$ & & & $-0.39 *$ & 0.19 & $-0.41 *$ & 0.19 & $-0.41 *$ & 0.19 \\
\hline Full-time MCS $\left(\gamma_{07}\right)$ & & & & & $1.42 *$ & 0.47 & $1.40 *$ & 0.47 \\
\hline Part-time MCS $(\gamma 08)$ & & & & & 0.27 & 0.40 & 0.20 & 0.40 \\
\hline \multicolumn{9}{|l|}{ Model for Gender slope $\left(\beta_{1}\right)$} \\
\hline Intercept $\left(\gamma_{10}\right)$ & & & -0.02 & 0.19 & -0.02 & 0.19 & -0.02 & 0.19 \\
\hline \multicolumn{9}{|l|}{ Model for Minority slope $\left(\beta_{2}\right)$} \\
\hline Intercept $\left(\gamma_{20}\right)$ & & & $-5.50 *$ & 0.25 & $-5.50 *$ & 0.25 & $-5.50 *$ & 0.25 \\
\hline \multicolumn{9}{|l|}{ Model for LEP slope $\left(\beta_{3}\right)$} \\
\hline Intercept $\left(\gamma_{30}\right)$ & & & $-10.69 *$ & 0.29 & $-10.68 *$ & 0.29 & $-10.68 *$ & 0.29 \\
\hline \multicolumn{9}{|l|}{ Model for Days Absent slope $\left(\beta_{4}\right)$} \\
\hline Intercept $\left(\gamma_{40}\right)$ & & & $-1.78^{*}$ & 0.11 & $-1.78^{*}$ & 0.11 & $-1.78 *$ & 0.11 \\
\hline \multicolumn{9}{|l|}{ Model for LIKEMATH ${ }^{\mathrm{a}}$ slope $\left(\beta_{5}\right)$} \\
\hline Intercept $\left(\gamma_{50}\right)$ & & & 0.10 & 0.06 & 0.10 & 0.06 & 0.10 & 0.06 \\
\hline Model for TECHMATH ${ }^{\mathrm{a}}$ slope $\left(\beta_{6}\right)$ & & & & & & & & \\
\hline $\begin{array}{l}\text { Intercept }\left(\gamma_{60}\right) \\
\text { Model for SELFEFFa slope }\left(\beta_{7}\right)\end{array}$ & & & $-1.84^{*}$ & 0.08 & $-1.84^{*}$ & 0.08 & $-1.84 *$ & 0.08 \\
\hline
\end{tabular}




\begin{tabular}{|c|c|c|c|c|c|c|c|}
\hline \multirow{2}{*}{\multicolumn{2}{|c|}{$\begin{array}{l}\text { Intercept }\left(\gamma_{70}\right) \\
\text { Model for Yrs Experience slope }\left(\beta_{8}\right)\end{array}$}} & $6.65 *$ & 0.06 & $6.65^{*}$ & 0.06 & $6.65^{*}$ & 0.06 \\
\hline & & & & & & & \\
\hline \multicolumn{2}{|c|}{$\begin{array}{l}\text { Model for Yrs Experience slope }\left(\beta_{8}\right) \\
\text { Intercept }\left(\gamma_{80}\right)\end{array}$} & $0.05^{*}$ & 0.01 & $0.05^{*}$ & 0.01 & $0.05^{*}$ & 0.01 \\
\hline \multicolumn{8}{|c|}{ Model for Math Degree slope $\left(\beta_{9}\right)$} \\
\hline Intercept $\left(\gamma_{90}\right)$ & & $0.98 *$ & 0.26 & $0.97 *$ & 0.26 & $0.97 *$ & 0.26 \\
\hline \multicolumn{8}{|c|}{ Model for DIFFINST ${ }^{\mathrm{a}}$ slope $\left(\beta_{10}\right)$} \\
\hline Intercept $\left(\gamma_{100}\right)$ & & $-0.80 *$ & 0.13 & $-0.80 *$ & 0.13 & $-0.80 *$ & 0.13 \\
\hline \multicolumn{8}{|c|}{ Model for EMPCONT ${ }^{\mathrm{a}}$ slope $\left(\beta_{11}\right)$} \\
\hline Intercept $\left(\gamma_{110}\right)$ & & $0.92 *$ & 0.08 & $0.91 *$ & 0.08 & $0.91 *$ & 0.08 \\
\hline \multicolumn{8}{|c|}{ Model for COMPUSE ${ }^{a}$ slope $\left(\beta_{12}\right)$} \\
\hline Intercept $\left(\gamma_{120}\right)$ & & -0.09 & 0.16 & -0.09 & 0.16 & -0.09 & 0.16 \\
\hline \multicolumn{8}{|c|}{ Model for INDPRAC ${ }^{\text {a }}$ slope $\left(\beta_{13}\right)$} \\
\hline Intercept $\left(\gamma_{130}\right)$ & & 0.22 & 0.14 & 0.22 & 0.14 & 0.22 & 0.14 \\
\hline \multicolumn{8}{|c|}{ Model for ASSESSPR ${ }^{\text {a }}$ slope $\left(\beta_{14}\right)$} \\
\hline Intercept $\left(\gamma_{140}\right)$ & & $0.72 *$ & 0.13 & $0.72 *$ & 0.13 & $0.72 *$ & 0.13 \\
\hline \multicolumn{8}{|l|}{ Model for IEP slope $\left(\beta_{15}\right)$} \\
\hline Intercept $\left(\gamma_{150}\right)$ & & $-15.00 *$ & 0.30 & $-15.00 *$ & 0.30 & $-15.21 *$ & 0.37 \\
\hline Full-time MCS $\left(\gamma_{151}\right)$ & & & & & & 0.35 & 0.65 \\
\hline Part-time MCS $\left(\gamma_{152}\right)$ & & & & & & 0.78 & 0.72 \\
\hline \multicolumn{8}{|c|}{ Variance estimates (random effects) } \\
\hline Var. in intercepts $\left(\tau_{\mathrm{oo}}\right)$ & $178.20 *$ & $99.99 *$ & & $99.76^{*}$ & & $99.75^{*}$ & \\
\hline Var. in IEP slope $\left(\tau_{15}\right)$ & & $81.65^{*}$ & & $81.64 *$ & & $81.52 *$ & \\
\hline Var. within schools $\left(\sigma^{2}\right)$ & 485.29 & 375.11 & & 375.11 & & 375.11 & \\
\hline
\end{tabular}

$* p<.05$

${ }^{\text {a }}$ Composite Covariates created using principal component analysis (see Tables 5 and 6 for more details) 
Table 11

Final Multi-level Model Examining the Relationship between Data Analysis, Statistics, and Probability Mathematics Achievement and a School's Policy of Providing a Full-Time or Part-Time Mathematics Coach/Specialist (MCS)

\begin{tabular}{|c|c|c|c|c|c|c|c|c|}
\hline \multirow[b]{2}{*}{ Fixed effects } & \multicolumn{2}{|c|}{$\begin{array}{l}\text { Unconditional } \\
\text { Model }\end{array}$} & \multicolumn{2}{|c|}{$\begin{array}{c}\text { Full Model } \\
\text { (all covariates) }\end{array}$} & \multicolumn{2}{|c|}{$\begin{array}{l}\text { Full Model - MCS } \\
\text { (intercept only) }\end{array}$} & \multicolumn{2}{|c|}{$\begin{array}{l}\text { Full Model - MCS } \\
\text { (int. \& IEP slope) }\end{array}$} \\
\hline & Coefficient & $S E$ & Coefficient & $S E$ & Coefficient & $S E$ & Coefficient & $S E$ \\
\hline \multicolumn{9}{|l|}{ Model for intercept math ach. $\left(\beta_{0}\right)$} \\
\hline Intercept $\left(\gamma_{00}\right)$ & $242.58 *$ & 0.24 & $248.65^{*}$ & 0.26 & $248.10^{*}$ & 0.33 & $248.12 *$ & 0.32 \\
\hline $\operatorname{Sector}\left(\gamma_{01}\right)$ & & & $3.07 *$ & 0.71 & $3.34 *$ & 0.69 & $3.34 *$ & 0.69 \\
\hline$\%$ Free Lunch $\left(\gamma_{02}\right)$ & & & $-0.20 *$ & 0.01 & $-0.21 *$ & 0.01 & $-0.21 *$ & 0.01 \\
\hline$\%$ Minority $\left(\gamma_{03}\right)$ & & & $-0.08^{*}$ & 0.01 & $-0.09 *$ & 0.01 & $-0.09 *$ & 0.01 \\
\hline$\% \operatorname{LEP}\left(\gamma_{04}\right)$ & & & $1.20 *$ & 0.11 & $1.20^{*}$ & 0.11 & $1.20 *$ & 0.11 \\
\hline$\%$ Gifted $\left(\gamma_{05}\right)$ & & & $1.57^{*}$ & 0.19 & $1.58 *$ & 0.19 & $1.58 *$ & 0.19 \\
\hline$\%$ Special Education $\left(\gamma_{06}\right)$ & & & -0.02 & 0.22 & -0.04 & 0.23 & -0.04 & 0.23 \\
\hline Full-time MCS $\left(\gamma_{07}\right)$ & & & & & $2.12 *$ & 0.42 & $2.07 *$ & 0.41 \\
\hline Part-time MCS ( $\left.\gamma_{08}\right)$ & & & & & 0.87 & $\mathbf{0 . 5 3}$ & 0.81 & 0.54 \\
\hline \multicolumn{9}{|l|}{ Model for Gender slope $\left(\beta_{1}\right)$} \\
\hline Intercept $\left(\gamma_{10}\right)$ & & & $-0.66^{*}$ & 0.20 & $-0.66^{*}$ & 0.20 & $-0.66^{*}$ & 0.20 \\
\hline \multicolumn{9}{|l|}{ Model for Minority slope $\left(\beta_{2}\right)$} \\
\hline Intercept $\left(\gamma_{20}\right)$ & & & $-8.38^{*}$ & 0.20 & $-8.38^{*}$ & 0.20 & $-8.38 *$ & 0.20 \\
\hline \multicolumn{9}{|l|}{ Model for LEP slope $\left(\beta_{3}\right)$} \\
\hline Intercept $\left(\gamma_{30}\right)$ & & & $-14.79 *$ & 0.31 & $-14.78 *$ & 0.31 & $-14.78^{*}$ & 0.31 \\
\hline \multicolumn{9}{|l|}{ Model for Days Absent slope $\left(\beta_{4}\right)$} \\
\hline Intercept $\left(\gamma_{40}\right)$ & & & $-2.28^{*}$ & 0.07 & $-2.28^{*}$ & 0.07 & $-2.28 *$ & 0.07 \\
\hline \multicolumn{9}{|l|}{ Model for LIKEMATH ${ }^{\mathrm{a}}$ slope $\left(\beta_{5}\right)$} \\
\hline Intercept $\left(\gamma_{50}\right)$ & & & $0.35^{*}$ & 0.12 & $0.35^{*}$ & 0.12 & $0.35 *$ & 0.12 \\
\hline \multicolumn{9}{|l|}{ Model for TECHMATH ${ }^{\mathrm{a}}$ slope $\left(\beta_{6}\right)$} \\
\hline Intercept $\left(\gamma_{60}\right)$ & & & $-2.35^{*}$ & 0.13 & $-2.35^{*}$ & 0.13 & $-2.35^{*}$ & 0.13 \\
\hline \multicolumn{9}{|l|}{ Model for SELFEFF ${ }^{a}$ slope $\left(\beta_{7}\right)$} \\
\hline Intercept $\left(\gamma_{70}\right)$ & & & $8.17 *$ & 0.13 & $8.17 *$ & 0.13 & $8.17 *$ & 0.13 \\
\hline
\end{tabular}




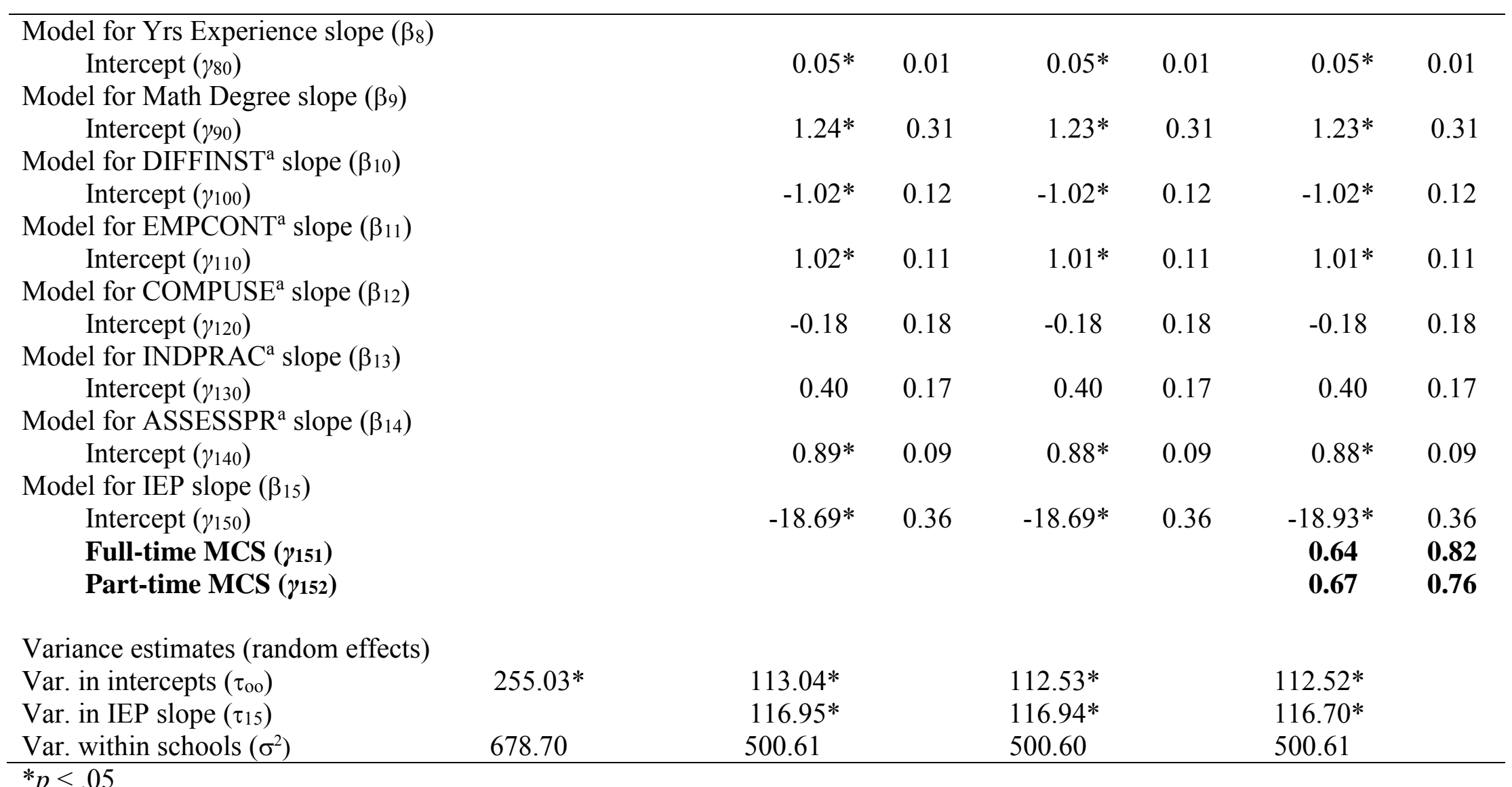

${ }^{a}$ Composite Covariates created using principal component analysis (see Tables 5 and 6 for more details) 
Table 12

Final Multi-level Model Examining the Relationship between Algebra Mathematics Achievement and a School's Policy of Providing a Full-Time or Part-Time Mathematics Coach/Specialist (MCS)

\begin{tabular}{|c|c|c|c|c|c|c|c|c|}
\hline \multirow[b]{2}{*}{ Fixed effects } & \multicolumn{2}{|c|}{$\begin{array}{c}\text { Unconditional } \\
\text { Model }\end{array}$} & \multicolumn{2}{|c|}{$\begin{array}{c}\text { Full Model } \\
\text { (all covariates) }\end{array}$} & \multicolumn{2}{|c|}{$\begin{array}{l}\text { Full Model - MCS } \\
\text { (intercept only) }\end{array}$} & \multicolumn{2}{|c|}{$\begin{array}{l}\text { Full Model - MCS } \\
\text { (int. \& IEP slope) }\end{array}$} \\
\hline & Coefficient & $S E$ & Coefficient & $S E$ & Coefficient & $S E$ & Coefficient & $S E$ \\
\hline \multicolumn{9}{|l|}{ Model for intercept math ach. $\left(\beta_{0}\right)$} \\
\hline Intercept $\left(\gamma_{00}\right)$ & $244.34 *$ & 0.20 & $250.05 *$ & 0.19 & $249.63 *$ & 0.24 & $249.65 *$ & 0.24 \\
\hline $\operatorname{Sector}\left(\gamma_{01}\right)$ & & & $4.43^{*}$ & 0.61 & $4.66^{*}$ & 0.60 & $4.66^{*}$ & 0.60 \\
\hline$\%$ Free Lunch $\left(\gamma_{02}\right)$ & & & $-0.18^{*}$ & 0.01 & $-0.18^{*}$ & 0.01 & $-0.18^{*}$ & 0.01 \\
\hline$\%$ Minority $\left(\gamma_{03}\right)$ & & & $-0.06^{*}$ & 0.01 & $-0.06 *$ & 0.01 & $-0.06 *$ & 0.01 \\
\hline$\% \operatorname{LEP}\left(\gamma_{04}\right)$ & & & $1.44^{*}$ & 0.15 & $1.45^{*}$ & 0.15 & $1.45^{*}$ & 0.15 \\
\hline$\%$ Gifted $\left(\gamma_{05}\right)$ & & & $1.62 *$ & 0.14 & $1.62 *$ & 0.13 & $1.62 *$ & 0.13 \\
\hline$\%$ Special Education $\left(\gamma_{06}\right)$ & & & -0.38 & 0.21 & -0.40 & 0.21 & -0.40 & 0.21 \\
\hline Full-time MCS $\left(\gamma_{07}\right)$ & & & & & $1.93 *$ & 0.43 & $1.89 *$ & 0.42 \\
\hline Part-time MCS ( $\left.\gamma_{08}\right)$ & & & & & 0.34 & 0.34 & 0.31 & 0.34 \\
\hline \multicolumn{9}{|l|}{ Model for Gender slope $\left(\beta_{1}\right)$} \\
\hline Intercept $\left(\gamma_{10}\right)$ & & & $-2.19^{*}$ & 0.17 & $-2.19^{*}$ & 0.17 & $-2.19 *$ & 0.17 \\
\hline \multicolumn{9}{|l|}{ Model for Minority slope $\left(\beta_{2}\right)$} \\
\hline Intercept $\left(\gamma_{20}\right)$ & & & $-6.89 *$ & 0.32 & $-6.89 *$ & 0.32 & $-6.89 *$ & 0.32 \\
\hline \multicolumn{9}{|l|}{ Model for LEP slope $\left(\beta_{3}\right)$} \\
\hline Intercept $\left(\gamma_{30}\right)$ & & & $-11.68 *$ & 0.23 & $-11.68 *$ & 0.23 & $-11.68 *$ & 0.23 \\
\hline \multicolumn{9}{|l|}{ Model for Days Absent slope $\left(\beta_{4}\right)$} \\
\hline Intercept $\left(\gamma_{40}\right)$ & & & $-2.02 *$ & 0.07 & $-2.03 *$ & 0.07 & $-2.02 *$ & 0.07 \\
\hline \multicolumn{9}{|l|}{ Model for LIKEMATH ${ }^{\mathrm{a}}$ slope $\left(\beta_{5}\right)$} \\
\hline Intercept $\left(\gamma_{50}\right)$ & & & $1.16^{*}$ & 0.12 & $1.16^{*}$ & 0.12 & $1.16^{*}$ & 0.12 \\
\hline \multicolumn{9}{|c|}{ Model for TECHMATH ${ }^{\mathrm{a}}$ slope $\left(\beta_{6}\right)$} \\
\hline Intercept $\left(\gamma_{60}\right)$ & & & $-2.17 *$ & 0.10 & $-2.17 *$ & 0.10 & $-2.17 *$ & 0.10 \\
\hline \multicolumn{9}{|l|}{ Model for SELFEFF ${ }^{\mathrm{a}}$ slope $\left(\beta_{7}\right)$} \\
\hline Intercept $\left(\gamma_{70}\right)$ & & & $7.35 *$ & 0.09 & $7.35^{*}$ & 0.09 & $7.35 *$ & 0.09 \\
\hline
\end{tabular}




\begin{tabular}{|c|c|c|c|c|c|c|c|}
\hline \multicolumn{8}{|c|}{ Model for Yrs Experience slope $\left(\beta_{8}\right)$} \\
\hline Intercept $\left(\gamma_{80}\right)$ & & $0.05^{*}$ & 0.01 & $0.05 *$ & 0.01 & $0.05^{*}$ & 0.01 \\
\hline \multicolumn{8}{|c|}{ Model for Math Degree slope $\left(\beta_{9}\right)$} \\
\hline Intercept $\left(\gamma_{90}\right)$ & & $1.15^{*}$ & 0.25 & $1.14 *$ & 0.25 & $1.14 *$ & 0.25 \\
\hline \multicolumn{8}{|c|}{ Model for DIFFINST ${ }^{\text {a }}$ slope $\left(\beta_{10}\right)$} \\
\hline \multirow{2}{*}{\multicolumn{8}{|c|}{ Model for EMPCONT ${ }^{\text {a }}$ slope $\left(\beta_{11}\right)$}} \\
\hline & & & & & & & \\
\hline Intercept $\left(\gamma_{110}\right)$ & & $0.80 *$ & 0.12 & $0.79 *$ & 0.12 & $0.79 *$ & 0.12 \\
\hline \multicolumn{8}{|c|}{ Model for COMPUSE ${ }^{\text {a }}$ slope $\left(\beta_{12}\right)$} \\
\hline Intercept $\left(\gamma_{120}\right)$ & & 0.02 & 0.11 & 0.01 & 0.11 & 0.01 & 0.11 \\
\hline \multicolumn{8}{|c|}{ Model for INDPRAC ${ }^{\text {a }}$ slope $\left(\beta_{13}\right)$} \\
\hline Intercept $\left(\gamma_{130}\right)$ & & $0.45 *$ & 0.14 & $0.46^{*}$ & 0.14 & $0.46^{*}$ & 0.14 \\
\hline \multicolumn{8}{|c|}{ Model for ASSESSPR ${ }^{\text {a }}$ slope $\left(\beta_{14}\right)$} \\
\hline Intercept $\left(\gamma_{140}\right)$ & & $0.91 *$ & 0.10 & $0.90 *$ & 0.10 & $0.90^{*}$ & 0.10 \\
\hline \multicolumn{8}{|l|}{ Model for IEP slope $\left(\beta_{15}\right)$} \\
\hline Intercept $\left(\gamma_{150}\right)$ & & $-19.21 *$ & 0.40 & $-19.21 *$ & 0.40 & $-19.51 *$ & 0.43 \\
\hline Full-time MCS $\left(\gamma_{151}\right)$ & & & & & & 0.94 & 0.59 \\
\hline Part-time MCS $\left(\gamma_{152}\right)$ & & & & & & 0.66 & 0.59 \\
\hline \multicolumn{8}{|c|}{ Variance estimates (random effects) } \\
\hline Var. in intercepts $\left(\tau_{o o}\right)$ & $183.80 *$ & $83.05^{*}$ & & $82.62 *$ & & $82.62 *$ & \\
\hline Var. in IEP slope $\left(\tau_{15}\right)$ & & $108.73^{*}$ & & $108.73 *$ & & $108.51 *$ & \\
\hline Var. within schools $\left(\sigma^{2}\right)$ & 553.26 & 395.90 & & 395.91 & & 395.91 & \\
\hline
\end{tabular}




\section{Research Question 2: The Differentials in the Relationship between having a MCS \\ (full-time or part-time) and Mathematics Achievement for Students based on}

\section{Disability Status}

The goal of the second set of analyses was to examine the differentials in achievement on the NAEP for fourth-grade students with and without disabilities when they have a MCS (full- or part-time) in their school or not. In other words, the goal was to examine whether being in a school with a MCS would moderate the lower achievement that students with disabilities generally experience. As with research question one, overall mathematics achievement (i.e., composite score), as well as mathematics achievement in the five content areas as defined in the NAEP dataset (i.e., number properties and operations; measurement; geometry; data analysis, statistics, and probability; and algebra) was explored.

Identical models from research question one were used in the model building process to examine research question two. The final contextual model for all achievement outcomes allowed the intercept, which included MCS variables are predictors, and students' disability status (IEP status) to vary between groups, as these were variables of interest. The remaining variables served as control variables at the school- and studentlevel and, therefore, their variances were not allowed to randomly vary. The addition of two level-2 predictors of the IEP slope allowed for the examination the differentials in all achievement outcomes for fourth-grade students with and without disabilities when they have a MCS (full- or part-time) in their school or not. Equation 3 illustrates the final contextual model estimating fourth-grade students' mathematics achievement on the NAEP after the inclusion of treatment variables as predictors of the intercept and the IEP 
slope:

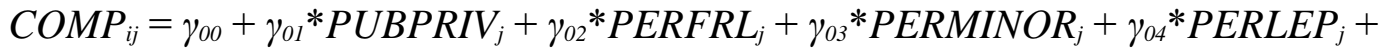

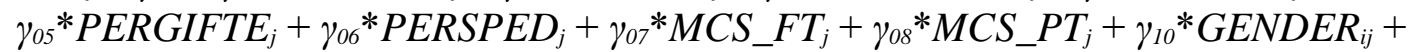

$$
\begin{aligned}
& \gamma_{20}{ }^{*} \text { MINORITY }_{i j}+\gamma_{30} * \operatorname{LEP}_{i j}+\gamma_{40} * \operatorname{DAYSABS}_{i j}+\gamma_{50}{ }^{*} \text { LIKEMATH }_{i j}+\gamma_{60}{ }^{*} \text { TECHMATH }_{i j}+ \\
& \gamma_{70} * \operatorname{SELFEFF}_{i j}+\gamma_{80} * \operatorname{YRSEXP}_{i j}+\gamma_{90} * \mathrm{MTHDGRE}_{i j}+\gamma_{100} * \operatorname{DIFFINST}_{i j}+ \\
& \gamma_{110} * E_{10 P C O N T_{i j}}+\gamma_{120} * \operatorname{COMPUSE}_{i j}+\gamma_{130} * \operatorname{INDPRAC}_{i j}+\gamma_{140} * \operatorname{ASSESSPR}_{i j}+ \\
& \gamma_{150}{ }^{*} I E P_{i j}+\gamma_{151} * \boldsymbol{M C S} \_\boldsymbol{F T}_{j} * \boldsymbol{I E P} \boldsymbol{P}_{i j}+\gamma_{152} * \boldsymbol{M C S} \_\boldsymbol{P T} \boldsymbol{T}_{j}^{*} \boldsymbol{I E P} \boldsymbol{P}_{i j}+u_{0 j}+u_{15 j} * I E P_{i j}+r_{i j}
\end{aligned}
$$

where $C O M P_{i j}$ is the averaged plausible value composite mathematics score for student $i$ in school $j, \gamma_{15 l}$ is the differential in composite score for having a full-time MCS compared to no MCS for students with disabilities, $\gamma_{152}$ is the differential in composite score for having a part-time MCS compared to no MCS for students with disabilities, $M C S \_F T_{j}$ indicates whether the school had a full-time $\mathrm{MCS}$, and $M C S \_P T_{j}$ indicates whether the school had a part-time MCS. Similar equations for the five content areas were used (substituting the specific content outcome variable into the equation for $\operatorname{COMP}(i j)$.

Results for research question two were equivalent for overall mathematics achievement (i.e., composite score) and across mathematics achievement in all five content areas (i.e., number properties and operations; measurement; geometry; data analysis, statistics, and probability; and algebra). The provision of a school providing a MCS (full- or part-time) was not a statistically significant predictor of the IEP slope ( $p>$ .05 ; see Tables 7 to 12). In other words, there were no significant differentials in the relationship between a school's provision of a MCS (full-time or part-time) and 
mathematics achievement for students based on disability status. After adjusting for all level-1 and level-2 controls used in the final models, students with and without disabilities receive the same statistically significant increase in achievement when schools provide a full-time MCS and no statistically significant increase in achievement when a school provides a part-time MCS (findings from research question one).

Table 13 provides a summary table of results for research questions one and two. The final models for the analyses are presented for all outcome variables. The summary table shows that across all outcome variables there is a statistically significant relationship between schools with full-time MCSs and fourth-grade students' mathematics achievement. This does not hold true for schools with part-time MCSs. Additionally, the summary table shows that across all outcome variables there are no statistically significant differentials in the relationship between a school's provision of a MCS (full-time or part-time) and mathematics achievement for students based on disability status. It can be concluded that being in a school with a MCS did not moderate the lower achievement that students with disabilities experience on the 2011 NAEP Mathematics Assessment (overall mathematics achievement and achievement across the five content areas). 
Table 13

Final Multi-level Models Examining the Relationship between a School's Policy of Providing a Full-Time or Part-Time Mathematics Coach/Specialist (MCS) and Students'Mathematics Achievement based on Disability Status

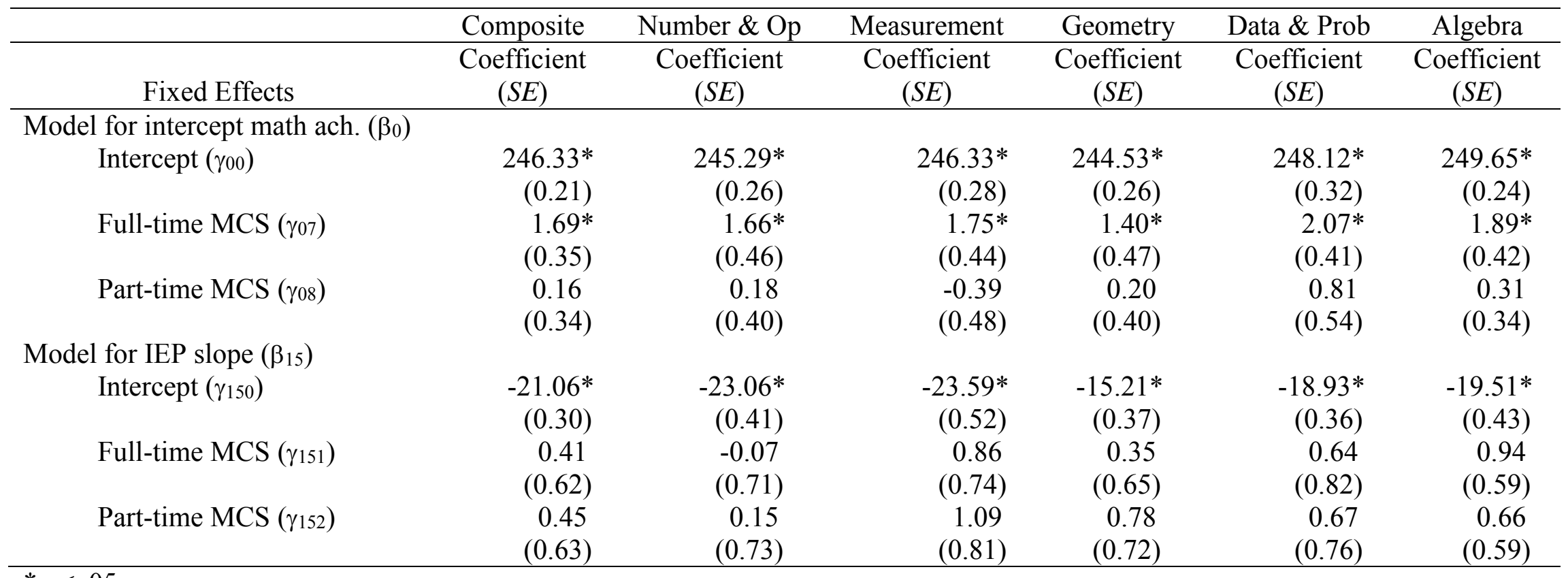

$* p<.05$

Note. The shown models are the final contextual models with all composite covariates and controls included. 


\section{Research Question 3: The Relationship between the Six Different Roles and Responsibilities of MCSs and Students' Mathematics Achievement}

The goal of the third set of analyses was to examine the relationship between principal-reported time spent on the six different roles and responsibilities of MCSs (see Table 14 for description of variables) and fourth-grade students' overall mathematics achievement (i.e., composite score), as well as mathematics achievement in the five content areas as defined in the NAEP dataset (i.e., number properties and operations; measurement; geometry; data analysis, statistics, and probability; and algebra). Results from research question one indicated that only full-time MCSs had a significant relationship with students' mathematics achievement; therefore, the analyses for research question three were explored only in schools that had full-time MCSs (excluding schools with part-time MCSs). 
Table 14

Roles and Responsibilities of Mathematics Coach/Specialist as defined in the 2011 NAEP

dataset

\begin{tabular}{|c|c|c|}
\hline \multicolumn{3}{|c|}{ Roles and Responsibilities of the Mathematics Coach/Specialist } \\
\hline ID & Variable Description & $\begin{array}{l}\text { Mean } \\
(S D)^{*}\end{array}$ \\
\hline C071401 & $\begin{array}{l}\text { Provide technical assistance/support to individual teachers } \\
\text { about mathematics content or the teaching of mathematics }\end{array}$ & $2.72(0.92)$ \\
\hline $\mathrm{C} 071402$ & $\begin{array}{l}\text { Conduct professional development for groups of teachers about } \\
\text { mathematics content or the teaching of mathematics }\end{array}$ & $2.01(1.05)$ \\
\hline C071403 & ction to students on various topics & $2.06(0.97)$ \\
\hline C071404 & $\begin{array}{l}\text { Provide mathematics instruction to students at various grade } \\
\text { levels }\end{array}$ & $2.03(1.01)$ \\
\hline $\mathrm{C} 071405$ & $\begin{array}{l}\text { Provide mathematics remediation/intervention to some student } \\
\text { groups }\end{array}$ & $2.04(1.04)$ \\
\hline C071406 & Provide mathematics enrichment to some student groups & $1.36(1.06)$ \\
\hline
\end{tabular}

* Means and standard deviations are weighted (weighted $n=9010$; unweighted $n=$ 1490); Roles and responsibilities coding: $0=$ not at all, $1=$ small extent, $2=$ moderate extent, and 3=large extent; MCS role and responsibility time allocation reported by the principal or vice-principal of each elementary school.

To explore research question three, as with the two prior research questions, a model-based approach (i.e., HLM) was used as it allowed for adjustments for the effects of covariates and addressed the nested nature of the data. The same school, teacher, and student composite covariates and controls were used in the contextual model for research question three that were used in prior research questions. All control variables remained in the models, regardless of statistical significance to enable comparisons of results across the six measures of mathematics achievement (i.e., composite, number properties and operations; measurement; geometry; data analysis, statistics, and probability; and algebra) and the six roles and responsibilities of MCSs. 
The final contextual model for all achievement outcomes allowed the intercept and students' disability status (IEP status) to vary between groups, as these were variables of interest. The remaining variables served as control variables at the schooland student-level and, therefore, their variances were not allowed to randomly vary. Equation 4 (identical to Equation 1 for research question one) illustrates the contextual model, prior to entering the secondary treatment variables-MCS roles and responsibilities:

$$
\begin{aligned}
& \text { COMP }_{i j}=\gamma_{00}+\gamma_{01} * \text { PUBPRIV } V_{j}+\gamma_{02} * \text { PERFRL }_{j}+\gamma_{03} * \text { PERMINOR }_{j}+\gamma_{04}{ }^{*} \text { PERLEP }_{j}+ \\
& \gamma_{05} * \text { PERGIFTE }{ }_{j}+\gamma_{06}{ }^{*} \text { PERSPED }_{j}+\gamma_{10} * \text { GENDER }_{i j}+\gamma_{20} * \text { MINORITY }_{i j}+\gamma_{30} * \operatorname{LEP}_{i j}+ \\
& \gamma_{40} * D_{1} \text { YYSABS }_{i j}+\gamma_{50}{ }^{*} \text { LIKEMATH }_{i j}+\gamma_{60} * \text { TECHMATH }_{i j}+\gamma_{70} * \operatorname{SELFEFF}_{i j}+ \\
& \gamma_{80} * \operatorname{YRSEXP}_{i j}+\gamma_{90} * \operatorname{MTHDGRE}_{i j}+\gamma_{100}{ }^{*} \text { DIFFINST }_{i j}+\gamma_{110}{ }^{*} \text { EMPCONT }_{i j}+ \\
& \gamma_{120} * \operatorname{COMPUSE}_{i j}+\gamma_{130} * \operatorname{INDPRAC}_{i j}+\gamma_{140} * \operatorname{ASSESSPR}_{i j}+\gamma_{150} * I E P_{i j}+u_{0 j}+ \\
& u_{15 j}^{*} I E P_{i j}+r_{i j}
\end{aligned}
$$

where $C O M P_{i j}$ is the averaged plausible value composite mathematics score for student $i$ in school $j$. Similar equations for the five content areas were used (substituting the specific content outcome variable into the equation for $\left.C O M P_{i j}\right)$.

To examine the relationship between principal-reported time spent on the six roles and responsibilities of full-time MCSs and fourth grade students' mathematics achievement on the NAEP, each role was added as a predictor of the intercept one at a time for each content area. Equation 5 illustrates the final contextual model estimating fourth-grade students' mathematics achievement after the inclusion of one secondary treatment variable (i.e., ROLE 1, ROLE 2, ROLE 3, etc.): 


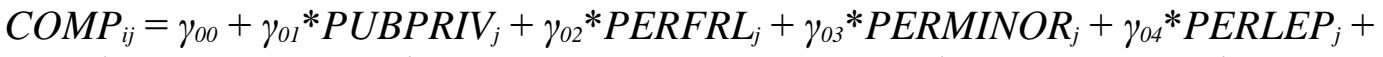

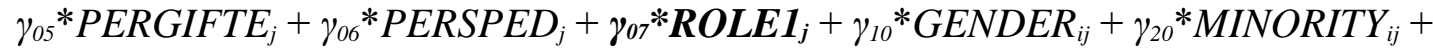

$$
\begin{aligned}
& \gamma_{30} * L E P_{i j}+\gamma_{40} * D A Y S A B S_{i j}+\gamma_{50} * L_{\text {LIKEMATH }}+\gamma_{60} * \text { TECHMATH }_{i j}+
\end{aligned}
$$

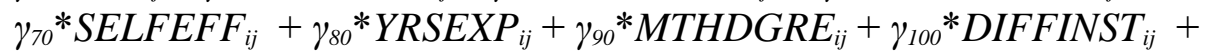

$$
\begin{aligned}
& \gamma_{110} * \operatorname{EMPCONT}_{i j}+\gamma_{120} * \operatorname{COMPUSE}_{i j}+\gamma_{130} * \operatorname{INDPRAC}_{i j}+\gamma_{140} * \operatorname{ASSESSPR}_{i j}+ \\
& \gamma_{150} * I E P_{i j}+u_{0 j}+u_{15 j} * I E P_{i j}+r_{i j}
\end{aligned}
$$

where $C O M P_{i j}$ is the averaged plausible value composite mathematics score for student $i$ in school $j, \gamma_{07}$ is the differential in composite score based on extent to which the full-time MCS engages in providing technical assistance/support to individual teachers about mathematics content or the teaching of mathematics, $M C S_{-} F T_{j}$ indicates whether the school had a full-time MCS, and $M C S \_P T_{j}$ indicates whether the school had a part-time MCS. Similar equations for the remaining six roles and five content areas were used (substituting the specific content outcome variable into the equation for $C O M P_{i j}$ and the specific role and responsibility of the MCS in for $R O L E 1_{j}$ ).

\section{Relationship between MCS Role 1 and Mathematics Achievement}

To examine the relationship between the extent to which full-time MCSs provide technical assistance/support to individual teachers about mathematics content or the teaching of mathematics (i.e., Role 1) and fourth-grade students' mathematics achievement on the NAEP, the Role 1 variable was entered as a level-2 predictor of the intercept along with the previously discussed composite covariates and controls. The six achievement variables (i.e., composite, number properties and operations; measurement; geometry; data analysis, statistics, and probability; and algebra) were used as outcome variables in separate models. This process was used for each MCS role, simply interchanging the needed role and outcome variables. 
The role of providing technical assistance/support to individual teachers about mathematics content or the teaching of mathematics (i.e., Role 1) had a statistically significant relationship with fourth-grade students' composite (i.e., overall) mathematics achievement $($ coefficient $=0.80, S E=0.36, p=.032)$, measurement achievement $($ coefficient $=1.26, S E=0.46, p=.007)$, and geometry achievement $($ coefficient $=1.14$, $S E=0.38, p=.004$; see Table 15). On average, these results indicate MCSs role of providing technical assistance/support to individual teachers about mathematics content or the teaching of mathematics (i.e., Role 1) in schools is related to higher achievement in overall mathematics achievement, as well as achievement in both measurement and geometry.

Providing technical assistance/support to individual teachers about mathematics content or the teaching of mathematics did not have a statistically significant relationship $(p>.05)$ with number properties and operations achievement, data analysis, statistics, and probability achievement, or algebra achievement on the NAEP for fourth-grade students.

\section{Relationship between MCS Role 2 and Mathematics Achievement}

MCS role 2, conduct professional development for groups of teachers about mathematics content or the teaching of mathematics, had statistically significant relationships with four of the six outcome variables: composite mathematics achievement $($ coefficient $=0.93, S E=0.34, p=.010)$, number properties and operations achievement $($ coefficient $=1.20, S E=0.40, p=.005)$, measurement $($ coefficient $=0.98, S E=0.47$, $p=.043)$ and data analysis, statistics, and probability achievement (coefficient $=0.93, S E$ $=0.38, p=.017 ;$ Table 15). On average, these results indicate MCSs spending more time on conducting professional development for groups of teachers about mathematics 
content or the teaching of mathematics (i.e., Role 2) in schools is related to higher achievement in overall mathematics achievement, as well as higher achievement in number properties and operations, measurement, and in data analysis, statistics, and probability.

Conducting professional development for groups of teachers about mathematics content or the teaching of mathematics did not have a statistically significant relationship $(p>.05)$ with geometry or algebra achievement on the NAEP for fourth-grade students.

\section{Relationship between MCS Role 3 and Mathematics Achievement}

Providing mathematics instruction to students on various topics (i.e., Role 3) did not have a statistically significant relationship $(p>.05$; see Table 15$)$ with any of the achievement outcome measures, which included composite (overall), number properties and operations; measurement; geometry; data analysis, statistics, and probability; and algebra. This simply means that there is not a statistically significant relationship between the amount of time an MCS provides mathematics instruction to students on various topics and fourth-grade students' mathematics achievement on the 2011 NAEP mathematics assessment.

\section{Relationship between MCS Role 4 and Mathematics Achievement}

Role 4, provide mathematics instruction to students at various grade levels, had a statistically significant relationship with both data analysis, statistics, and probability achievement (coefficient $=-0.70, S E=0.34, p=.041$ ) and algebra achievement $($ coefficient $=-0.61, S E=0.27, p=.021$; see Table 15). Providing mathematics instruction to students at various grade levels did not have a statistically significant 
relationship $(p>.05)$ with composite achievement, measurement achievement, or geometry achievement.

\section{Relationship between MCS Role 5 and Mathematics Achievement}

The role of providing mathematics remediation/intervention to some student groups (i.e., Role 5) had statistically significant relationships with fourth-grade students' overall (composite) mathematics achievement (coefficient $=-0.58, S E=0.29, p=.047$ ). In addition, providing mathematics remediation/intervention to some student groups was statistically associated with data analysis, statistics, and probability achievement (coefficient $=-0.73, S E=0.33, p=.031)$ and algebra achievement $($ coefficient $=-0.58$, $S E=0.28, p=.043)$. No statistically significant association between providing mathematics remediation/intervention to some student groups and number properties and operations, measurement, or geometry achievement was found.

As previously noted, given the correlational nature of this study, the lack of a control group for this research question, and the inability to control for achievement prior to having an MCS, directionality cannot be established for the relationship between principal-reported time spent on the roles and responsibilities and fourth-grade students' mathematics achievement on the NAEP. For instance, given the positive relationship between having an MCS and achievement found in research question one, it is likely that schools with lower achievement require MCSs to spend more of their time on Role 5 rather than the more time an MCS spends on Role 5 causes achievement to decrease. Therefore, the statistically significant relationships noted likely mean that schools with lower achievement in overall scores, data analysis, statistics, and probability scores, and 
algebra scores require MCSs to spend more of their time on providing mathematics remediation/intervention to some student groups (i.e., Role 5).

\section{Relationship between MCS Role 6 and Mathematics Achievement}

Similar to the results between MCS role 3 and achievement, MCS role 6, providing mathematics enrichment to some student groups, was not statistically significantly related ( $p>.05$; see Table 15$)$ to any of the achievement outcome measures (i.e., composite (overall), number properties and operations; measurement; geometry; data analysis, statistics, and probability; and algebra). This simply means that there is no relationship between the amount of time MCSs spend providing mathematics enrichment to some student groups and fourth-grade students' mathematics achievement on the NAEP. 
Table 15

Final Multi-level Models Examining the Relationship between Principal-Reported Time Spent on the Six Different Roles and

Responsibilities of Full-Time Mathematics Coaches/Specialists (MCS) and Students' Mathematics Achievement

\begin{tabular}{|c|c|c|c|c|c|c|}
\hline & Composite & Number \& Op & Measurement & Geometry & Data \& Prob & Algebra \\
\hline Fixed Effects & $\begin{array}{l}\text { Coefficient } \\
\text { (SE) }\end{array}$ & $\begin{array}{l}\text { Coefficient } \\
(S E)\end{array}$ & $\begin{array}{l}\text { Coefficient } \\
(S E)\end{array}$ & $\begin{array}{l}\text { Coefficient } \\
(S E)\end{array}$ & $\begin{array}{l}\text { Coefficient } \\
(S E)\end{array}$ & $\begin{array}{l}\text { Coefficient } \\
\text { (SE) }\end{array}$ \\
\hline \multicolumn{7}{|l|}{ Model for intercept math ach. $\left(\beta_{0}\right)$} \\
\hline \multirow[t]{2}{*}{ Intercept $\left(\gamma_{00}\right)$} & $244.39 *$ & $243.28 *$ & $243.43 *$ & $243.30 *$ & $246.28 *$ & $248.46^{*}$ \\
\hline & $(0.40)$ & $(0.43)$ & $(0.53)$ & $(0.50)$ & $(0.46)$ & $(0.48)$ \\
\hline \multirow[t]{2}{*}{$\operatorname{ROLE~} 1^{\mathrm{a}}\left(\gamma_{07}\right)$} & $0.80 *$ & 0.75 & $1.26 *$ & $1.14 *$ & 0.46 & 0.45 \\
\hline & $(0.36)$ & $(0.43)$ & $(0.46)$ & $(\mathbf{0 . 3 8})$ & $(0.45)$ & $(0.34)$ \\
\hline Var. in intercepts $\left(\tau_{\mathrm{oo}}\right)_{\text {Full }}$ & $77.47 *$ & $102.36^{*}$ & $155.39 *$ & $99.15^{*}$ & $109.88^{*}$ & $80.42 *$ \\
\hline Var. in intercepts $\left(\tau_{\mathrm{oo}}\right)_{\text {Controls }}$ & $77.71^{*}$ & $102.57 *$ & $156.01 *$ & $99.81 *$ & $109.90 *$ & $80.61 *$ \\
\hline \multicolumn{7}{|l|}{ Model for intercept math ach. $\left(\beta_{0}\right)$} \\
\hline \multirow[t]{2}{*}{ Intercept $(\square 00)$} & $244.42 *$ & $243.33 *$ & $243.43 *$ & $243.29 *$ & $246.33 *$ & $248.48 *$ \\
\hline & $(0.40)$ & $(0.43)$ & $(0.53)$ & $(0.51)$ & $(0.46)$ & $(0.48)$ \\
\hline \multirow[t]{2}{*}{$\operatorname{ROLE} 2^{\mathrm{b}}\left(\gamma_{07}\right)$} & $0.93 *$ & $1.20 *$ & $0.98 *$ & 0.74 & $0.93 *$ & 0.58 \\
\hline & $(0.34)$ & $(0.40)$ & (0.47) & $(0.47)$ & (0.38) & $(0.31)$ \\
\hline Var. in intercepts $\left(\tau_{\mathrm{oo}}\right)_{\text {Full }}$ & $77.22 *$ & $101.66^{*}$ & $155.60 *$ & $99.48^{*}$ & $109.46^{*}$ & $80.42 *$ \\
\hline Var. in intercepts $\left(\tau_{\mathrm{oo}}\right)_{\text {Controls }}$ & $77.71^{*}$ & $102.57^{*}$ & $156.01 *$ & $99.81 *$ & $109.90^{*}$ & $80.61^{*}$ \\
\hline \multicolumn{7}{|l|}{ Model for intercept math ach. $\left(\beta_{0}\right)$} \\
\hline \multirow[t]{2}{*}{ Intercept $\left(\gamma_{00}\right)$} & $244.38 *$ & $243.27 *$ & $243.38 *$ & $243.23 *$ & $246.30 *$ & $248.47 *$ \\
\hline & $(0.40)$ & $(0.43)$ & $(0.53)$ & $(0.50)$ & $(0.45)$ & $(0.48)$ \\
\hline \multirow[t]{2}{*}{$\operatorname{ROLE~} 3^{\mathrm{c}}\left(\gamma_{07}\right)$} & -0.42 & -0.53 & -0.45 & 0.08 & -0.66 & -0.46 \\
\hline & $(0.30)$ & $(0.32)$ & $(0.46)$ & $(0.33)$ & $(0.36)$ & $(0.28)$ \\
\hline Var. in intercepts $\left(\tau_{\mathrm{oo}}\right)_{\text {Full }}$ & $77.50^{*}$ & $102.26^{*}$ & $155.80 *$ & $99.79 *$ & $109.34 *$ & $80.38^{*}$ \\
\hline Var. in intercepts $\left(\tau_{\mathrm{oo}}\right)_{\text {Controls }}$ & $77.71^{*}$ & $102.57 *$ & $156.01 *$ & $99.81 *$ & $109.90 *$ & $80.61 *$ \\
\hline \multicolumn{7}{|l|}{ Model for intercept math ach. $\left(\beta_{0}\right)$} \\
\hline \multirow[t]{2}{*}{ Intercept $\left(\gamma_{00}\right)$} & $244.38 *$ & $243.26^{*}$ & $243.38 *$ & $243.25 *$ & $246.30^{*}$ & $248.48 *$ \\
\hline & $(0.40)$ & $(0.43)$ & $(0.53)$ & $(0.50)$ & $(0.45)$ & $(0.48)$ \\
\hline
\end{tabular}




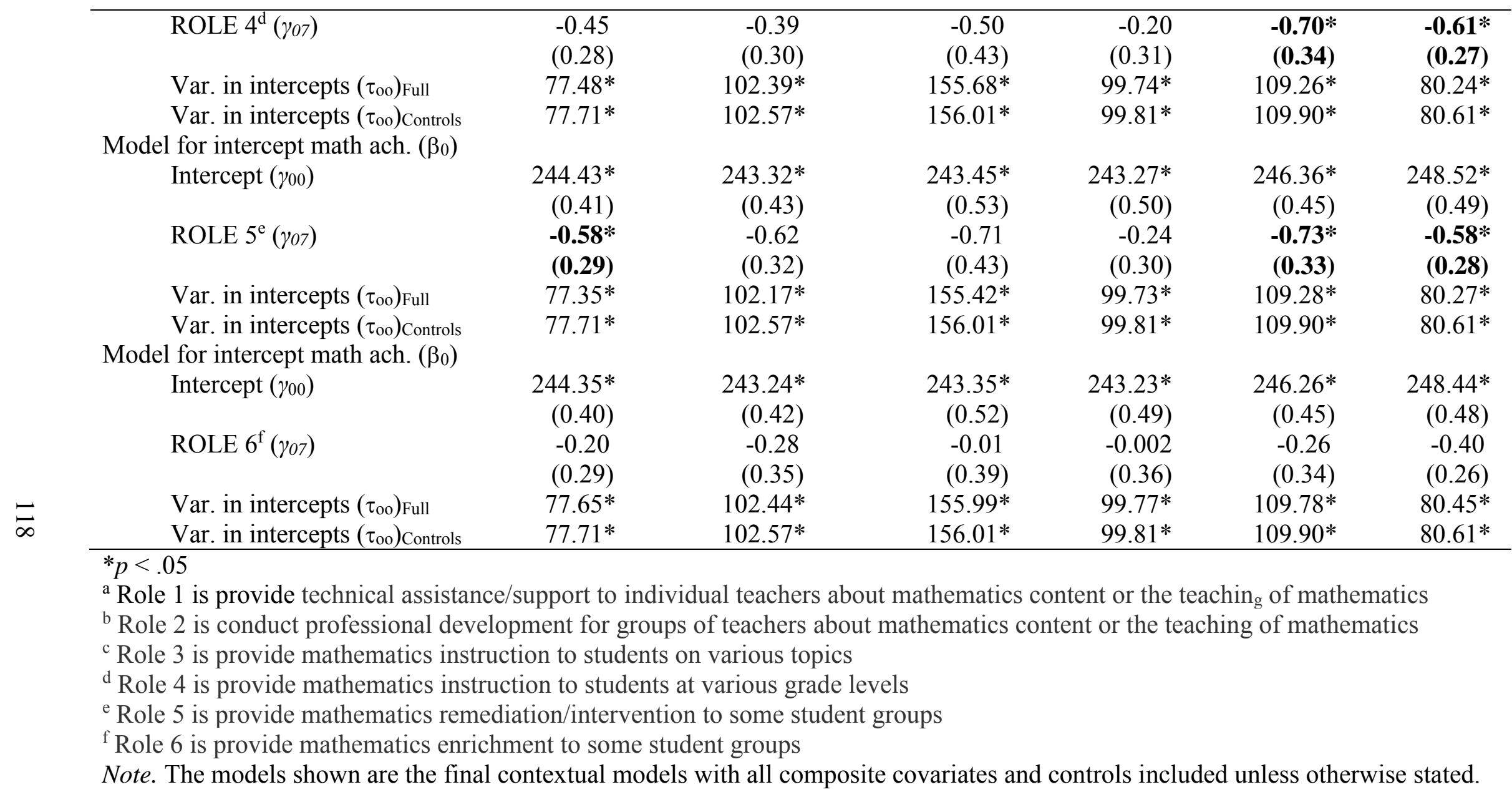




\section{Chapter IV Summary}

Using data from the 2011 NAEP, these results provided a broad, national look at the relationship between mathematics coaches and specialists and fourth-grade students' mathematics achievement. The findings indicated, on average, schools that utilized fulltime MCSs can expect to see increases in all measured achievement outcomes.

Specifically, there was a statistically significant relationship between having a full-time MCS and fourth grade students' overall mathematics achievement and their achievement in five specific mathematics content areas (i.e., number properties and operations; measurement; geometry; data analysis, statistics, and probability; and algebra). This relationship did not statistically significantly differ between students with and without disabilities. Statistically significant relationships between principal-reported time spent on the various roles and responsibilities provided by full-time MCS and achievement outcomes were noted, including relationships between achievement and MCSs providing assistance to both teachers and students. Chapter V further discusses the conclusions and implications of these results as well as the limitations of this study and suggestions for future research. 


\section{CHAPTER V \\ DISCUSSION AND IMPLICATIONS}

Chapter V presents a summary of the current study and related results, as well as general conclusions that can be drawn from the findings described in Chapter IV. Additionally, Chapter V includes a discussion of the implications of the results, limitations of the current study, and recommendations for future research.

\section{Summary of the Study}

\section{Restatement of Problem Statement}

In recent years, an emphasis on accountability and an effort to improve student performance and achievement in mathematics has gained national attention (e.g., Campbell \& Malkus, 2011; Hartman, 2013). With the reauthorization of the Individuals with Disabilities Education Act ([IDEA], 2004), the authorization of the No Child Left Behind Act ([NCLB], 2008), states, districts, schools, and teachers have felt an increased pressure to ensure that all students achieve at a high level in mathematics across K-12 (Fennell, 2006; Hartman, 2013), including students at risk for mathematical failure and students with disabilities (Judge \& Watson, 2011). However, it is noted that students continue to struggle in mathematics compared to their international counterparts (International Association for the Evaluation of Educational Achievement [IEA], 2013; NMAP, 2008). Furthermore, research indicates that students with learning disabilities and those at risk for mathematic failure continue to perform at levels below students without disabilities in measures of mathematic achievement (Faulkner, Crossland, \& Stiff, 2013; 
Judge \& Watson, 2011; NAEP, 2011, 2013). In addition to the issues noted in students' mathematics performance, research indicates that elementary school teachers often have fragmented mathematical knowledge and focus on procedures as opposed to conceptual understanding during instruction (e.g., Ball, 1991; Ma, 2010). Even with the implementation of the Common Core State Standards (CCSSI, 2014), which aim to improve the teaching and learning of mathematics, without a way to support teachers' growth in both content knowledge and pedagogical content knowledge, incorporating the Common Core Standards and the Mathematical Practices may not produce the meaningful mathematics learning that is the foundation of their development and implementation.

One way in which many districts and schools are trying to ensure high mathematics achievement from all students and support elementary teachers in their use of effective and research-based practices in the classroom is through the use of mathematics coaches and/or specialists (MCS; Chval et al., 2010; Sailors \& Shanklin, 2010). However, limited empirical research has been conducted to determine how the use of MCS impacts student learning and achievement (Campbell \& Malkus, 2009; Marsh et. al, 2010; NMAP, 2008). The dearth of research on the effectiveness of MCS (NMAP, 2008) leaves states, districts, schools, administrators, and educators making policy and financial decisions to implement the use of MCS without a solid evidence base to support this decision.

\section{Restatement of Purpose and Research Questions}

The purpose of the study was to examine the relationship between MCS and the mathematics achievement of fourth-grade students on the NAEP; examine whether that 
relationship differed for students with and without disabilities; and, examine the relationships between principal-reported time spent on the six different NAEP-defined roles and responsibilities of MCS and fourth-grade students' mathematics achievement.

Additionally, the study aimed to answer the call for high-quality educational research by using a large-scale, nationally representative dataset along with advanced statistical analyses in order to provide methodologically rigorous, empirically derived evidence of the relationship between MCSs and students' mathematics achievement. Specifically, the study focused on the following three research questions:

1. What is the relationship between having an elementary school-based MCS (full or part time) and fourth-grade students' achievement on the NAEP, specifically: a) their overall mathematics achievement and b) their achievement in five specific mathematics content areas (i.e., number properties and operations; measurement; geometry; data analysis, statistics, and probability; and algebra)?

2. What are the differentials in achievement of students with and without disabilities when they have an MCS in their elementary school or not, specifically differentials in: a) their overall mathematics achievement on the NAEP and b) their achievement in five specific mathematics content areas (i.e., number properties and operations; measurement; geometry; data analysis, statistics, and probability; and algebra)?

3. For schools that have MCS, how does principal-reported time spent on the six different roles and responsibilities, which include providing assistance to teachers and students (See Table 3 for a complete list), relate to students' achievement, specifically: a) their overall mathematics achievement and b) their achievement in 
five specific mathematics content areas (i.e., number properties and operations; measurement; geometry; data analysis, statistics, and probability; and algebra)?

\section{Review of Methodology and Approach to Analyses}

This research used a quasi-experimental design, or an observational study design (Schneider et al., 2007; Shadish et. al, 2002), with the fourth-grade mathematics survey and assessment data from the restricted-use 2011 National Assessment of Education Progress (NAEP) dataset. The school sample included approximately 7,490 schools, with $62 \%$ of schools reporting no MCS available and $28 \%$ of schools reporting having an MCS available (50\% full-time and 50\% part-time). The student sample included approximately 191,190 students with $88 \%$ of students without disabilities and $12 \%$ of students with a disability (based on IEP status). As both school and student sampling weights were incorporated into all analyses to attempt to ensure that the results were representative of the targeted populations, the analytic sample size for schools included 58,685 schools, with $68 \%$ of schools reporting no MCS available and $32 \%$ of schools reporting having an MCS available (49\% full-time and 51\% part-time). The analytic student sample size included 3,522,262 students with $89 \%$ of students without disabilities and $11 \%$ of students with a disability (based on IEP status). The outcome variables included a composite mathematics achievement score, in addition to five specific content area scores (i.e., number properties and operations; measurement; geometry; data analysis, statistics, and probability; and algebra). An elementary school's policy of providing a MCS served as the treatment variable and principal-reported time spent on the six specific roles and responsibilities of the MCS served as the secondary treatment variables (used for research question three). 
As missing data are often problematic in large-scale datasets, multiple imputation $(\mathrm{MI}=5)$ was used as it allows the analyst to deal with the missing data problem in the outset and move forward with standard complete-data methods of analysis (Rubin, 1987; Schafer, 1999). This was done by using replacement values that represent a distribution of possibilities (i.e., plausible values) that were imputed for each missing piece of the data in the original dataset (excluding treatment and outcomes variables; McKnight \& McKnight, 2011; Rubin, 1987). As a large number of theoretically important duringtreatment covariates were identified, principal component analysis (PCA) was used to reduce the number of predictors (Stevens, 2009). The obtained composite covariates, as well as additional control variables, were then used in a series of multi-level analyses (i.e., hierarchical linear modeling; HLM) to explore the relationships between MCSs, fourth-grade students' mathematics achievement on the NAEP, and students' disability status. Because students were nested within schools in the NAEP dataset, HLM allowed for individual- and school-level variables to be appropriately modeled at different levels (level-1 and level-2, respectively).

\section{Summary of Findings}

Findings indicated a statistically significant relationship between elementary schools that had full-time MCSs and fourth-grade students' overall mathematics achievement and students' achievement in five specific mathematics content areas as defined in the NAEP dataset (i.e., number properties and operations; measurement; geometry; data analysis, statistics, and probability; and algebra). This significant relationship between full-time MCSs and mathematics achievement did not hold true when schools utilized part-time MCSs. Additionally, results showed that being in a 
school with an elementary MCS did not moderate the lower achievement that students with disabilities experienced on the 2011 NAEP Mathematics Assessment (overall mathematics achievement and achievement in the five content areas). Significant relationships between principal-reported time spent on the various NAEP-defined roles and responsibilities provided by full-time MCS and achievement outcomes were noted, including relationships between achievement and MCSs providing assistance to both teachers and students. The most frequent MCS roles and responsibilities associated with fourth-grade students' mathematics achievement were conducting professional development for groups of teachers about mathematics content or the teaching of mathematics (i.e., Role 2), providing technical assistance/support to individual teachers about mathematics content or the teaching of mathematics (i.e., Role 1), and providing mathematics remediation/intervention to some student groups (i.e., Role 5).

\section{Discussion and Implications for Mathematics Education}

The first finding of note was that, on average, there was a statistically significant relationship between elementary schools providing full-time MCSs and all fourth-grade students' mathematics achievement (after controlling for all individual- and school-level composite covariates and controls). As this relationship was positive, it can be tentatively concluded that schools with full-time MCS can expect higher achievement in all fourthgrade mathematics outcomes (i.e., overall or composite achievement, as well as number properties and operations, measurement, geometry, data analysis, statistics, and probability, and algebra achievement) compared to schools with no MCSs. This positive relationship between MCSs and overall mathematics achievement was echoed in previous research on MCSs and student achievement (e.g., Brosnan \& Erchick, 2010; Campbell \& 
Malkus, 2011; Foster \& Noyce, 2004). Unique to this study is the breakdown of overall mathematics achievement into the five NAEP-defined content areas. Establishing significant relationships between each of the five content areas and full-time MCSs only heightens the support of the policy of providing full-time MCSs as they were found to have a positive relationship to overall mathematics achievement and across all mathematics content areas.

Findings from prior research on MCSs often made generalizations problematic with the use of purposive sampling designs (e.g., Foster \& Noyce, 2004), however, the current study provided a broad, nationally representative view favoring the use of fulltime MCSs, thus continuing to substantiate the link between MCS and improved learning and achievement in mathematics. Although the relationship between full-time MCSs and fourth-grade students' mathematics achievement was significant, the increase in achievement may be viewed as relatively small (e.g., 1.69 points higher for overall mathematics achievement). This could be due to the fact that the current study provided only snapshot of a one-year period (2011) as opposed to a longitudinal design. Campbell and Malkus (2011) provided strong empirical evidence for the continued use of MCS by demonstrating that over a 3-year period, upper elementary students in the treatment group outperformed those in the control group on Virginia's mathematics achievement tests. In their study, no statistically significant treatment effects were found in the initial year of the MCSs work but significant gains in achievement were reported in the second and third year the MCS was in the treatment schools. Therefore, it is possible that the significant relationship found in the current study could strengthen over time. This issue could not be explored in the current study, as the NAEP main assessment data utilized 
were not longitudinal in nature (schools are randomly chosen to participate in each assessment cycle); additionally, the NAEP dataset provided no information on the length of time MCSs had been working in each elementary school.

Another important finding from the current study was the significant, positive relationship between full-time MCSs and fourth-grade students' mathematics achievement did not hold true for part-time MCSs and achievement. As reported in the literature review, to date, no evidence on the effects of full-time versus part-time coaching support was found. Although the current results cannot report on the effects (i.e., casual inferences) of full-time versus part-time MCSs, this study did reveal that across all mathematics achievement measures on the NAEP, fourth-grade students in schools with part-time MCS did not differ on their mathematics achievement from fourthgrade students in schools without an MCS, whereas students in schools with full-time MCSs did show higher achievement score than students in schools with no MCS. This suggested that as more and more states, districts and schools hire and rely on MCSs to be effective change agents in the teaching and learning of mathematics (e.g., Fennell, 2006, 2011; Reys \& Fennell, 2003), these stakeholders should focus their resources on providing full-time MCSs in order to see the strongest relationship with higher fourthgrade mathematics achievement.

The current study found the well-known achievement gap between students with and without disabilities (e.g., Bryant et al., 2008; Faulkner et al., 2013; Judge \& Watson, 2011) remains prevalent in the 2011 NAEP Mathematics Assessment results for fourthgrade students. For instance, after controlling for all variables used in the final models, a student without a disability (based on IEP status) in a school with a full-time MCS can 
expect an average overall mathematics achievement score 20.65 points higher than a student with a disability in a school with a full-time MCS (a difference of 21.06 points between students without and with a disability occured in schools with no MCS). This deficit for students with disabilities persisted across all five NAEP-defined mathematics content areas. As MCSs may provide a way to enhance the mathematics instruction and learning for students with disabilities, this study examined whether being in a school with a MCS moderated the lower achievement that students with disabilities experienced. Results indicated that there were no significant differentials in the relationship between a school's provision of a MCS (full-time or part-time) and mathematics achievement (overall and in all content areas) for students based on disability status. After adjusting for all level-1 and level-2 controls used in the final models, students with and without disabilities received essentially the same statistically significant increase in achievement when schools provide a full-time MCS. In other words, all students received the same statistically significant increase in mathematics achievement in schools with full-time MCSs (see Figure 4).

Although an additional increase in achievement for students with disabilities would be desired, the findings are not surprising as the achievement gap between students with and without disabilities has been persistently documented; mathematical learning disabilities have typically received far less attention than learning disabilities in other content areas (e.g., reading); and the connection between mathematics education and special education is often understudied (e.g., Bryant et al., 2008; Faulkner et al., 2013; Gersten et. al, 2007; Judge \& Watson, 2011). Confounding results could also be possible when exploring the relationship between MCSs and mathematics achievement for 
students with and without disabilities, as students with disabilities may have little to no interactions with the MCSs as interventions may be provided by special education teachers, paraprofessionals, or others. As there was no information regarding which students the MCSs worked with in the NAEP dataset, this issue was beyond the scope of the current study. However, it is critical to note that the overall results of the current study did indicate that fourth-grade students with disabilities, as well as students without disabilities, benefit from elementary schools providing full-time MCSs (see Tables 7 to 12 and Figure 4).

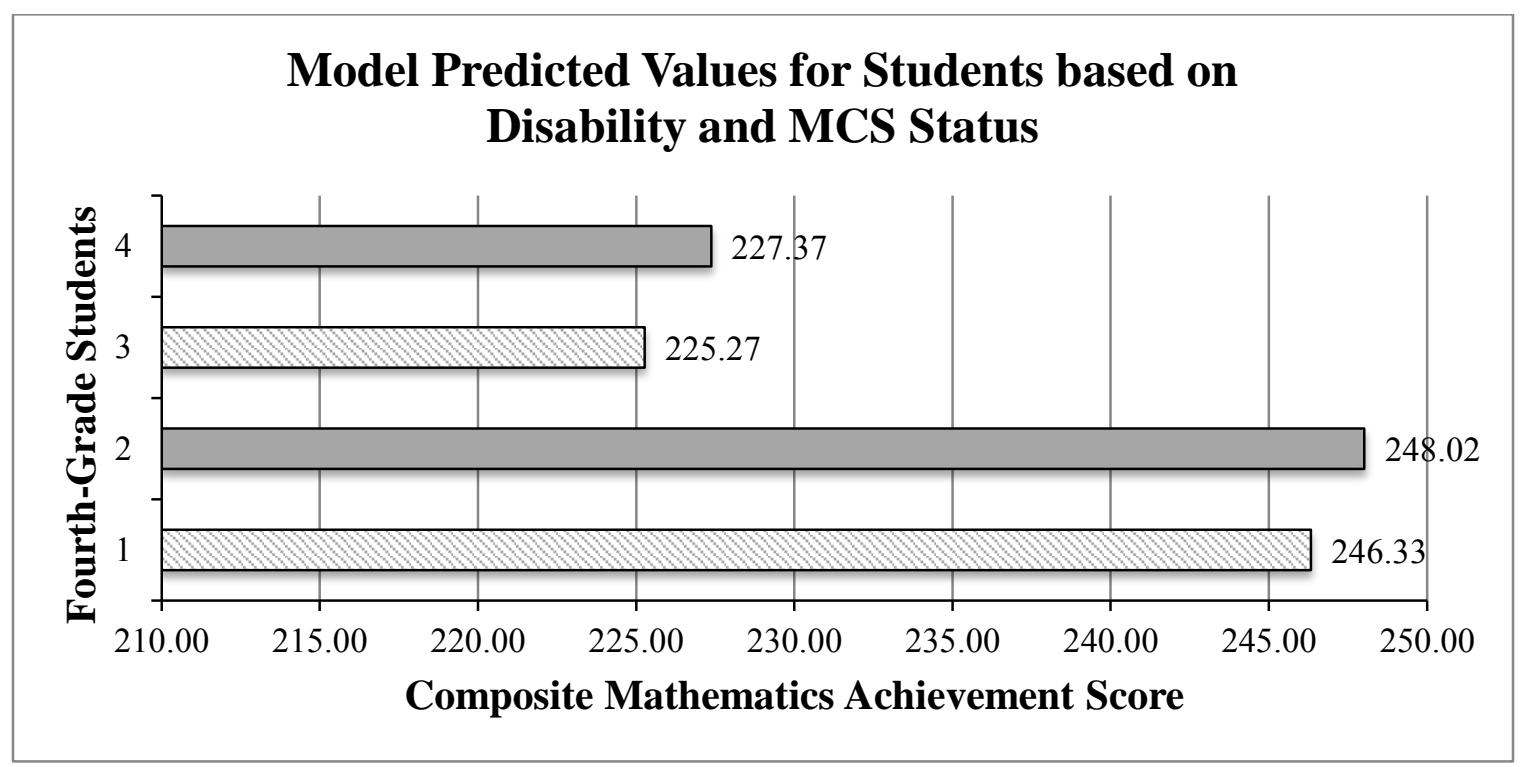

Figure 4. Model Predicted Values for Composite Mathematics Achievement Scores for Fourth-Grade Students based on Disability and Mathematics Coach/Specialist (MCS) Status. Note: All predicted values were computed using the final contextual model with all composite covaraites, controls, and treatment variables included.

${ }^{1}$ Student without a disability in a school with no MCS available. ${ }^{2}$ Student without a disability in a school with a full-time MCS. ${ }^{3}$ Student with a disability in a school with no MCS available. ${ }^{4}$ Student with a disability in a school with a full-time MCS. 
The relationships between principal-reported time spent on the six different NAEP-defined roles and responsibilities of MCSs and fourth-grade students' mathematics achievement provided additional information on this school policy. As fulltime MCSs were significantly related to achievement (no significant relationship between part-time MCSs and achievement), analyses on the roles and responsibilities were conducted only on schools that provided the full-time services of MCSs. A simple examination of descriptive statistics (see Table 14) revealed that principals or vice principals of schools with full-time MCSs reported that MCSs, on average, allocated a moderate to large extent of time on providing technical assistance/support to individual teachers about mathematics content or the teaching of mathematics (i.e., Role 1); a moderate extent of time conducting professional development for groups of teachers about mathematics content or the teaching of mathematics (i.e., Role 2), providing mathematics instruction to students on various topics (i.e., Role 3), providing mathematics instruction to students at various grade levels (i.e., Role 4), and providing mathematics remediation/intervention to some student groups (i.e., Role 5); and, a small to moderate extent of time providing mathematics enrichment to some student groups (i.e., Role 6). However, it should be noted that these measurements on the extent of time MCSs spend on each role and responsibility were not proportional in nature. This means that the extent of time spent on each role was measured independently; thus, it cannot be assumed that the measurements represented the percent of time MCSs engaged in each role. Even so, noted statistically significant relationships between principal-reported time spent on the NAEP-defined roles and achievement revealed valuable information in an area with limited research and provided information for a literature base that has an 
unclear definition of the effective roles and responsibilities of MCSs (e.g., McGatha, 2009; NMAP, 2008; Obara, 2010).

For instance, statistically significant relationships existed between full-time MCSs working with both students and teachers (see Table 16). Interestingly, statistically significant positive relationships occurred between the full-time MCSs time allocation spent working with teachers (reported by the principal or vice principal of each school) and mathematics achievement, whereas statistically significant negative relationships occurred between time allocation spent working with students and mathematics achievement. These results must be interpreted with caution as they are correlational in nature and must be interpreted while keeping the results of research question one in mind.

Because research question one showed that full-time MCSs have a positive relationship with fourth-grade students' mathematics achievement, it is likely that the positive relationship between MCS Roles 1 and 2 (working with teachers) means that as MCSs spend more time working with teachers, higher mathematics achievement can be expected. In particular, Role 2 (i.e., conduct professional development for groups of teachers about mathematics content or the teaching of mathematics) appears to be the most worthwhile role in regards to working with teachers as it is significantly associated with four of the six achievement measures (see Table 16). In regards to working with students, full-time MCSs in schools with lower mathematics achievement are more likely to spend their time involved with providing mathematics instruction to students at various grade levels (i.e., Role 4) and providing mathematics remediation/intervention to some student groups (i.e., Role 5; see Table 16). 
Table 16

Statistically Significant Relationships between Principal-reported Time Spent on the NAEP-defined Mathematics Coaches/Specialists (MCS) Roles and Responsibilities and Fourth-Grade Students' Mathematics Achievement

\begin{tabular}{|c|c|}
\hline MCS roles working with TEACHERS & MCS roles working with STUDENTS \\
\hline $\begin{array}{l}\text { Provide technical assistance/support to } \\
\text { individual teachers about mathematics } \\
\text { content or the teaching of mathematics } \\
\text { (Role 1) } \mathrm{C}, \mathrm{M}, \mathrm{G}\end{array}$ & $\begin{array}{l}\text { Provide mathematics instruction to students } \\
\text { at various grade levels (Role } 4)^{\mathrm{D}, \mathrm{A}}\end{array}$ \\
\hline $\begin{array}{l}\text { Conduct professional development for } \\
\text { groups of teachers about mathematics } \\
\text { content or the teaching of mathematics } \\
(\text { Role } 2) \text { C, N, M, D }\end{array}$ & $\begin{array}{l}\text { Provide mathematics } \\
\text { remediation/intervention to some student } \\
\text { groups }(\text { Role } 5)^{\mathrm{C}, \mathrm{D}, \mathrm{A}}\end{array}$ \\
\hline *Both positive relationships & *Both negative relationships \\
\hline $\begin{array}{l}\mathrm{C} \text { composite (i.e., overall) } \\
\mathrm{N} \text { number properties and operations } \\
\mathrm{M} \text { measurement } \\
\mathrm{G} \text { geometry } \\
\mathrm{D} \text { data analysis, statistics, and probability } \\
\mathrm{A} \text { algebra } \\
\text { Note. Roles } 3 \text { and } 6 \text { did not have statistica } \\
\text { achievement. }\end{array}$ & ignificant relationships with mathematics \\
\hline
\end{tabular}

Overall, the results of research question three suggested that it may be beneficial to have MCSs spend significant time with teachers providing assistance, support, and professional development and that when achievement is low, schools utilize MCSs to work with students mostly providing remediation and intervention (see Tables 15 and 16). Given that the NAEP questionnaire refers to coaches and/or specialists in one question, rather than asking about coaches and specialists separately, these dual relationships (with teachers and with students) that were found to be related to 
achievement are consistent with how McGatha (2009) define mathematics coaches (works with teachers) versus mathematics specialists (works with students).

\section{Limitations and Recommendations}

Several limitations to validity of findings were present in the current study and should be considered as conclusions are interpreted. A brief description of some of the limitations of the study follows. As analyses were limited to the variables available in the 2011 NAEP mathematics data, the majority of the limitations resulted from the use of a pre-existing dataset (i.e., variables collected prior to the current study).

As noted in Chapter III, initially propensity score analysis (PSA) was attempted to lessen the selection bias that arose due to the non-random design of the current study and to simulate the effects of random assignment (Holmes, 2014; Schneider et al., 2007). This simulated random-assignment allows for differences in the outcome(s) to be attributed to the treatment, as opposed to group differences (Shadish et al., 2002). In PSA, propensity score variables or covariates are used to estimate the conditional probability of receiving treatment (i.e., a school having a MCS; Guo \& Fraser, 2010). PS variables are used to determine the propensity of treatment, or in other words, provide a balancing score between treated participants and control participants (Adelson, 2013; Guo \& Fraser, 2010) and "should be related to both group selection and to the outcome" (Holmes, 2014, p. 77). Although the use of PSA would have allowed for causal inferences to be drawn from the current study, the propensity scores were not able to achieve balance on the pretreatment variables. Therefore, the current study relied on the use of numerous duringtreatment composite covariates and control variables to strengthen the quasi-experimental study design, but does not allow for casual inferences. The addition of variables that are 
considered known predictors of future achievement, particularly prior achievement, could help to alleviate this problem and allow for balance on pretreatment variables to be reached.

As there are no standard regulations on the roles of MCSs, individual states, districts, and schools have the option to utilize MCSs in ways they feel meet their specific needs. Unfortunately, NCES did not collect data (particularly on the 2011 NAEP) regarding the length of time the MCS served as the MCS at a particular school, background characteristics of the MCSs, the amount of time spent working with certain grade levels or groups of students, or the proportion of time spent engaged in the MCS roles and responsibilities. As shown in analyses of research question three, findings indicated what principal-reported time spent on the MCS roles had significant relationships with mathematics achievement; however, with the addition of variables describing the percent of time the MCSs spend on each role (i.e., a proportional variable with percent of time on each role equaling $100 \%$ ), researchers could answer vitally important questions, such as do MCSs who spend more time working with students or working with teachers have a greater impact on student achievement? Additionally, prior research revealed that, although not ideal, some MCSs spend a portion of their time on school-wide work and administrative duties (e.g., Chval et al., 2010). As such, when thinking of developing a measure to capture the proportion of time MCSs engage in certain roles and responsibilities, administrative tasks should be included on the NAEP list, as well as an "other" category to capture activities not directly related to working with students and/or teachers. 
Another limitation of the current study involved the way the MCSs information was collected. All MCS variables, including those about the extent each MCS engaged in the various roles and responsibilities, was obtained from the school survey. Because of this, results were determined based on how the principal or vice-principal viewed the role of the MCS in their particular school. Findings could be influenced based on who provides this information. A recommendation for future data collection is to allow the MCS at each school to answer all questions pertaining to their roles and responsibilities in order strengthen the validity of conclusions drawn from these variables.

Lastly, a clear definition of "part-time" MCS was not provided in the NAEP dataset. This parallels with what is seen in schools and the literature, as MCSs may be in a school one to four days a week, in a school multiple days a week for a few hours, or any combination resulting in the definition of "part-time.". Providing different categories for "part-time" would provide researchers the opportunity to further explore the use of parttime MCSs based on the amount of time spent in each school. Different definitions of "part-time" have the potential to influence the conclusions from the current study, as no statistically significant relationship was found between the undefined part-time MCS and fourth-grade students' mathematics achievement on the 2011 NAEP.

\section{Future Research}

This study should serve as a launching point for the examination of the link between MCS and student achievement on a larger-scale. The review of literature highlights the need for additional and continued research on the impact of elementary MCSs, as at this time few methodologically rigorous studies have done so (e.g., Campbell \& Malkus, 2011; NMAP, 2008). Policy makers, states, districts, and schools 
should be seeking evidence on this potentially positive practice, the provision of MCSs, which is gaining national attention. Agencies collecting large-scale, national data should focus on collecting additional data on elementary MCSs, such as the proportion of time allocated to certain roles and responsibilities, background information on the MCSs, the amount of time devoted to working with certain grade levels and groups of students, and clearly-defined information on what constitutes "part-time."

Extensions of the current study could expand our knowledge on the relationships between MCSs and students with disabilities, as well as the relationship between MCSs and eight-grade student achievement. The first extension of the current study could explore the relationship between MCSs and students with specific learning disabilities (SLD). The current study explored the relationship between MCSs and achievement of students with and without disabilities, based solely on IEP status. As the 2011 NAEP dataset provides information on students' specific disabilities, including the specific learning disability variable, an exploration of mathematics achievement based on disability type may provide much needed information to expand the literature base on the intersection of mathematics education and special education. The second extension of the current study could explore the relationship between MCS and eighth-grade students' mathematics achievement by using the 2011 NAEP dataset and the methodology of the employed in the current study. This would provide a snapshot of MCS and mathematics achievement relationship at a middle school level, as opposed to the elementary level.. The vast majority of research on MCSs has been conducted at the elementary level; therefore, an exploration at the middle school level could substantially add to the literature base. As with the findings from this study, casual inferences could not be 
drawn, unless balance of the pretreatment variables was achieved (i.e., propensity score analysis was successful). The third extension and follow up to the current study could use future NAEP assessments to explore if the findings from the current study remain consistent or if noted changes in the relationship between a school's policy of providing and MCS and fourth-grade students' mathematics achievement occur. For instance, using the restricted-use 2013 NAEP dataset (once it is released for use), the researcher could conduct similar analyses as used in the current study to explore any changes based on the most recent round of data collection. As more states are developing certification programs for MCSs and the impact of the implementation of the Common Core State Standards would likely be more prevalent, it would be interesting to see if the relationships between MCSs and student achievement reflect these policy changes. Analyses similar to the current study, with the inclusion of PSA, could also be conducted using other large-scale datasets if the needed variables were provided (i.e., pretreatment and during-treatment covariates, and most importantly the treatment, MCS, variable). For instance, analyses using the Trends in International Mathematics and Science Study (TIMSS) could provide information on the use of MCSs on an international level. By incorporating PSA, the pretreatment differences and lack of random assignment in TIMSS could be addressed, while HLM with adjustments for composite covariates and control variables, could account for the nested nature of the data. By combining these analyses, casual inferences on the impact of MCSs could be drawn for not only students in the United States but for students in other countries as well. A similar approach could be used with the Early Childhood Longitudinal Study (ECLS-K). This dataset would be ideal as it is longitudinal in nature and would provide 
the much-needed prior achievement variables that are thought to be needed for PSA to be successful and allow for causal inferences based on the results obtained in analyses. Additionally, the longitudinal nature of the data would allow for the examination of how mathematics achievement changes with prolonged use of MCSs, thus providing nationally, representative findings to build on the work of Campbell and Malkus (2011). However, the ECLS-K dataset does not currently collect information on MCSs, a muchneeded addition to the current cycle of data collection.

In addition to work with large-scale datasets, researchers can continue the methodologically sound research on MCSs that has been done in Virginia schools by Campbell and Malkus (2009; 2011). To begin, researchers must first start by collecting a rich set of pretreatment variables, including prior student mathematics achievement, prior professional development in mathematics pedagogy provided to teachers (not by the MCSs), and information on how long the MCSs have been working in each school. Campbell and Malkus (2011) were able to use a randomized, controlled trial for their research in elementary schools; although this study design is ideal, it may be difficult to replicate. If the researcher is unable to conduct a randomized control trial due to financial or ethical considerations, by collecting a vast number of pretreatment variables to use in PSA, the effect of MCSs on achievement can still be examined. This type of study design could be utilized in states and districts as they implement MCSs in their schools.

Analyses could be conducted in various grade levels and with different groups of students with the simple addition of needed variables during data collection (which should be determined before data collection begins). By tracking MCS and achievement data over 
time, states and districts can also see the impact and changes MCSs have on mathematics achievement over time.

Future research exploring the use of MCSs in elementary schools is also needed. Addressing the impact of MCSs on students' mathematics achievement by focusing on the similarities and differences for issues at the primary grade levels versus intermediate grade levels could provide vital information for the effective use of MCSs at these different levels, answering questions such as: Do primary teachers and students need the same support as intermediate teachers and students? How can MCSs better support teachers and students depending on grade level curriculum, teachers' pedagogical and content knowledge needed to teach specific grade level mathematics, and common misconceptions on grade level topics?

Lastly, as the impact of how MCSs spend their time and how that influences student achievement is vital, a measure to address the proportionality of time MCSs engage in certain activities is needed. Using the NAEP-defined roles and responsibilities would provide the researcher a solid foundation on which to build upon. By simply adding in different roles, such as administrative tasks and "other," as well as any additional roles reviewed in the literature, the researcher would then need to change the scale used to measure the extent of time spent on each role to a proportional value that would sum to $100 \%$. The NAEP dataset currently measures each role/responsibility independently on a Likert-scale ranging from 1 (no extent) to 4 (large extent). With this design, survey respondents could mark 4 for every question (or any combination of 1 to 4 for their responses). A survey measuring the roles proportionally (i.e., totaling 100) would provide the needed information to address pressing questions such as: what is the 
most effective role, or use of time, for elementary school based MCSs? Does working with students or teachers have a greater impact on students' mathematics achievement? After designing this measure, the researcher could survey schools across the country (or more localized samples for smaller-scale research) that provide MCSs to begin gathering data to establish the relationships between the varying roles and student achievement. The survey could also be included in studies utilizing an experimental design, which could then establish a casual link between the amount of time spent on certain roles and its impact on student achievement across various grade levels and groups of students.

\section{Conclusion}

This study used nationally representative, restricted-use data from the 2011 NAEP Mathematics Assessment to examine the relationships among MCSs, fourth-grade students' mathematics achievement, and students' disability status. The results indicate that all fourth-grade students in schools with full-time MCSs can expect slightly higher overall mathematics achievement (and achievement the five targeted content areas) compared to students in schools with no MCSs. Students in schools with part-time MCSs, however, cannot expect to see this increase in achievement over students in schools with no MCSs. Results also show that being in a school with MCSs did not moderate the lower achievement that students with disabilities experience on the 2011 NAEP Mathematics Assessment (overall mathematics achievement and achievement across the five content areas). Additionally, statistically significant relationships between principalreported time spent on the various roles and responsibilities provided by full-time MCS and achievement outcomes are noted, including relationships between fourth-grade 
students' mathematics achievement and MCSs providing assistance to both teachers and students.

The results of this study along with previous research provide evidence of the positive influence MCSs have on elementary students' mathematics achievement. However, because this is an area with limited research, additional research is needed to establish a casual relationship between MCSs and improved mathematics performance. Research to identify the most effective use of a MCSs time and how MCSs can help close the achievement gap in mathematics between students with and without disabilities should be of primary concern. 


\section{REFERENCES}

Adelson, J. L. Educational research with real-world data: Reducing selection bias with propensity scores. Practical Assessment, Research \& Evaluation, 18(15), 1-11.

Ai, X. \& Rivera, N. (2003). Linking ideas to practice: Effectiveness of coaching upon teacher practice. Paper presented at the annual meeting of the American Educational Research Association, April 23, Chicago, IL.

Alloway, M. \& Jilk, L. M. (2010). Supporting students by supporting teachers: Coaching moves that impact learning. Paper presented in P. Brosnan, D. B. Erchick, \& L. Flevares (Eds.) Proceedings of the $32^{\text {nd }}$ annual meeting of the North American Chapter of the International Group for the Psychology of Mathematics Education (Volume VI, p. 1420-1427). Columbus, OH: The Ohio State University.

Association of Mathematics Teacher Educators. (2013). Standards for elementary mathematics specialists: A reference for teacher credentialing and degree programs. San Diego, CA: AMTE.

Atkinson, D. (1997). A critical approach to critical thinking in TESOL. TESOL Quarterly, 31(1), 71-94.

Baldinger, E.M. (2014). Learning together: Looking for learning in coach-teacher interactions. Paper presented at the National Council of Teachers of Mathematics Research Conference, New Orleans, LA.

Balfanz, R., Mac Iver, D. J., Byrnes, V. (2006). The implementation and impact of evidence-based mathematics reforms in high poverty middle schools: A multi- 
site, multi-year study. Journal for Research in Mathematics Education, 37, 33-64.

Ball, D. L. (1990). The mathematical understandings that prospective teachers bring to teacher education. Elementary School Journal, 90, 449-466.

Ball, D.L. (1991) Research on teaching mathematics: Making subject matter knowledge part of the equation. Retrieved from: http://www.teoeducation.com/teophotos/albums/userpics/10_1_1_118_4400.pdf.

Becker, J. R. (2001). Classroom coaching: An emerging method of professional development. In R. Speiser, C. Maher \& C. Walter (Eds.), Proceedings of the Twenty-third Annual Meeting of the North American Chapter of the International Group for the Psychology of Mathematics Education (Vol. 2, pp. 751-760). Snowbird, UT.

Birman, B.F., Desimone, L., Porter, A.C., Garet, M.A. (2000). Designing professional development that works. Educational Leadership, 57(8), 28-33.

Borko, H. (2004). Professional Development and Teacher Learning: Mapping the Terrain. Educational Researcher, 33(8), 3-15.

Broderick, A., Mehta-Parekh, H., \& Reid, D. K. (2005). Differentiating instruction for disabled students in inclusive classrooms. Theory into Practice, 44, 194-202.

Brosnan, P. \& Erchick, D. (2010). Mathematics coaching and its impact on student achievement. Paper presented in P. Brosnan, D. B. Erchick, \& L. Flevares (Eds.) Proceedings of the $32^{\text {nd }}$ annual meeting of the North American Chapter of the International Group for the Psychology of Mathematics Education (Volume VI, p. 1362-1370). Columbus, OH: The Ohio State University. 
Bryant, B. R., Bryant, D. P., Kethley, C., Kim, S. A., Pool, C., \& Seo, Y. J. (2008).

Preventing mathematics difficulties in the primary grades: The critical features of instruction in textbooks as part of the equation. Learning Disability Quarterly, 31, 21-35.

Campbell, P. F. (1996). Empowering children and teachers in the elementary mathematics classrooms of urban schools. Urban Education, 30, 449-475.

Campbell, P. F., \& Malkus, N. N. (2009). School improvement through elementary coaches: Impact on teacher beliefs and student achievement. Paper presented at the Annual Meeting of the American Educational Research Association, San Diego, CA.

Campbell, P. F., \& Malkus, N. N. (2011). The impact of elementary mathematics coaches on student achievement. The Elementary School Journal, 111, 430-454.

Cattell, R. B. (1966). The scree test for the number of factors. Multivariate Behavioral Research, 1, $245-276$.

Chval, K. B., Arbaugh, F., Lannin, J. K., van Garderen, D., Cummings, L., Estapa, A. T., \& Huey, M. E. (2010). The transition from experienced teacher to mathematics coach: Establishing a new identity. The Elementary School Journal, 111, 191-216.

Collins, A., Brown, J. S., \& Newman, S. E. (1987). Cognitive apprenticeship: Teaching the crafts of reading, writing, and mathematics (Technical Report No. 403).

Washington, DC: National Institute of Education. Retrieved from http://files.eric.ed.gov/fulltext/ED284181.pdf. 
Common Core State Standards Initiative. (2014). Common core state standards initiative: Preparing America's students for college and careers. Retrieved from http://www.corestandards.org/.

Coniam, S. (2010). Mathematics coaching and its impact on urban fourth grade students' mathematics proficiency on high stakes testing. Paper presented in P. Brosnan, D. B. Erchick, \& L. Flevares (Eds.) Proceedings of the $32^{\text {nd }}$ annual meeting of the North American Chapter of the International Group for the Psychology of Mathematics Education (Volume VI, p. 1379-1386). Columbus, OH: The Ohio State University.

Costa, A. L. \& Garmston, R. J. (1994). Cognitive coaching. Norwood, MA: ChristopherGordon.

Costa, A. L. \& Garmston, R. J. (2002). Cognitive coaching: A foundation for renaissance schools. Norwood, MA: Christopher-Gordon.

Dennen, V. P. (2004). Cognitive apprenticeship in educational practice: Research on scaffolding, modeling, mentoring, and coaching as instructional strategies. In D. H. Jonassen (Ed.), Handbook of research on educational communications and technology, $2^{\text {nd }}$ edition (p. 813-828). Mahwah, NJ: Lawrence Erlbaum Associates.

Desimone, L. M. (2009). Improving impact studies of teachers' professional development: Toward better conceptualizations and measures. Educational Researcher, 38, 181-199.

Dossey, J. A. (1984). One point of view: Elementary school mathematics specialists: Where are they?. Arithmetic Teacher, 32(3), 3, 50. 
Faulkner, V. N., Crossland, C. L., \& Stiff, L. V. (2013). Predicting eighth-grade Algebra placement for students with Individualized Education Programs. Exceptional Children, 79, 329-345.

Fennell, F. (2006). We need elementary school mathematics specialists now. NCTM News Bulletin, 43(4).

Fennell, F. (2011). We need elementary mathematics specialists now, more than ever: A historical perspective and call to action. NCSM Journal, Summer/Fall, 53-60.

Foster, D. \& Noyce, P. (2004). The mathematics assessment collaborative: Performance testing to improve instruction. Phi Delta Kappan, 85, 367-374.

Garet, M.S., Porter, A.C., Desimone, L., Birman, B.F.\& Yoon, K.S. (2001). What Makes Professional Development Effective? Results From a National Sample of Teachers. American Educational Research Journal, 38(4), 915-945.

Garson, G. D. (Ed.). (2013). Hierarchical linear modeling: Guide and applications. Thousand Oaks, CA: Sage Publications, Inc.

Gersten, R., Clarke, B. \& Mazzocco, M. (2007). Historical and contemporary perspectives on mathematical learning disabilities. In D.B. Berch and M. Mazzocco (Eds.), Why is math so hard for some children? The nature and origins of mathematical learning difficulties and disabilities (p. 7-27). Baltimore, MD: Paul H. Brookes Publishing Co., Inc.

Guo, S., \& Fraser, M. W. (2010). Propensity score analysis: Statistical methods and applications. Los Angeles, CA: Sage.

Guskey, T.R. (2002). Professional Development and Teacher Change. Teachers and Teaching: theory and practice, 8(3/4), 381-390. 
Guskey, T.R. (2003). What Makes Professional Development Effective? Phi Delta Kappan, 84(10), 748-750.

Harrison, R., Higgins, C., Zollinger, S., Brosnan, P., \& Erchick, D. (2011). Mathematics coaching program fidelity and its impact on student achievement. Paper presented in L. R. Weist \& T. Lamberg (Eds.) Proceedings of the $33^{\text {nd }}$ annual meeting of the North American Chapter of the International Group for the Psychology of Mathematics Education (p. 1545-1553). Reno, NV: University of Nevada, Reno.

Hartman, S. (2013). Math coaching in a rural school: Gaining entry: A vital first step. Journal of Education, 193, 57-67.

Hedges, L. V., \& Hedberg, E. C. (2007). Intraclass correlation values for planning grouprandomized trials in education. Educational Evaluation and Policy Analysis, 29, $60-87$.

Hill, H. C. (2009). Fixing teacher professional development. Phi Delta Kappan, 90(7), 470-477.

Holmes, W. M. (2014). Using propensity scores in quasi-experimental designs. Thousand Oaks, CA: SAGE Publications, Inc.

Horn, J. L. (1965). A rationale and test for the number of factors in factor analysis. Psychometrica, 32, $179-185$.

Hox, J. (2002). Multilevel analysis: Techniques and applications. Mahwah, NJ: Erlbaum. IBM Corp. Released 2012. IBM SPSS Statistics for Windows, Version 21.0. Armonk, NY: IBM Corp.

Individuals With Disabilities Education Act, 20 United States Code (U.S.C.) $§ 1400$ (2004). 
Ingvarson, L., Meiers, M. \& Beavis, A. (2005). Factors affecting the impact of professional development programs on teachers' knowledge, practice, student outcomes \& efficacy. Education Policy Analysis Archives, 13(10). Retrieved [October 6, 2012] from http://epaa.asu.edu/epaa/v13n10/.

International Association for the Evaluation of Educational Achievement. (2013). Trends in international mathematics and science study, TIMSS, 2011. Retrieved from http://timss.bc.edu/timss2011/.

Judge, S., \& Watson, S. M. (2011). Longitudinal outcomes for mathematics achievement for students with learning disabilities. The Journal of Educational Research, 104, $147-157$.

Kaiser, H. F. (1960). Directional statistical decisions. Psychological Review, 67, 160.

Kaiser, H. F. (1970). A second generation Little Jiffy. Psychometrica, 35, 401 - 415.

Knight, J. (2005). A Primer on Instructional Coaches. Principal Leadership, 5(9), 16-21.

Koellner, K., Jacobs, J., \& Borko, H. (2011). Mathematics Professional Development: Critical Features for Developing Leadership Skills and Building Teachers' Capacity. Mathematics Teacher Education and Development, 13(1), 115-136.

Kretlow, A. G., Wood, C. L., \& Cooke, N. L. (2011). Using in-service and coaching to increase kindergarten teachers' accurate delivery of group instructional units. The Journal of Special Education, 44, 234-246.

Kretlow, A. G., Cooke, N. L., \& Wood, C. L. (2012). Using in-service and coaching to increase teachers' accurate use of research-based strategies. Remedial and Special Education, 33, 348-361.

Ma, L. (2010). Knowing and teaching elementary mathematics: Teachers' understanding 
of fundamental mathematics in China and the United States (2nd ed.). New York: Routledge.

Marsh, J. A., McCombs, J. S., \& Martorell, P. (2010). How instructional coaches support data-driven decision making. Educational Policy, 20(10), 1-37.

Mayrowetz, D. (2009). Instructional practice in the context of converging policies teaching mathematics in inclusive elementary classrooms in the standards reform era. Educational Policy, 23, 554-588.

McCoach, D. B., \& Adelson, J. L. (2010). Dealing with dependence (Part 1): Understanding the effects of clustered data. Gifted Child Quarterly, 54, 152-155. McGatha, M. (2008). Levels of engagement in establishing coaching relationships. Teacher Development, 12, 139-150.

McGatha, M. (2009). Mathematics Specialists and Mathematics Coaches: What Does the Research Say?. NCTM Research Briefs.

McKnight, P.E. \& McKnight, K.M. (2011). Missing data in secondary data analysis. In K. H. Trzesniewski, M. B. Donnellan, \& R. E. Lucas (Eds.), Secondary data analysis: An introduction for psychologists (p. 83-101). Washington, DC: American Psychological Association.

Meyers, L. S., Gamst, G., \& Guarino, A. J. (2006). Applied multivariate research: Design and interpretation. SAGE Publications, Incorporated.

Mullis, I.V.S., Martin, M.O., Foy, P., \& Arora, A. (2012). TIMSS 2011 international results in mathematics. Chestnut Hill, MA: TIMSS \& PIRLS International Study Center, Boston College. 
National Assessment for Educational Progress. (2013). The Nation's report card. National Center of Education Statistics, Institute of Education Sciences. Retrieved from http://www.nationsreportcard.gov/.

National Center for Education Statistics (2009). NAEP Technical Documentation. Institute of Education Sciences, U.S. Department of Education, Washington, D.C. Retrieved http://nces.ed.gov/nationsreportcard/tdw/.

National Center for Education Statistics (2010, March 2). Range of response codes, percent agreement, and Cohen's Kappa or intraclass correlation for the constructed-response items used in scaling, grade 4 mathematics combined national and state main assessment, by item and block: 2007. Retrieved from http://nces.ed.gov/nationsreportcard/tdw/analysis/2007/initial_itemscore_2007mat hg4.aspx.

National Center for Education Statistics (2011). The Nation's Report Card: Mathematics 2011 (NCES 2012-458). Institute of Education Sciences, U.S. Department of Education, Washington, D.C.

National Center for Education Statistics (2013). NAEP 2011 mathematics and reading restricted-use data files data companion (NCES 2014473), by A.M. Rogers and J. J. Stoeckel. U.S. Department of Education. Institute of Education Sciences, Washington, DC.

National Council of Teachers of Mathematics. (2014). Principles to actions: Ensuring mathematical success for all. Reston, VA: The National Council of Teachers of Mathematics, Inc. 
National Governors Association Center for Best Practices \& Council of Chief State School Officers. (2010). Common Core State Standards for Mathematics. Washington, DC: National Governors Association Center for Best Practices, Council of Chief State School Officers. Retrieved from http://www.corestandards.org/Math/.

National Mathematics Advisory Panel. (2008). Foundations for success: The final report of the national mathematics advisory panel. Washington, DC: U.S. Department of Education.

Neuberger (2012). Benefits of a teacher and coach collaboration: A case study. The Journal of Mathematical Behavior, 31, 290-311.

Neufeld, B., \& Roper, D. (2003). Coaching: A Strategy for Developing Instructional Capacity: Promises \& Practicalities. Aspen Institute.

Newton, K.J. (2008). An extensive analysis of preservice elementary teachers' knowledge of fractions. American Educational Research Journal, 45(4), 10801110.

No Child Left Behind Act of 2001, Pub. L. No. 107-110, 20 U.S.C. 6301 (2002).

Obara, S. (2010). Mathematics coaching: A new kind of professional development. Teacher Development, 14, 241-251.

Olson, J. C. (2005). Evoking pedagogical curiosity: A coaching approach to support teacher's professional growth. The Mathematics Educator, 8(2), 84-94.

Olson, J. C., \& Barrett, J. E. (2004). Coaching teachers to implement mathematics reform recommendations. Mathematics Teacher Education and Development, 6, 63-78.

Polly, D., Mraz, M., \& Algozzine, R. (2013). Implications for developing and researching 
elementary school mathematics coaches. School Science and Mathematics, 113, 297-307.

Race, K., Ho, E., \& Bower, L. (2002, April 1-5). Documenting in-classroom support and coaching activities of a professional development program directed toward school-wide change: An integral part of an organization's evaluation efforts. Paper presented at the Annual Meeting of the American Educational Research Association, New Orleans, LA.

Raudenbush, S., \& Bryk, A. (2002). Hierarchical linear models (2nd ed.). Newbury Park, CA: Sage.

Raudenbush, S., Bryk, A., Cheong, Y., Congdon, R., Toit, M. (2011). HLM 7:

Hierarchical Linear and Nonlinear Modeling (manual). Lincolnwood, IL: Scientific Software International, Inc.

Raudenbush, S.W., Bryk, A.S, \& Congdon, R. (2011). HLM 7 for Windows [Computer software]. Skokie, IL: Scientific Software International, Inc.

Reys, B. J. \& Fennell, F. (2003). Who should lead mathematics instruction at the elementary school level? A case for mathematics specialists. Teaching Children Mathematics, 9, 277-282.

Rubin, D. B. (1987). Multiple imputation for nonresponse in surveys. New York, NY: John Wiley \& Sons, Inc.

Rubin, D. B. (1996). Multiple imputation after 18+ years. Journal of the American Statistical Association, 91(434), 473-489. 
Rudd, L. C., Lambert, M. C., Satterwhite, M., \& Smith, C. H. (2009). Professional development + coaching $=$ enhanced teaching: Increasing usage of math mediated language in preschool classrooms. Early Childhood Education Journal, 37, 63-69.

Schafer, J. L. (1999). Multiple imputation: A primer. Statistical Methods in Medical Research, 8, 3-15.

Schneider, B., Carnoy, M., Kilpatrick, J., Schmidt, W. H., \& Shavelson, R. J. (2007). Estimating causal effects: Using experimental and observational designs. Washington, DC: American Educational Research Association.

Shadish, W.R., Cook, T.D., \& Campbell, D. T. (2002). Experimental and quasiexperimental designs for generalized causal inference. New York: Houghton Mifflin.

Siegler, R., Carpenter, T., Fennell, F., Geary, D., Lewis, J., Okamoto, Y., Thompson, L., \& Wray, J. (2010). Developing effective fractions instruction for kindergarten through 8th grade: A practice guide (NCEE \#2010-4039). Washington, DC: National Center for Education Evaluation and Regional Assistance, Institute of Education Sciences, U.S. Department of Education. Retrieved from whatworks.ed.gov/ publications/practiceguides.

Stevens, J. P. (2009). Applied multivariate statistics for the social sciences (5 $5^{\text {th }}$ ed.). New York, NY: Routledge.

Sutton, J. T., Burroughs, E. A., \& Yopp, D. A. (2011). Coaching knowledge: Domains and definitions. NCSM Journal of Mathematics Education Leadership, 13(2), 1220. 
Tatto, M. T., Peck, R., Schwille, J., Bankov, K., Senk, S. L., Rodriguez, M., Ingvarson, L., Reckase, M., \& Rowley, G. (2012). Policy, practice, and readiness to teach primary and secondary mathematics in 17 countries: Findings from the IEA Teacher Education and Development Study in Mathematics (TEDS-MM). International Association for the Evaluation of Educational Achievement. Herengracht 487, Amsterdam, 1017 BT, The Netherlands.

Tirosh, D., Fischbein, E., Graeber, A. O., \& Wilson, J. W. (1999). Prospective elementary teachers' conceptions of rational numbers. Retrieved from http://jwilson.coe.uga.edu/texts.folder/tirosh/pros.el.tchrs.html.

Tirosh, D. (2000). Enhancing prospective teachers' knowledge of children's conceptions: The case of division of fractions. Journal for Research in Mathematics Education, $31(1), 5-25$.

Zhou, Z., Peverly, S.T., and Xin, T. (2006). Knowing and teaching fractions: A crosscultural study of American and Chinese mathematics teachers. Contemporary Educational Psychology, 31, 438-457.

Zollinger, S., Brosnan, P., Erchick, D., \& Bao, L. (2010). Mathematics coaching: Impact on student proficiency levels after one year of participation. Paper presented in P. Brosnan, D. B. Erchick, \& L. Flevares (Eds.) Proceedings of the $32^{\text {nd }}$ annual meeting of the North American Chapter of the International Group for the Psychology of Mathematics Education (Volume VI, p. 1371-1378). Columbus, OH: The Ohio State University. 
Appendix A

Full List of Potential School, Teacher, and Student Covariates Considered for PCA Work

and All Additional Control Variables Used in the HLM Analyses

School Covariates

$\underline{\mathrm{ID}}$

PUBPRIV $^{\mathrm{c}} \quad$ Public/Private School

PCTTFRL $^{\mathrm{c}} \quad$ Percent FRL

SSCHWHT $^{\mathrm{c}}$ Percent Minority

C046501 ${ }^{\mathrm{c}} \quad$ Percent LEP

C044004 ${ }^{\mathrm{c}} \quad$ Percent Gifted and Talented

$\mathrm{C} 044007^{\mathrm{c}} \quad$ Percent Special Education

Teacher Covariates

ID

T044201

$\mathrm{T} 106801^{\mathrm{a}}$

$\mathrm{T} 106802^{\mathrm{a}}$

$\mathrm{T} 106803^{\mathrm{a}}$

$\mathrm{T} 106804^{\mathrm{a}}$

$\mathrm{T} 106805^{\mathrm{a}}$

T075352 ${ }^{\mathrm{a}}$

T075353 ${ }^{\mathrm{a}}$

T075354 ${ }^{\mathrm{a}}$

T075355

$\mathrm{T} 106601^{\mathrm{a}}$

T016602

T106609

$\mathrm{T} 107001^{\mathrm{a}}$

$\mathrm{T} 107002^{\mathrm{a}}$

T107003 ${ }^{\mathrm{a}}$

T107004

T047402

$\mathrm{T} 047403^{\mathrm{a}}$

T057404 ${ }^{\mathrm{a}}$

$\mathrm{T} 117001^{\mathrm{b}}$

T088001 ${ }^{\mathrm{b}}$

$\mathrm{T} 057401^{\mathrm{b}}$

$\mathrm{T} 044401^{\mathrm{b}}$

T089201 ${ }^{\mathrm{b}}$

T075351 ${ }^{\mathrm{b}}$

$\mathrm{T} 106603^{\mathrm{b}}$
Variable Description

Variable Description

Create groups in math class based on ability

Teaching math-set different standards for some students

Teaching math-use other materials some students

Teaching math-engage some students in different activities

Teaching math-use different methods for some students

Teaching math-change pace for some students

Emphasis on measurement

Emphasis on geometry

Emphasis on data analysis

Emphasis on algebra and functions

Students use computer to practice/review math

Students use computer to extend math learning

Students use computer to play math games

Individual math students-discuss current performance level

Individual math students-set goals for specific program

Individual math students-discuss progress toward goal

Individual math students-adjust teaching strategies to meet needs of students

Assess math with problem sets

Assess math with short or long written responses

Assess math with individual or group projects

Number of students in this class for mathematics

Time per week on math instruction

Assess math with multiple-choice tests

Amount of math homework assigned per day

Use calculator for math lessons

Emphasis on numbers and operations

Students use computer to research a math topic 


\begin{tabular}{ll}
\hline T106606 & Students use computer to draw geometric shapes \\
T106610 & Students use computer to use 4-function calculator \\
T106701 & Resources provided by school system for math \\
T077101 & Years experience (elementary or secondary) \\
Combined $^{\mathrm{c}}$ & Math Degree (minor or major in any math related field)
\end{tabular}

\section{Student Covariates}

ID

$\mathrm{M} 824701^{\mathrm{a}}$

M824801 ${ }^{\mathrm{a}}$

$\mathrm{M}^{2} 24401^{\mathrm{a}}$

${\mathrm{M} 814301^{\mathrm{a}}}^{\mathrm{a}}$

$\mathrm{M}^{2} 23901^{\mathrm{a}}$

M814601 ${ }^{\mathrm{a}}$

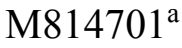

$\mathrm{M} 814501^{\mathrm{a}}$

$\mathrm{M} 814901^{\mathrm{a}}$

M824201

$\mathrm{M} 824301^{\mathrm{a}}$

M824501 ${ }^{\mathrm{a}}$

$\mathrm{M} 824601^{\mathrm{a}}$

M815001 ${ }^{\mathrm{b}}$

M815301 ${ }^{\mathrm{b}}$

M821401

DSEX $^{\mathrm{b}}$

SRACE10

$\mathrm{LEP}^{\mathrm{b}}$

$\mathrm{IEP}^{\mathrm{b}}$

B018101

\section{$\underline{\text { Variable Description }}$}

Like math

Math is a favorite subject

Like what is done in math class

Use computer at school for math

Use computer at home for math homework

Use computer to practice or drill on math

Use computer to play math games

Use computer to make charts or graphs for math

Use the Internet to learn things about math

Math work is too hard

Math work is too easy

Can do good job on math tests

Can do good job on math assignments

Use calculator

Use calculator for math tests-student

Do math at after-school or tutoring program

Gender

Student Minority Status

Student ELL Status

Student Disability Status (IEP)

Days Absent Last Month

${ }^{a}$ Covariate retained in PCA

${ }^{\mathrm{b}}$ Covariates eliminated during PCA

${ }^{\mathrm{c}}$ Covariates used as controls (not used in PCAs) 


\title{
CURRICULUM VITA
}

\author{
Kristin E. Harbour \\ Curriculum and Instruction-Mathematics Education \\ College of Education and Human Development \\ University of Louisville \\ Louisville, KY 40292
}

\section{EDUCATION}

Ph.D. Doctoral of Philosophy in Curriculum and Instruction

(Mathematics Education), University of Louisville, Louisville, Kentucky

Dissertation Title: A multi-level analysis using NAEP data: Examining the relationships among mathematics coaches and specialists, student achievement, and disability status

M.A. Masters of Arts in Elementary Education with a concentration in Middle School Mathematics, West Virginia University, Morgantown, West Virginia, 2005

B.A. Bachelor of Arts in Multi-Disciplinary Studies (Elementary Education with a concentration in Middle School Mathematics), West Virginia University, Morgantown, West Virginia, 2005

\section{PROFESSIONAL EXPERIENCE}

\section{$\underline{\text { Research Experience }}$}

- Designing measures, collecting and scoring data, and data analysis with Dr. Adelson for the Magnifying Math in the Middle project, funded by the Kentucky Center for Mathematics (2014-current)

- Examining mathematics teaching and learning for students with and without disabilities using the ECLS-K dataset with Dr. J. Adelson (2013-current)

- Developing and implementing the Effects of Schema-Based Instruction on Mathematical Problem Solving of $2^{\text {nd }}$ Grade Students with Mathematical Difficulties research project with Dr. Lingo (2013-current)

- Examining issues of urban school districts with Dr. Hochbein using the Common Core of Data (CCD) large-scale database (2013-current) 
- Investigating teaching mathematics to students with disabilities with Dr. Scott and Dr. Lingo through an OSEP Leadership Grant and an Academic and Behavioral Response to Intervention Grant (2012-current)

- Action Research Project: The effects of daily mental math computations on students' strategy use and attitudes towards mathematics (2004-2005)

\section{University Teaching Experience}

Teaching Assistant, Hierarchical Linear Modeling, ECPY 765 (spring 2015)

- Assisted with the instruction and assessment of graduate level students on conducting research using the advanced statistical technique of hierarchical linear modeling

Guest Lecturer, Mathematics Methods for Elementary Teachers, EDTP 604 (fall 2014)

Mathematics Instructional Leader for an International Teaching Experience in Belize, EDAP 694 (spring 2014)

- Taught pre-service teachers to plan, prepare, and implement mathematics lessons to build conceptual knowledge in grades preK-8

- Guided pre-service teachers in lesson development to meet the needs of diverse learners

- Provided professional development to Belizean teachers on how to incorporate concrete materials into mathematics instruction

Co-Instructor, Mathematics Methods for Elementary Teachers, EDTP 604 (fall 2013)

- Taught and assessed P-5 mathematics methods to pre-service graduate level elementary teacher candidates

Summer Portfolio Institute Leader for the "You've Got the Write One" Summer Program, EDAP 611 (summer 2013)

- Taught graduate level practicing and pre-service teachers in developing curriculum and planning for a summer camp that integrates mathematics, writing, and technology

- Engaged practicing and pre-service teachers in developing critical thinking for students in elementary and middle grades

\section{K-12 Teaching Experience}

2007-2011 Mathematics Subject Area Lead Teacher

Belmont Ridge Middle School, Leesburg, VA

- Revised mathematics program for the county: focused on vertical K12 , restructured grades 6-7 course content, developed and implemented instructional strategies for grades 6- 7 
- Provided professional development to all seventh grade mathematics teachers in the county on curriculum changes and the use of research based teaching practices

- Supported all grade level mathematics teams to incorporate the use of the most effective instructional and assessment practices

- Mentored all pre-service and newly hired in-service teachers of mathematics

- Member of the hiring committee for mathematics teachers

2005-2011 Mathematics Teacher, grades 6 and 7

Belmont Ridge Middle School, Leesburg, VA

- Worked collaboratively to create and implement lessons using research based instructional strategies and a variety of assessments to ensure that all students received opportunities to learn

- Provided daily morning and after school math workshops for students

\section{PUBLICATIONS}

\section{Book Chapters}

Hochbein, C. \& Harbour, K. E. Accepted). Large and small urban school districts: Empirical identification and comparison utilizing student population. In K. L. Sanzo, I. Sutherland, \& J. Scribner (Eds.), Leading Small and Mid-Sized Urban School Districts. Bingley, UK: Emerald Group Publishing Limited.

\section{$\underline{\text { Referred Journal Articles }}$}

Harbour, K. E. , Evanovich, L. L., Sweigart. C. A., \& Hughes, L. E.. (2015). A brief review of effective teaching practices that maximize student engagement. Preventing School Failure: Alternative Education for Children and Youth, 59, 513.

\section{$\underline{\text { Work in Progress }}$}

Harbour, K.E. \& Lingo, A.S. (in progress). Examining the impact of problem-solving instruction on second grade students' mathematics performance in a tier 2 setting.

Harbour, K.E. \& Lingo, A. S. (in progress). How incorporating addition and subtraction problem structures into everyday instruction can benefit all students.

Harbour, K.E. \& Adelson, J. L. (in progress). The relationship between students' mathematics performance, teacher judged ability, and students' self-perceptions: A comparison of students with and without disabilities. 


\section{PROFESSIONAL PRESENTATIONS}

\section{$\underline{\text { Invited Presentations }}$}

Harbour, K. E. (September, 2014). Diving into Division with Whole Numbers and Fractions. Presentation at the fall meeting of the Greater Louisville Council of Teachers of Mathematics. Louisville, KY.

\section{Refereed National Conference Presentations}

Harbour, K. E. \& Lingo, A. S. (April 2015). Solve it! Using a "structured" approach to problem solving. Presentation at the Annual Meeting of the National Council of Teachers of Mathematics. Boston, MA.

Lingo, A. S., Harbour, K. E., \& Brown, E. T. (April 2015). Role of service-learning in understanding and applying mathematical content. Presentation at the Annual Meeting of the National Council of Teachers of Mathematics. Boston, MA.

Lingo, A. S. \& Harbour, K. E. (April 2015). Examining the Impact of Schema-based Instruction on Problem Solving Performance. Poster presentation at the National Council of Teachers of Mathematics 2015 Research Conference. Boston, MA.

Lingo, A. S., Harbour, K. E., \& Karp, K. S. (April 2015). The impact of schema-based mathematics instruction in a tier-2 setting. Presentation at the Annual Council for Exceptional Children Convention and Expo. San Diego, CA.

Harbour, K. E., Lingo, A. S., \& Karp, K. S. (February 2015). Linking service-learning to field experience as a way to broaden perspectives in mathematics education. Presentation at the Annual Association of Mathematics Teacher Educators Conference. Orlando, FL.

Hochbein, C. \& Harbour, K. E. (November 2014). Examining the construct of urban school districts: A tale of two cities. Presentation at the University Council for Educational Administration Annual Convention. Washington, D. C.

Higgins, R. \& Harbour, K. E. (April 2014). Crunched for time? Make the data work for you. Presentation at the Annual Meeting of the National Council of Teachers of Mathematics. New Orleans, LA.

Lingo, A. S. \& Harbour. K. E. (April, 2014). Schema-based instruction: A strategy to teach problem solving. Presentation at the Annual Meeting of the National Council of Teachers of Mathematics. New Orleans, LA.

Hochbein, C. \& Harbour, K. E. (March, 2014). The tale of two types of cities: Exploration of the research and reform implications resulting from urban district size. Presentation at the Annual Urban Affairs Association Conference. San Antonio, TX. 


\section{$\underline{\text { Refereed Regional and Local Conference Presentations }}$}

Harbour, K. E. (November 2014). What's the deal with division? Examining whole numbers and fractions. Presentation at the Annual Kentucky Exceptional Children's Conference. Louisville, KY.

Harbour, K. E. \& Lingo, A. S. (October 2014). Creating effective problem solvers using schema-based instruction. Presentation at the Annual Regional Meeting of the National Council of Teachers of Mathematics. Indianapolis, IN.

Harbour, K. E., \& Hughes, L. (November, 2013). Discovering the big ideas behind multiplication and division. Presentation at the Annual Kentucky Exceptional Children's Conference. Louisville, KY.

Harbour, K. E. , Hughes, L. E. , \& Sweigart, C. A. (November, 2013). The whole truth: Building conceptual knowledge of whole number operations. Presentation at the Annual Regional Meeting of the National Council of Teachers of Mathematics. Louisville, KY.

Flynn, T., Harbour, K. E., \& Bryden-Miller, B. (October, 2009). Efficacy, expectations, and excellence: The pillars of academic achievement. Presentation at the Annual Meeting of the Virginia Middle School Association. Richmond, VA.

\section{SERVICE}

Membership Chair, Greater Louisville Council of Teachers of Mathematics (2013present)

Graduate Student Council Teaching and Learning Representative, University of Louisville

$(2013$ - present)

Research and Faculty Development Student Representative, College of Education and Human Development, University of Louisville (2012 - present)

\section{$\underline{\text { Service to Schools }}$}

Shelby County (KY) Public Schools (2013-2014)

- Clear Creek Elementary: Developed and implemented mathematics interventions for third grade students

Jefferson County (KY) Public Schools (2013)

- St. Matthews Elementary School: Barnes Foundation Project-integrating art and mathematics 
- Myers Middle School: Developed and implemented a unit on fractions for $7^{\text {th }}$ grade students with disabilities (with T. Whitney)

\section{$\underline{\text { Review Work }}$}

Review for the American Educational Research Journal - Teaching, Learning and Human Development (2015-present)

Reviewer for the Journal of Educational Research (2014-present)

Reviewer for the 2015 National Council of Teachers of Mathematics Research Conference

(fall 2014).

\section{HONORS AND AWARDS}

Research and Faculty Development Grant, University of Louisville, College of Education and Human Development, 2014. Student Development Grant for attendance to a seminar on Propensity Score Analysis, $\$ 1,635$

Graduate Student Travel Award, University of Louisville, Graduate Student Council, 2014. Attendance to the National Council of Teachers of Mathematics , $\$ 250$

Comprehensive Exams-Passed with Honors (spring 2014)

Institute on Statistical Analysis for Education Policy on Mathematics Education and Equity. (2013). American Educational Research Association, Washington, D.C.

University Fellowship, University of Louisville, School of Interdisciplinary and Graduate Studies, 2012-present.

- Fellowship includes stipend, full tuition, and health insurance to help recruit high quality doctoral students.

\section{PROFESSIONAL MEMBERSHIPS AND AFFILIATIONS}

American Educational Research Association (AERA)

Association of Mathematics Teacher Educators (AMTE)

Council for Exceptional Children (CEC)

Greater Louisville Council of Teachers of Mathematics (GLCTM)

-Membership Chair (2013-present) 
National Council of Teachers of Mathematics (NCTM)

Golden Key International Honour Society

\section{OTHER PROFESSIONAL EXPERIENCE}

Propensity Score Analysis, seminar taught by Shenyang Guo, Ph.D. (November, 2014). Statistical Horizons, Philadelphia, PA.

Institute on Statistical Analysis for Education Policy on Mathematics Education and Equity. (2013). American Educational Research Association, Washington, D.C. 